\title{
Structure, function and inhibition of critical protein-protein interactions involving mixed lineage leukemia 1 and its fusion oncoproteins
}

Xin $\mathrm{Li}^{1}$ and Yongcheng Song ${ }^{1,2^{*}}$

\begin{abstract}
Mixed lineage leukemia 1 (MLL1, also known as MLL or KMT2A) is an important transcription factor and histone-H3 lysine-4 (H3K4) methyltransferase. It is a master regulator for transcription of important genes (e.g., Hox genes) for embryonic development and hematopoiesis. However, it is largely dispensable in matured cells. Dysregulation of MLL1 leads to overexpression of certain Hox genes and eventually leukemia initiation. Chromosome translocations involving MLL1 cause 75\% of acute leukemia in infants and $5-10 \%$ in children and adults with a poor prognosis. Targeted therapeutics against oncogenic fusion MLL1 (onco-MLL1) are therefore needed. Onco-MLL1 consists of the N-terminal DNA-interacting domains of MLL1 fused with one of $>70$ fusion partners, among which transcription cofactors AF4, AF9 and its paralog ENL, and ELL are the most frequent. Wild-type (WT)- and onco-MLL1 involve numerous protein-protein interactions (PPI), which play critical roles in regulating gene expression in normal physiology and leukemia. Moreover, WT-MLL1 has been found to be essential for MLL1-rearranged (MLL1-r) leukemia. Rigorous studies of such PPIs have been performed and much progress has been achieved in understanding their structures, structure-function relationships and the mechanisms for activating gene transcription as well as leukemic transformation. Inhibition of several critical PPIs by peptides, peptidomimetic or small-molecule compounds has been explored as a therapeutic approach for MLL1-r leukemia. This review summarizes the biological functions, biochemistry, structure and inhibition of the critical PPIs involving MLL1 and its fusion partner proteins. In addition, challenges and perspectives of drug discovery targeting these PPIs for the treatment of MLL1-r leukemia are discussed.
\end{abstract}

Keywords: Mixed lineage leukemia 1, MLL1-rearranged leukemia, Protein-protein interactions, Protein structure, Drug discovery, Protein inhibition

\section{Introduction}

Chromosome translocations involving mixed lineage leukemia 1 (MLL1, also known as MLL or KMT2A) gene located at chromosome 11q23 cause approximately $75 \%$ of acute leukemia in infants and $5-10 \%$ in children and adults [1], which can be clinically characterized to be acute lymphocytic leukemia (ALL) or acute myeloid

\footnotetext{
*Correspondence: ysong@bcm.edu

${ }^{1}$ Department of Pharmacology and Chemical Biology, Baylor College of Medicine, 1 Baylor Plaza, Houston, TX 77030, USA

Full list of author information is available at the end of the article
}

leukemia (AML). Unlike other pediatric ALLs (with a 5-year survival of 90\%), MLL1-rearranged (MLL1-r) ALL shows a poor prognosis with 5-year survival rates of $34-39 \%$ [1-4], while MLL1-r AML patients have similarly poor outcomes to other AMLs with 5 -year survival rates of $\sim 50 \%$ for younger $(<45$ years) and $<35 \%$ for older patients [5]. In addition, treatment with DNAtopoisomerase II inhibitors poses a risk of $2 \%-15 \%$ to induce MLL1 rearrangement and cause therapy-related secondary leukemia [6, 7]. Current treatments for MLL1$r$ leukemias are conventional chemotherapeutics, which non-selectively kill all rapidly proliferating cells including original author(s) and the source, provide a link to the Creative Commons licence, and indicate if changes were made. The images or other third party material in this article are included in the article's Creative Commons licence, unless indicated otherwise in a credit line to the material. If material is not included in the article's Creative Commons licence and your intended use is not permitted by statutory regulation or exceeds the permitted use, you will need to obtain permission directly from the copyright holder. To view a copy of this licence, visit http://creativecommons.org/licenses/by/4.0/. The Creative Commons Public Domain Dedication waiver (http://creativeco mmons.org/publicdomain/zero/1.0/) applies to the data made available in this article, unless otherwise stated in a credit line to the data. 
normal stem/progenitor cells in the bone marrow and other organs (e.g., intestines). This causes severe toxicities, side effects, and even secondary cancers. Targeted therapeutics against oncogenic fusion MLL1 that drives the malignancy are therefore needed.

First described in $1992[8,9]$, MLL1 is a large, multidomain protein containing 3,696 amino acid residues (Fig. 1a). Its $\mathrm{N}$-terminal $\sim 1,400$ residues including AT-hooks (ATH) and CxxC domains act as a transcription factor, recognizing and binding MLL1-target genes, while its C-terminal SET (Su(Var)3-9, enhancer-of-zeste, trithorax) domain, a homolog of Drosophila trithorax, is a histone-H3 lysine-4 (H3K4) methyltransferase [10]. MLL1 plays crucial roles during early embryonic development and hematopoiesis by regulating the Hox cluster genes expression [11]. In MLL1-r leukemia, chromosome translocation produces an oncogenic fusion protein consisting of the N-terminal DNA-interacting domains of MLL1 (residues 1- 1400) fused with one of $>70$ fusion partner proteins (Fig. 1a) [12-14], among which transcription cofactor proteins AF4 $(\sim 36 \%)$, AF9 $(\sim 19 \%)$ and its paralog ENL ( $\sim 13 \%)$, AF10 $(\sim 8 \%)$, ELL $(\sim 4 \%)$ and AF6 $(\sim 4 \%)$ are the most frequent [14] (Fig. 1b).

MLL1 as well as its major fusion partners involve numerous protein-protein interactions (PPI), which plays critical roles in regulating gene expression in normal physiology and in leukemia initiation and maintenance. Moreover, the wild-type (WT) MLL1 in the other allele has been found to be essential for MLL1-r leukemia [15]. Rigorous biochemical, biophysical (particularly X-ray crystallography and NMR) and biological studies of such PPIs have been performed and much progress has been achieved in understanding their structures and structure-function relationships as well as the mechanism for leukemogenesis. To a lesser extent, pharmacological inhibition of several critical PPIs has been explored as a targeted therapeutic approach for MLL1-r
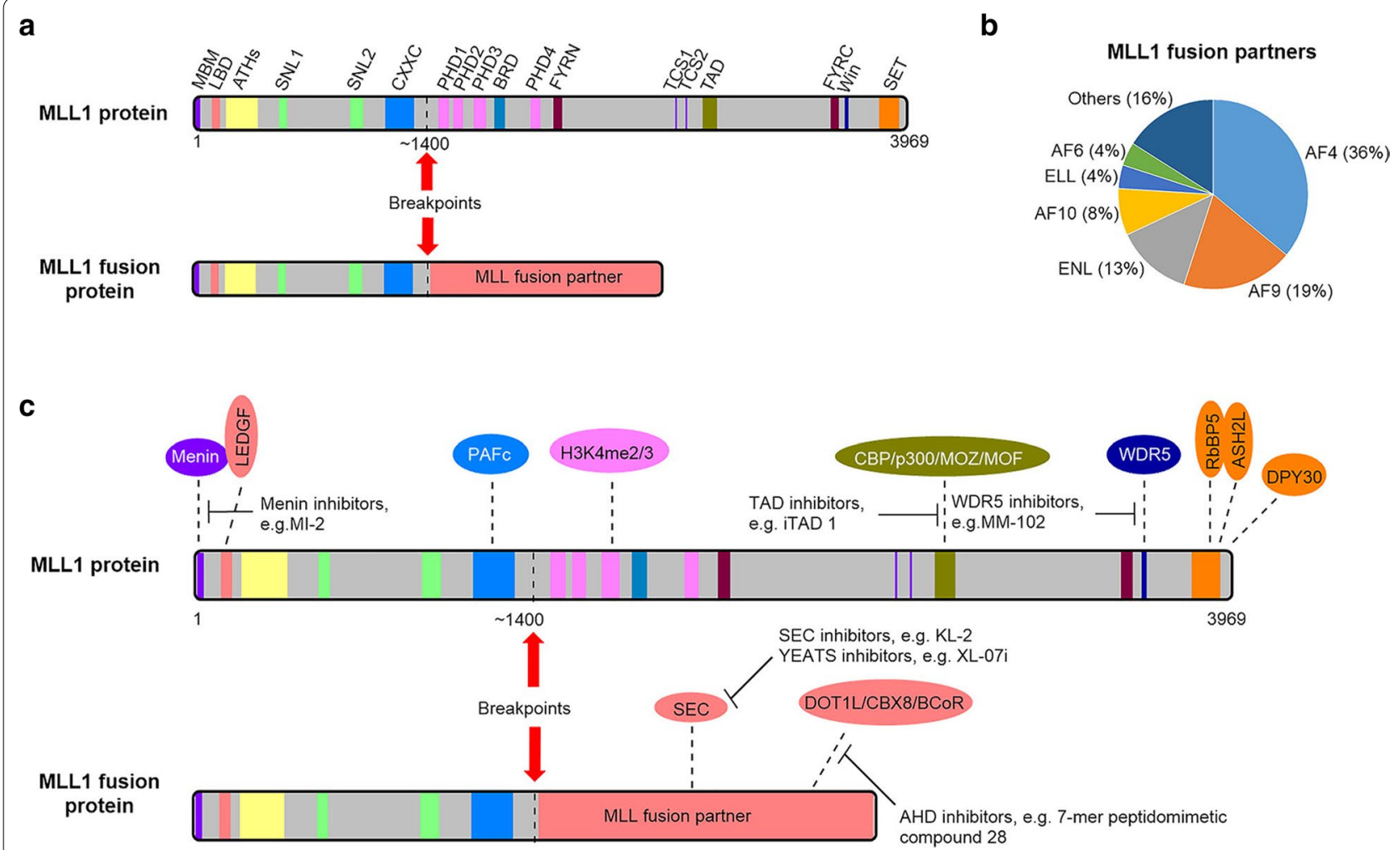

Fig. 1 MLL1 and oncogenic MLL1 fusion proteins. a Illustrations of MLL1 and onco-MLL1 fusion proteins showing their functional domains. MLL1 with 3969 amino acids contains domains of (from the N- to C-terminus) Menin-binding motif (MBM, residues 2-40), LEDGF-binding domain (LBD, 109-153), AT-hooks (ATHs, 142-400), nuclear-localization signals 1 and 2 (SNL1, 400-443 and SNL2, 1008-1106), CxxC domain (1147-1337), plant homology domains 1-4 (PHD1, 1431-1482; PHD2, 1479-1533; PHD3, 1566-1627; PHD4, 1931-1978), bromodomain (BRD, 1703-1748), FYRN domain (2018-2074), Taspase 1 cleavage sites 1 and 2 (TCS1, 2666-2670 and TCS2, 2718-2722), transactivation domain (TAD, 2829-2883), FYRC domain (3666-3747), WDR5 interaction motif (Win, 3762-3773), and SET domain (3829-2945). The breakpoints of MLL1 are located in the region of 1400. b Frequencies of the MLL1 fusion partner proteins in the clinic, with transcription cofactors AF4 ( 36\%), AF9 ( 19\%) and its paralog ENL $(\sim 13 \%)$, AF10 ( 8\%), ELL $(\sim 4 \%)$ and AF6 ( $\sim \%)$ being the most common. c lllustration of current approaches to inhibit PPIs involving MLL1 and its fusion proteins 
leukemia, as exemplified by $\mathrm{KO}-539$, an inhibitor of the MLL1-Menin interaction, being in clinical trials [16].

Human MLL1 belongs to the MLL/KMT2 family of lysine methyltransferases (KMT), which includes MLL2 (KMT2D), MLL3 (KMT2C), MLL4 (KMT2B), MLL5 (KMT2E), SET1A (KMT2F), and SET1B (KMT2G). The other MLL1 family proteins are also key regulators for gene transcription and play important roles in normal physiology and diseases [17-19]. This review is focused on MLL1, since it is the most studied and involved in a number of chromosomal translocations causing 5-10\% acute leukemia in children and adults with a poor prognosis $[10,20]$. We summarize the biology, structures, structure-function relationships and inhibition of the critical PPIs involving MLL1 as well as its major fusion proteins (Fig. 1c).

\section{Wild-type and oncogenic fusion MLL1}

Although classified as a lysine methyltransferase (KMT), MLL1 is mainly a transcription factor and has been found to bind thousands of gene promoters and regulate their expression. It has a global role in the positive regulation of transcription of many important genes in mammals, such as clustered Hox genes which mediate the differentiation of multiple tissues, including the hematopoietic system, during embryogenesis [11, 21, 22]. MLL1 is required during early development and its knockout is embryonic lethal in mice with multiple developmental deficiencies [11]. Conditional MLL1 deletion in mice did not affect the development of mature hematopoietic cells as well as their differentiation, while self-renewal of the stem cells was compromised in fetal liver and adult bone marrow [23]. Moreover, dysregulation of MLL1 leads to constitutive or over-expression of certain Hox genes (e.g., HoxA9), which has been found to cause leukemia [24].

Upon translation, MLL1 is cleaved by the protease Taspase 1 [25], with the N-terminal fragment (MLL1-N) and C-terminal fragment (MLL1-C) forming a protein complex through the interactions between FYRN (Phe/ Tyr-rich N-terminal) and FYRC (Phe/Tyr-rich C-terminal) domains [26]. As illustrated in Fig. 1a, MLL1-N contains domains of MBM (menin-binding motifs), LBD (lens epithelium-derived growth factor (LEDGF)-binding domain), ATH (AT-hooks), SNL1 and 2 (nuclear-localization signals 1 and 2), CxxC, PHD1-4 (plant homology domains 1-4), BRD (bromodomain) and FYRN [1]. MBM and LBD can recruit Menin and LEDGF and form a ternary MLL1-Menin-LEDGF complex, which interacts with DNA/chromatin through LEDGF [27]. ATHs bind to the minor groove of AT-rich DNA regions, while CxxC interacts with non-methylated CpG DNA for target gene recognition [28]. The CxxC domains also associate with PAFc (polymerase-associated factor complex) to facilitate MLL1 to recognize its target genes (e.g., HoxA9 and Meis1) [29]. MLL1's PHD domains mainly recognize di- or tri-methylated H3K4 (H3K4-Me2/3) and facilitate MLL1-mediated gene transcription [30, 31].

MLL1-C consists of a TAD (transactivation domain), FYRC, Win (WD repeat protein 5 (WDR5) interaction motif), and SET domain [1]. TAD can recruit histone acetyltransferases $\mathrm{CBP} / \mathrm{p} 300, \mathrm{MOZ}$ and $\mathrm{MOF}$ to acetylate histone lysine residues (e.g., H3K27, H3K9 and H4K16) for gene expression activation [32]. The SET domain is a H3K4 methyltransferase, but it is catalytically inactive by itself. Complexation with three other proteins, including WDR5 (WD repeat-containing protein 5), RbBP5 (retinoblastoma binding protein 5), and ASH2L (Set1/Ash2 HMT complex subunit ASH2-like) is required to efficiently methylate H3K4 [1].

Onco-MLL1 proteins contain MLL1 $(1-\sim 1400)$ merged with a variety of fusion partners (Fig. 1a, b). The main function of MLL1 portion is to recognize and bind MLL1-target genes with a high affinity through multivalent interactions involving MLL1-Menin-LEDGF, $\mathrm{ATH}$, and CxxC. This is critical to MLL1-r leukemia, as disruption of any one of these MLL1-DNA/chromatin interactions abrogates onco-MLL1's capability of leukemogenesis. It is also noted that onco-MLL1 has been found to occupy different gene loci from WT-MLL1 [33] and only regulates a small subset of MLL1-target genes [34]. Moreover, the functions of onco-MLL1 rely on the pre-binding of WT-MLL1 to DNA, which is believed to create an "open" chromatin state and facilitate recruitment of onco-MLL1 as well as its mediated gene expression [15]. Knockdown of WT-MLL1 inhibited aberrant gene expression as well as proliferation of MLL1-r leukemia cells $[15,35,36]$. Arguably, a recent research indicated that MLL2, a homolog of MLL1, plays more important roles in sustaining MLL1-r leukemia through a distinct pathway [37].

Although there are $>70$ documented fusion partners of MLL1, transcription cofactors AF4 (also known as AFF1) and its paralog AFF4, AF9 and its paralog ENL, and ELL are found in $>70 \%$ MLL1-r leukemias (Fig. 1b) $[10,38]$. These proteins have been found to associate with each other in several isolated transcription complexes, which have been commonly called super elongation complexes (SEC) $[25,39,40]$. The biological function of SEC is to release RNA polymerase II (Pol II) from transcription pausing and start transcription elongation. SEC is essential for expression of characteristic genes of MLL-r leukemia (e.g., HoxA9 and Meis1) as well as leukemia transformation. Moreover, SEC was also found to be recruited by MLL1-AF6 and -AF10, two other major fusion partners (Fig. 1b) [25, 40]. Thus, the common feature of these frequent MLL1 fusion partners is 
their ability to recruit SEC and other associated proteins. Indeed, despite the phenotypic difference (either AML or ALL), MLL1-r leukemias overlap in their gene expression profiles [41], also supporting a common mechanism of leukemogenesis.

\section{PPIs involving WT-MLL1}

MLL1 regulates transcription of critical genes during development. Many proteins have been identified to associate with MLL1 and form a large transcription complex with a molecular mass of $\sim 2$ million daltons [42]. These proteins play important roles in MLL1-mediated gene regulation. For example, germline knockout of LEDGF, which forms a ternary complex with MLL1 and Menin, is also embryonic lethal in mice showing dysregulated expression of Hox genes [43], suggesting MLL1's function is dependent on LEDGF. Moreover, formation of such protein complex can stabilize and protect MLL1 from ubiquitination and proteasome-mediated degradation [42]. Table 1 summarizes the binding affinity (dissociation constant $K_{\mathrm{d}}$ ), availability of the X-ray/NMR structures and inhibitors of these PPIs.

\section{Menin-MLL1(1-40) interaction Biological function}

Menin, the product of MEN1 gene, contains 610 amino acids [104]. Originally, it was identified as a tumor suppressor in endocrine organs and mutation of Menin resulted in multiple endocrine neoplasia type 1 syndrome [104, 105]. Menin is not homologous to any domains of a known protein [106, 107] and directly interacts with a variety of proteins, showing different functions depending on the context of cell types [108, 109]. Menin is critical for MLL1 to regulate its target genes [110-112]. Menin is also required for MLL1-r leukemia, as conditional knockout of Menin inhibited MLL1-AF9 mediated leukemia transformation and suppressed expression of HoxA9, a characteristic gene for the leukemia. [106, 113]. Menin binds MBM (residues 1-40) of MLL1 (or onco-MLL1) with a high affinity $\left(K_{\mathrm{d}}=9.8 \mathrm{nM}\right)$ and forms a ternary Menin-MLL1-LEDGF complex [44, 45], which greatly enhances MLL1's ability to recruit LEDGF [69] and tethers MLL1 to chromatin through LEDGF-chromatin interactions (see below). Recent biological studies have shown that Menin's ability to strengthen the MLL1-LEDGF interaction is critical to MLL-r leukemia. A mutant MLL1(D123-153)-ENL, which can bind Menin but not LEDGF, failed to cause leukemia initiation, while an artificial LEDGF(1-93)$\operatorname{MLL1}(\Delta 1-40)$-ENL (which cannot recruit Menin), in which the LEDGF(1-93) insert can directly tether MLL1ENL to chromatin, can cause leukemia transformation [114].

Nonetheless, the Menin-MLL1 interaction is essential for the biological functions of MLL1 and onco-MLL1. There are two Menin-binding motifs in MLL1, termed as MBM1 (residues 2-15) and MBM2 (residues 23-40) [44], with the former having $>20 \times$ higher binding affinity. As for onco-MLL1, disruption of the Menin-MLL1 interaction through deletion of a high-affinity MBM motif (residues 6-10) on MLL1-ENL abolished its leukemia transforming ability in vitro and in vivo [106]. In addition, co-expression of the MLL1(2-44) peptide, which is a dominant negative inhibitor of the Menin-MLL1 interaction, inhibited proliferation of MLL1-AF9 transformed leukemia cells with significantly reduced expression of Meis1 [115]. These studies show that the Menin-MLL1 interaction is a potential drug target for the treatment of MLL1-r leukemia.

Table 1 Binding affinity $\left(K_{d}\right)$, structure, and inhibitors of the critical PPIs involving MLL1

\begin{tabular}{|c|c|c|c|}
\hline PPIs & $K_{d}(\mu \mathrm{M})$ & Structures (PDB code) & Inhibitors \\
\hline Menin-MLL1 & 0.01 or $0.082[44,45]$ & $3 \cup 85$ [45], 4GQ6 [46] & {$[16,46-68]$} \\
\hline LEDGF-Menin-MLL1 & 0.47 or $1.4[45,69]$ & $3 \cup 88[45]$ & {$[69,70]$} \\
\hline LEDGF-MLL1 & $14.7[69]$ & 2MTN [69], 2MSR [70] and 6EMQ [71] & {$[70]$} \\
\hline MLL1(PHD3)-H3K4me3 & 19 or $30[31,72]$ & 3LQJ [30] & None \\
\hline MLL1(PHD3)-H3K4me2 & $158[31]$ & 3LQI [30] & None \\
\hline MLL1 (PHD3-BRD)-H3K4me3 & $4.3[30]$ & 3LQJ [30] & None \\
\hline MLL1(PHD3-BRD)-H3K4me2 & $6.9[30]$ & 3LQI [30] & None \\
\hline MLL1(PHD3)-Сyp33 & $14.7[72]$ & 2KU7 [30] & None \\
\hline MLL1-CBP(KIX) & 2.8 or $3.8[73,74]$ & $2 \mathrm{AGH}[75]$ & {$[76-78]$} \\
\hline MLL1-RbBP5-ASH2L & $126[19]$ & 5F6L [19] & None \\
\hline MLL3-RbBP5-ASH2L & $0.13[19]$ & 5F6K [19] & None \\
\hline MLL1-WDR5-RbBP5 & None & $3 \mathrm{P} 4 \mathrm{~F}[79]$ & None \\
\hline MLL1-WDR5 & 0.12 or $1.7[80,81]$ & 3EG6 [81], 3EMH [82], and 4ESG [83] & {$[36,81,84-103]$} \\
\hline
\end{tabular}


(See figure on next page.)

Fig. 2 X-ray structures of Menin in complex with MLL1(6-13) peptide and inhibitors. a The active site of Menin-MLL1 complex (PDB: 3U85). b A close-up view of the Menin-MLL1 interaction. c Superimposed active sites of Menin-MLL1, Menin-MI-2 (PDB: 4GQ3), Menin-MI-503 (PDB: 4X5Y), and Menin-MI-1481 (PDB: 6BXY). d A close-up view of the Menin-MI-2 interactions. e Superimposed active sites of Menin-MLL1, Menin-MIV-6R (PDB: 4OG8), Menin-M-525 (PDB: 6B41), Menin-M-808 (PDB: 6WNH), Menin-M-89 (PDB: 6E1A). f A close-up view of the Menin-MIV-6R interactions. MLL1 peptide with $\mathrm{C}$ atoms in yellow is shown as a tube model in (a) and (b), while a line model in (c)-(f). Compounds MI-2, MI-503, MI-1481, MIV-6R, M-525, M-808, and M-89 are shown as tube models with C atoms in green, magentas, cyan, purple, grey, blue, and orange, respectively. Menin is shown as an electrostatic surface and hydrogen bonds are shown as dashed lines

\section{Structure}

The crystal structure of Menin in complex with MLL1(613) peptide (PDB: 3U85) showed that the MLL1 peptide folds into a bow-shaped conformation and occupies the big central cavity of Menin (Fig. 2a, b) $[45,46]$. The sidechain of Arg8 forming an intramolecular hydrogen bond with Pro13 constitutes the "string". Mutation of either of the two residues significantly decreased the binding affinity. Phe9 occupies a deep hydrophobic cleft formed by Menin residues Leu177, Ala182 and Met228. Mutation of Phe9 with a more polar residue Tyr or His led to $>100$ fold affinity reduction. The positively charged Arg12 sidechain inserts into a pocket formed by acidic residues Glu359, Glu363 and Tyr319 of Menin with strong electrostatic and $\mathrm{H}$-bond interactions. A R12A mutation resulted in $\sim$ fourfold loss of binding affinity. Pro13 is located between Menin residues Tyr319 and Tyr323 with favorable hydrophobic interactions. Mutation of either Tyr319 or Tyr323 disrupted these interactions and significantly decreased the binding affinity. The polar and nonpolar interactions account for the high binding affinity of MLL1 to Menin with a $K_{\mathrm{d}}$ value of $82 \mathrm{nM}$ [45] (Table 1 ).

\section{Inhibitors}

Through high throughput screening (HTS) followed by medicinal chemistry studies, a series of thienopyrimidine compounds have been found to be the first small-molecule inhibitors of the Menin-MLL1 interaction with $\mathrm{IC}_{50}$ values as low as $3.6 \mathrm{nM}[46,48-51,53,54]$. These compounds compete with MLL1 to bind Menin and inhibit the Menin-MLL1 interaction, with the representative compound MI-2 (Fig. 3) exhibiting a $K_{\mathrm{d}}$ of $158 \mathrm{nM}$ [47]. It also inhibited such interaction in cells, which downregulated expression of the MLL1 target genes, inhibited proliferation (with $\mathrm{EC}_{50}$ values of 7-18 $\mu \mathrm{M}$ ) and induced hematopoietic differentiation of several MLL1-r leukemia cells. An analog of MI-2 exhibited high synergistic effects when combined with an HDAC inhibitor chidamide against the proliferation of MLL1-r leukemia cells in vitro and in vivo [116]. The crystal structure of Menin in complex with MI-2 (PDB: 4GQ3) shows the inhibitor occupies the binding pocket of the MLL1 peptide (Fig. 2c, d) [46]. The nitrogen atoms of the pyrimidine ring form hydrogen bonds with Tyr276 and Asn282 of
Menin. Binding of MI-2 to Menin is further strengthened by favorable hydrophobic interactions between its 6-propyl-thienopyrimidine core structure and Ser155, Leu177, Ser178, His181, Ala182, Phe238, Cys241, Tyr276 and Met278, as well as those between the 4,5-dihydro-thiazole fragment of MI-2 and Tyr319, Met322, and Tyr323.

Further optimization of MI-2 yielded the secondgeneration inhibitors [46, 50-54] with low nanomolar binding affinities to Menin as well as improved cellular activities, such as MI-503 and MI-1481 (Fig. 3). Combination treatment with EPZ004777, an inhibitor of H3K79 methyltransferase DOT1L, had more profound antitumor activity against MLL1-r leukemia [117]. In addition to MLL1-r leukemia cell lines, MI-503 inhibited proliferation of the primary cells from MLL1-r leukemia patients. It was found to have good oral bioavailability, metabolic stability and pharmacokinetics (PK) profiles. MI-503 also exhibited potent in vivo antitumor efficacy in a mouse model of MLL1-r leukemia without apparent toxicity [50, 52]. MI-1481 is the most potent inhibitor in the series with $\mathrm{IC}_{50}$ of $3.6 \mathrm{nM}, \mathrm{EC}_{50}$ of $34-61 \mu \mathrm{M}$ as well as strong in vivo antitumor activity [53, 54]. While its oral availability was low, MI-1481 has a high drug exposure in animal plasma. X-ray structures of Menin in complex with MI-503 (PDB: 4X5Y) and MI-1481 (PDB: $6 \mathrm{BXY}$ ) indicate the inhibitor binds to Menin similarly to MI-2 (Fig. 2c), while their longer 1-substituted-piperidin4-ylamino groups extending into a side pocket with more favorable hydrophobic and hydrogen bond interactions. This explains their significantly enhanced activities. Further optimization led to more potent analog MI-3454 [55]. BAY-155 is another derivative with low nanomolar inhibitory activity against the Menin-MLL1 interaction as well as MLL1-r leukemia [48, 49].

The second series of inhibitors of the Menin-MLL1 interaction were discovered from HTS followed by medicinal chemistry studies, including MIV-6 (Fig. 3) and its analogs [56-58]. These compounds selectively inhibited the PPI $\left(\mathrm{IC}_{50}=50-90 \mathrm{nM}\right)$ as well as the proliferation of MLL1-r leukemia cells $\left(\mathrm{EC}_{50}=3-5 \mu \mathrm{M}\right)$. They also induced cell differentiation and decreased expression of HoxA9 and Meis1 genes. The crystal structure of Menin in complex with the R-enantiomer of MIV-6 (PDB: 4OG8) shows the inhibitor mimics the key interactions 

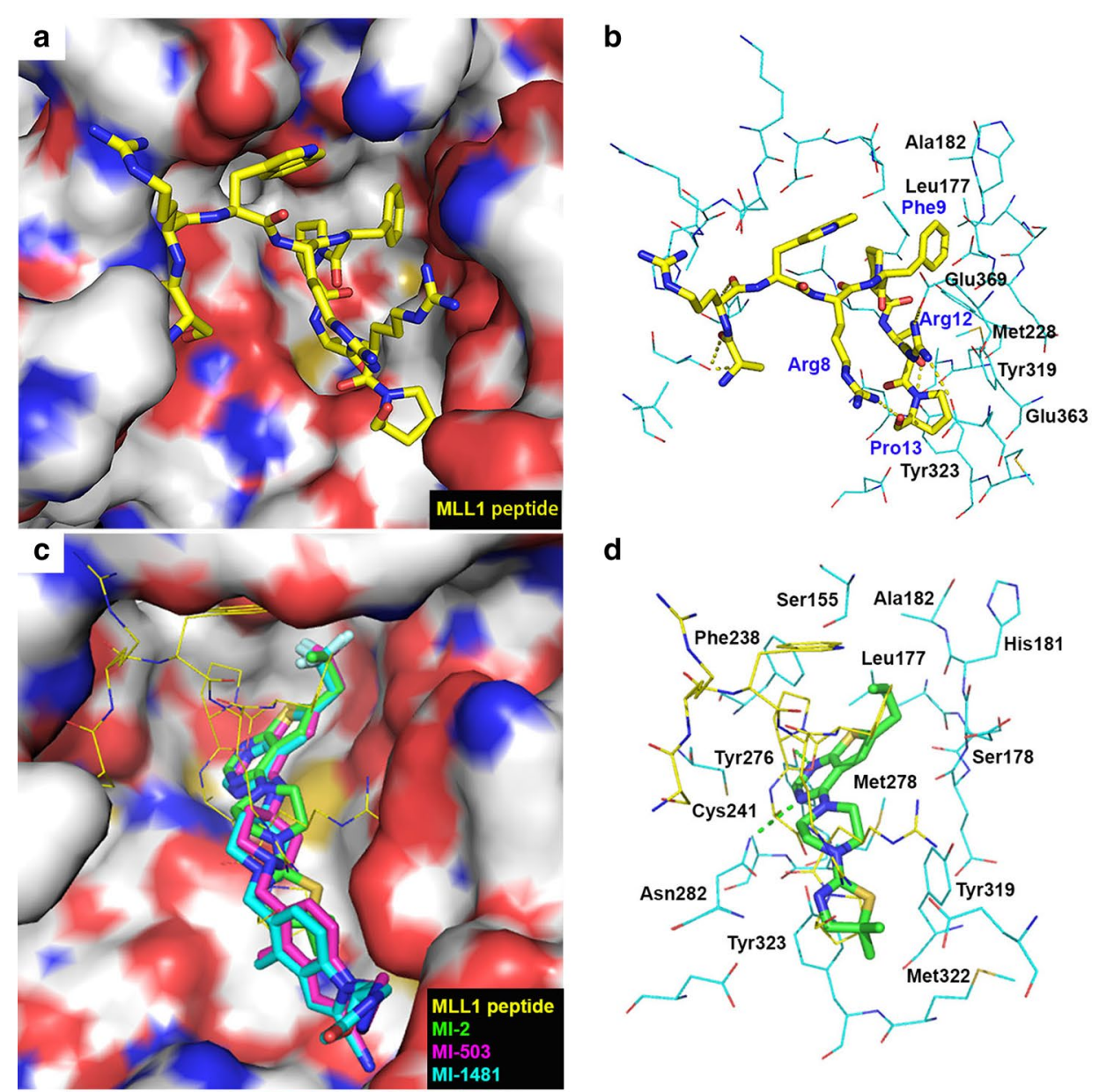

d
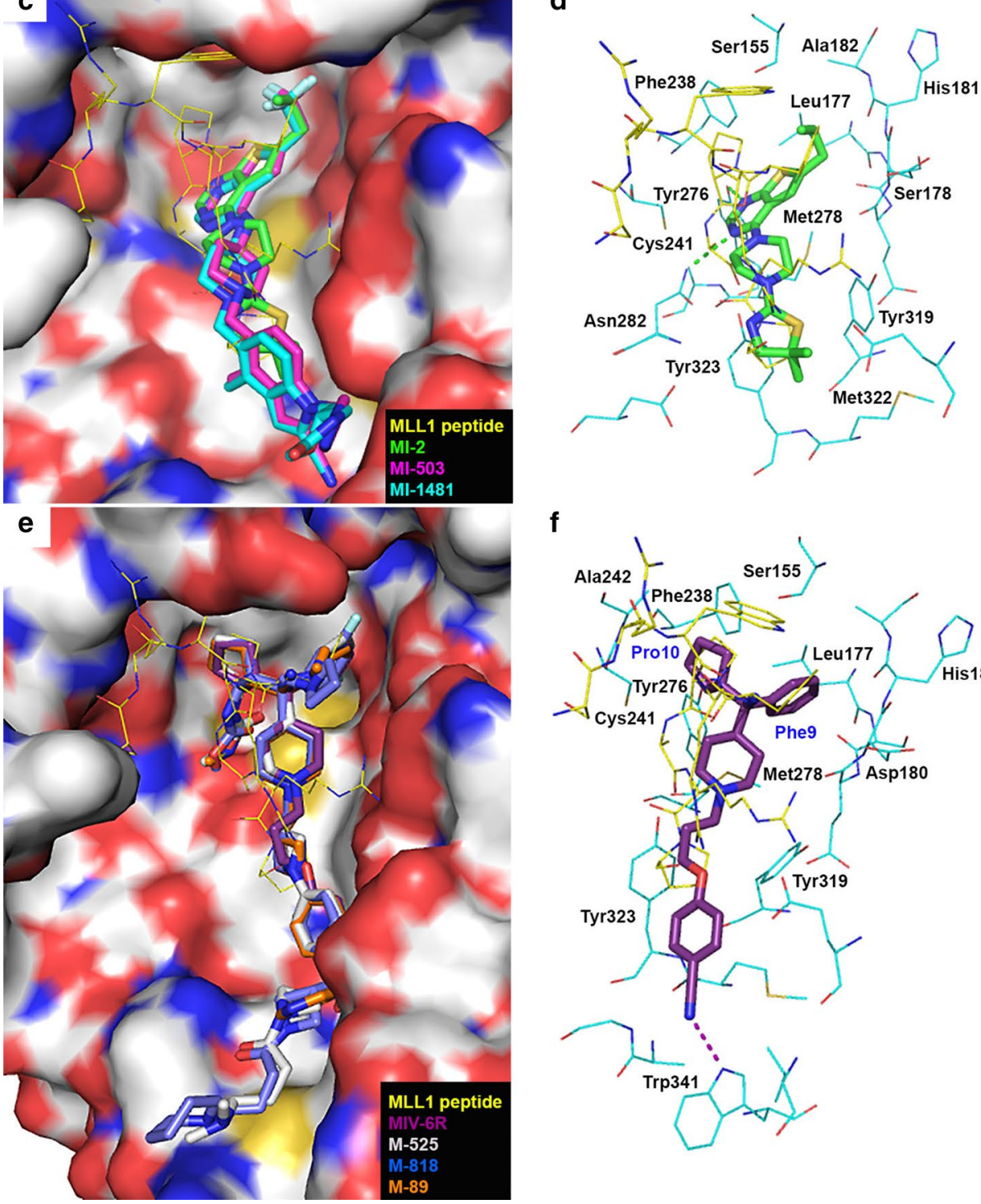

f

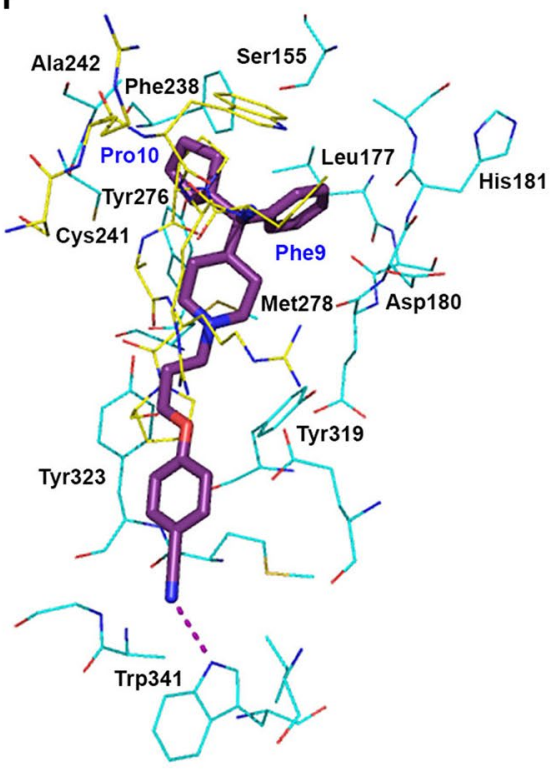




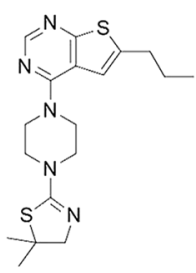

MI-2

Biochemical activity

$\mathrm{IC}_{50}=0.45 \mu \mathrm{M}$

$K_{\mathrm{d}}=158 \mathrm{nM}$

Cellular anti-proliferation activity

$\mathrm{EC}_{50}$ (MLL1-r leukemia cell lines)

$=7.2-18 \mu \mathrm{M}$

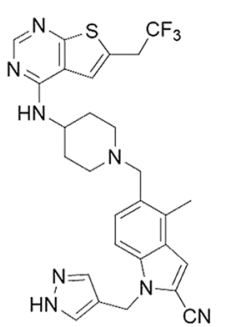

MI-503

Biochemical activity

$1 \mathrm{C}_{50}=14.7 \mathrm{nM}$

$K_{d}=9.3 \mathrm{nM}$

Cellular anti-proliferation activity

$\mathrm{EC}_{50}$ (MLL1-r leukemia cell lines)

$=0.22-0.57 \mu \mathrm{M}$

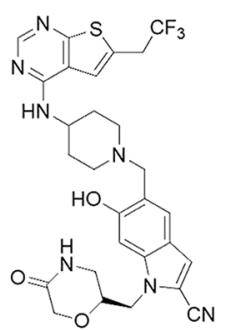

MI-1481

Biochemical activity

$\mathrm{IC}_{50}\left(\right.$ Menin-MLL $\left.\mathrm{L}_{4-43}\right)=3.6 \mathrm{nM}$

$K_{\mathrm{d}}=9 \mathrm{nM}$

Cellular anti-proliferation activity

$E_{50}$ (MLL1-r leukemia cell lines)

$=34-61 \mathrm{nM}$

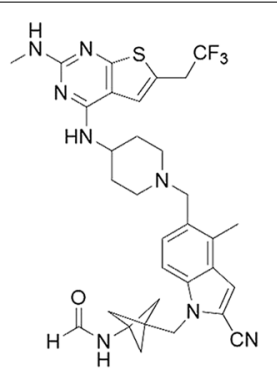

MI-3454

Biochemical activity

$I_{50}=0.51 \mathrm{nM}$

Cellular anti-proliferation activity

$\mathrm{EC}_{50}$ (MLL1-r leukemia cell lines)

$=7.6-27.1 \mathrm{nM}$

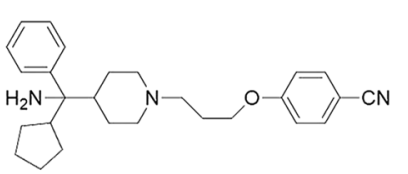

MIV-6

Biochemical activity

$\mathrm{IC}_{50}=67 \mathrm{nM}$

$\mathrm{IC}_{50}$ (R isomer) $=56 \mathrm{nM}$

$\mathrm{IC}_{50}$ (S isomer) $=81 \mathrm{nM}$

$K_{\mathrm{d}}(\mathrm{R}$ isomer $)=85 \mathrm{nM}$

Cellular anti-proliferation activity

$E_{50}$ (MLL1-r leukemia cell lines)

$=2.8-3.7 \mu \mathrm{M}$

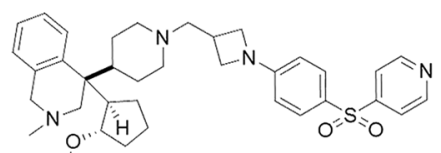

HN

M-89

Biochemical activity

$\mathrm{IC}_{50}=5 \mathrm{nM}$

$K_{d}=1.4 \mathrm{nM}$

Cellular anti-proliferation activity

$\mathrm{EC}_{50}$ (MLL1-r leukemia cell lines)

$=25-55 \mathrm{nM}$

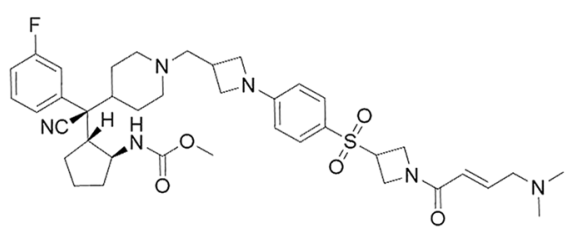

M-525

Biochemical activity

$\mathrm{IC}_{50}=3.3 \mathrm{nM}$

Cellular anti-proliferation activity

$\mathrm{EC}_{50}$ (MLL1-r leukemia cell lines)

$=2.3-31.3 \mathrm{nM}$

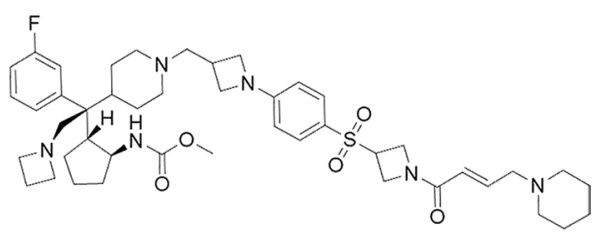

M-808

Biochemical activity

$\mathrm{IC}_{50}=2.6 \mathrm{nM}$

Cellular anti-proliferation activity

$\mathrm{EC}_{50}$ (MLL1-r leukemia cell lines)

$=1-4 \mathrm{nM}$

Fig. 3 Inhibitors of the Menin-MLL1 interaction

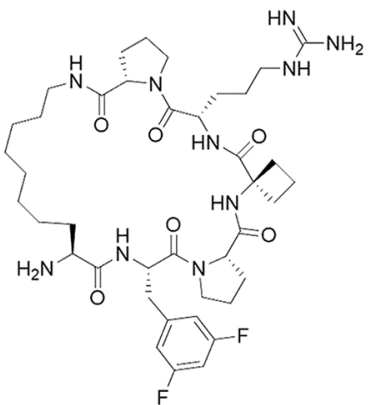

MCP-1

Biochemical activity

$K_{\mathrm{i}}=4.7 \mathrm{nM}$

$\mathrm{IC}_{50}=18.5 \mathrm{nM}$

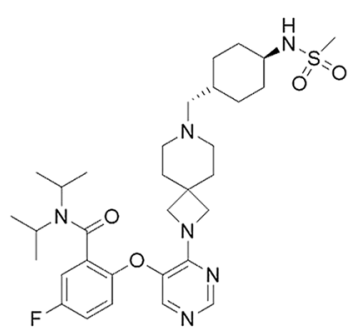

VTP-50469

Cellular anti-proliferation activity

$\mathrm{EC}_{50}$ (MLL1-r leukemia cell lines)

$=13-37 \mathrm{nM}$

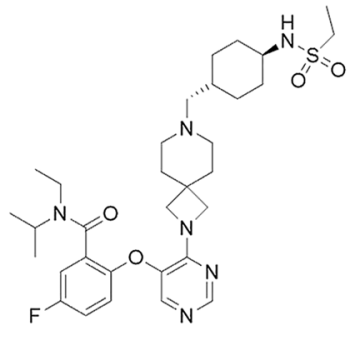

SNDX-5613 between MLL1 and Menin (Fig. 2e, f). The phenyl ring of the compound is located in the binding pocket of MLL1 Phe9, while the cyclopentyl ring fits nicely in that of MLL1 Pro10. The alkoxy linker of the inhibitor mimics the binding of MLL1 Pro13 and the benzonitrile moiety extended into a mostly hydrophobic side pocket, forming a hydrogen bond with Menin residue Trp341.

Systematic optimization of MIV- 6 resulted in the discovery of a covalent inhibitor M-525 with an $\mathrm{IC}_{50}$ of $3.3 \mathrm{nM}$ [59]. Its X-ray structure (PDB: 6B41) shows
M-525 adopts a similar binding mode to MIV-6 (Fig. 2e), while its acrylamide group forms a covalent bond with the Menin residue Cys329, leading to a significantly enhanced binding affinity. Compound M-525 potently inhibited proliferation of MLL1-r leukemia cells with $\mathrm{EC}_{50}$ of 2-30 nM, 1000-fold more active than its noncovalent analogs. Another derivative compound M-808 (Fig. 3) [60] showed more potent biological activities than M-525 with a similar binding structure (Fig. 2e). Compound M-808 at a well-tolerated dose was found to cause 
Table 2 Inhibitors targeting PPIs involving MLL1 in clinical trials

\begin{tabular}{|c|c|c|}
\hline Drug & KO-539 & SNDX 5613 \\
\hline Tumor type & $\begin{array}{l}\text { Advanced malignant neoplasm; Acute myeloid leukemia; Mixed } \\
\text { lineage leukemia; Mixed lineage acute leukemia; Acute leuke- } \\
\text { mia of ambiguous lineage; Mixed phenotype acute leukemia }\end{array}$ & $\begin{array}{l}\text { Acute myeloid leukemia; Acute lymphoblastic leukemia; Mixed } \\
\text { lineage acute leukemia; Mixed phenotype acute leukemia; } \\
\text { Acute leukemia of ambiguous lineage }\end{array}$ \\
\hline Phase & Phase 1, Phase 2 & Phase 1 , Phase 2 \\
\hline Clinical efficacy & Not released & Not released \\
\hline Safety (\% patients) & Not released & Not released \\
\hline Trial number & NCT04067336 & NCT04065399 \\
\hline Status & Recruiting & Recruiting \\
\hline
\end{tabular}

tumor regression in a leukemia xenograft mouse model. Modification of MIV-6 also yielded a non-covalent inhibitor M-89 with comparable biochemical and biological activities to covalent inhibitor M-525 [61]. Crystallographic studies showed that the overall binding of M-89 (Fig. 2e, PDB: 6E1A) mimics that of MIV-6, while M-89 possesses additional favorable interactions, including hydrogen bond interactions of its carbamate group with Tyr276 as well as more hydrophobic interactions. Treatment with M-89 significantly blocked the growth of MLL1-r leukemia cell lines with low nanomolar $\mathrm{EC}_{50}$ values. It also suppressed the expression of MLL1 target genes and induced apoptosis and differentiation of these cells.

There are other inhibitors of the Menin-MLL1 interaction, including macrocyclic peptidomimetic compound MCP-1 [118], a peptidomimetic compound 25 [62], VTP50469 [63] [64], neomycin [65], tobramycin [65], loperamide [66], DCZ_M123 [67], DC-YM21 [66], and cytisine derivative 1a [68].

Two inhibitors of the MLL1-Menin interaction are in clinical trials (Table 2). Compound KO-539 $\left(\mathrm{IC}_{50}=22 \mathrm{nM}\right.$, structure undisclosed) potently inhibited proliferation of a panel of MLL1-r leukemia cell lines with $\mathrm{EC}_{50} \mathrm{~s}$ of $<25 \mathrm{nM}$ [16]. Treatment with KO-539 significantly reduced tumor burden and prolonged the survivals of mice transplanted with MLL1-r leukemia cells. In addition, treatment with KO-539 also achieved complete remission in mouse models of patient-derived xenograft (PDX) leukemias without overt toxicity. The compound has been in Phase I clinical trial (NCT04067336, https:// clinicaltrials.gov/) against relapsed or refractory AML. SNDX-5613 (Fig. 3) [119] has entered a phase 1/2 trial for the treatment of relapsed/refractory leukemias, including those harboring MLL1-r or nucleophosmin 1 (NPM1) mutation (NCT04065399, https://clinicaltrials.gov/).

\section{LEDGF-MLL1(1-160)-Menin interaction Biological function}

LEDGF/p75, as well as its splice variant p52, was first identified as a transcription coactivator [120]. The fulllength LEDGF/p75 consists of 530 amino acids and contains a PWWP (Pro-Try-Try-Pro) domain, AT-hooks (ATH), three charged regions (CR1-3) and an IBD (lentivirus/HIV integrase binding domain) domain (Fig. 4a) [121]. Its shorter p52 variant does not have IBD.

LEDGF's PWWP domain, which is conserved for the protein family, interacts with the chromatin and is essential for the protein function. NMR and other biochemical studies showed that PWWP recognizes and binds mono-nucleosomes containing trimethylated H3K36 (H3K36-Me3) with a high binding affinity $\left(K_{\mathrm{d}} \sim 100 \mathrm{nM}\right)$ [27]. PWWP has a well-defined hydrophobic cavity that selectively interacts with $\mathrm{H} 3 \mathrm{~K} 36-\mathrm{Me}$, while its adjacent basic surface binds DNAs non-specifically. Both events are necessary and cooperative for the tight binding, as PWWP exhibited significantly reduced affinity to either H3K36-Me3 peptide or reconstituted mono-nucleosomes with unmethylated H3K36.

LEDGF's IBD domain was initially found to bind the integrase of human immunodeficiency virus (HIV) and is required for the function of the integrase and viral replication [123-124]. LEDGF IBD has now been found to bind several other proteins, including MLL1 [45, 114], JPO2, and PogZ [125], and recruit them to the chromatin. Importantly, such PPIs are crucial to the functions of these proteins. For MLL1, LEDGF is indispensable for MLL1-dependent transcription [114]. Knockdown of LEDGF by shRNA decreased colony-forming ability of MLL1-ENL transformed cells with downregulated expression of HoxA9. MLL1-ENL with deleted LBD domain $(\Delta 112-153)$ or F129A point mutation, which cannot bind to LEDGF with a high affinity, failed to cause leukemic transformation [114].

Further characterization of the MLL1-LEDGF IBD interaction showed that MLL1 has two IBD-binding motifs (IBM) including IBM1 for residues 123-134 and IBM2 for 147-152 [69, 70]. Both are required for the tight 


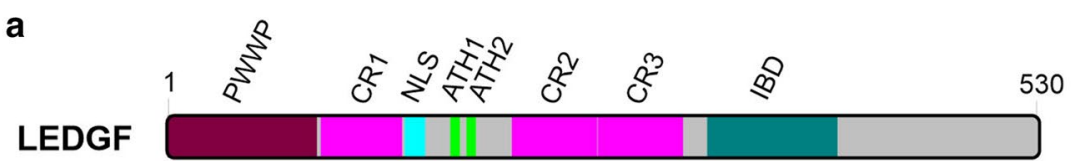

b

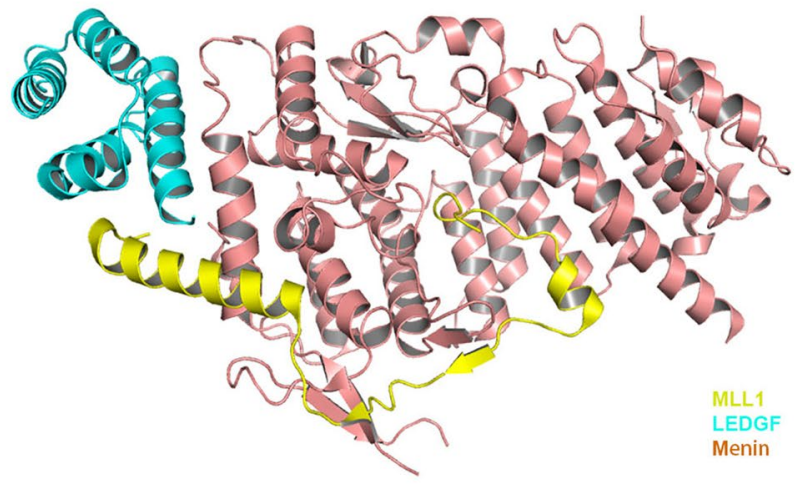

C

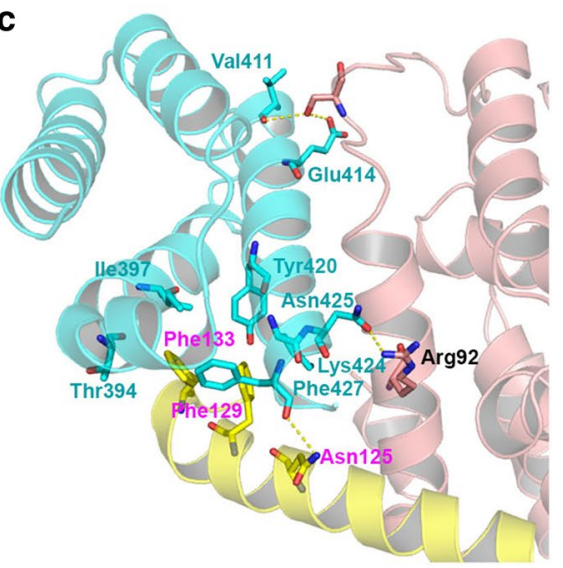

e

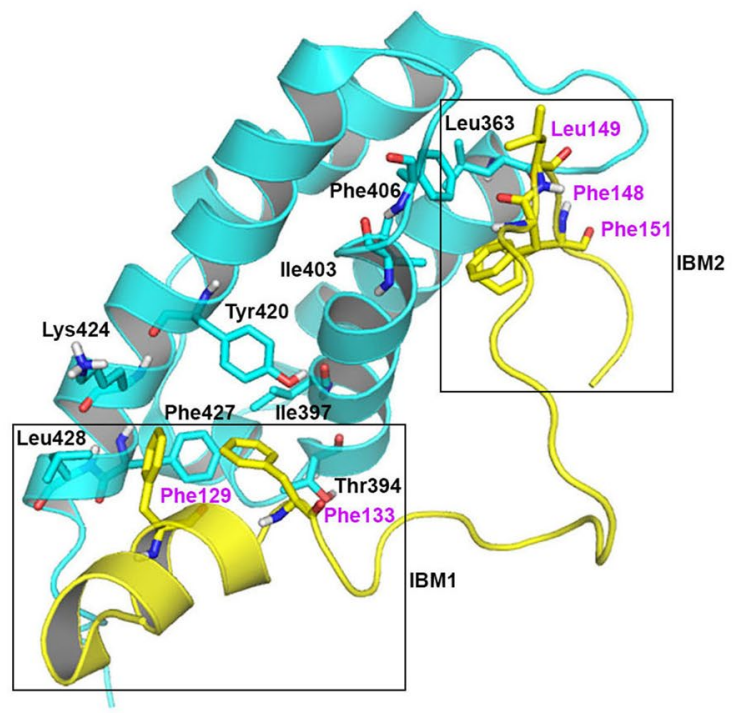

d

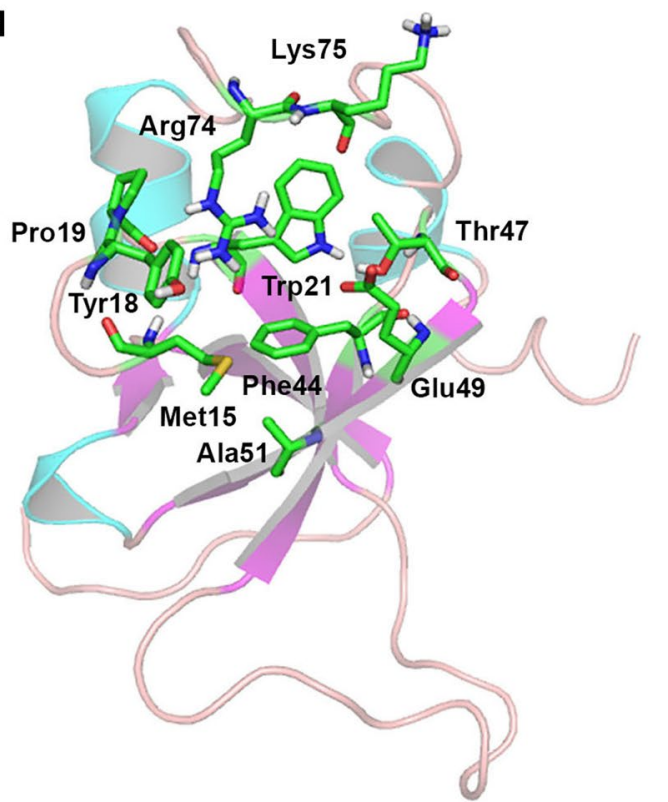

Fig. 4 Schematic illustration and structures of LEDGF. a Schematic illustration of LEDGF containing a PWWP (residues 1-93), CR1 (charged region 1, residues 106-142), NLS (nuclear localization signal, residues 146-156), ATH1 and 2 (AT-hooks 1 and 2, residues 178-183 and 191-197), CR2 and CR3 (residues 208-266 and 266-325), and IBD (integrase binding domain, residues 347-429) domain. b, c X-ray structure of LEDGF-Menin-MLL1 complex (PDB: 3U88). The proteins are shown as cartoon with LEDGF in cyan, Menin in orange, and MLL1 in yellow. Overview of the LEDGF-MeninMLL1 complex in $\mathbf{b}$ and a close-up view of the interactions between LEDGF and Menin-MLL1 in $\mathbf{c}$. The key residues involved in the interaction are shown as stick models. Hydrogen bonds are shown as yellow dashed lines. $\mathbf{d}$, e NMR structure of LEDGF-MLL1 complex (PDB: 2MTN) and LEDGF PWWP (PDB: 2M16). LEDGF-MLL1 complex with LEDGF in cyan and MLL1 in yellow in d and a close-up view of H3K36-Me3 pocket of LEDGF PWWP in e. LEDGF PWWP is presented as cartoon with a-helices in cyan, $\beta$-sheets in magenta and loops in brown. The key residues involved in the formation of this pocket are shown as stick models with $\mathrm{C}$ atoms in yellow

binding of LEDGF to MLL1 as well as the biological functions of MLL1/onco-MLL1. Similar to the F129A mutation in IBM1 [114], point mutations of IBM2 (e.g., F148A and L149A) disrupted the MLL1-LEDGF interaction and abrogated leukemogenic transformation of MLL1AF9 $[69,70]$. These and later studies [126] also revealed 
that LEDGF IBD binds a consensus peptide sequence of D/ExExFxGF in MLL1 IBM2 and several other proteins and such binding is mutually exclusive. These proteins compete with MLL1 to bind to LEDGF IBD and consequently, they are inhibitors of the MLL1-LEDGF interaction. For example, co-expression of HIV integrase or the MLL1(110-160) peptide can disrupt the LEDGF-MLL1 interaction and inhibit proliferation of MLL1-AF9 transformed leukemic cells.

Collectively, high-affinity binding of MLL1 to LEDGF through the MLL1-Menin-LEDGF interactions is essential for MLL1's biological functions. With its PWWP domain, LEDGF provides an additional anchoring point for MLL1 (in addition to MLL1's ATH and CxxC domains) to interact with its target genes in the chromatin, which is critical to MLL1's functions [114]. Deletion of PWWP caused significantly reduced or loss of interaction of LEDGF with the chromatin [121, 127], while substitution of LEDGF PWWP with a PWWP domain from another protein can restore the functions of LEDGF [128-129]. Moreover, while MLL1-ENL without MBM (Menin-binding motif 1-40) cannot cause leukemic transformation, replacement of MBM with LEDGF PWWP (1-93) enabled the engineered MLL-ENL to cause leukemia [114]. However, W21A point mutation in the PWWP of the modified MLL1-ENL failed to do so. These observations show anchoring MLL1 (or oncoMLL1) to the chromatin through its interaction with LEDGF is crucial [114].

\section{Structures of the PPI involving LEDGF}

The first crystal structure of the Menin-MLL1(6-153)LEDGF(IBD) ternary complex (PDB: 3U88) was determined at $2.8 \AA$ resolution (Fig. 4b, c) [45]. It is noted MLL1's IBM2 was not included in the protein complex. LEDGF IBD is bound to a V-shape cleft formed by the Menin N-terminal $\alpha$-helix and the MLL1 IBM1 $\alpha$-helix, which is consistent with the observation that LEDGF only strongly interacts with the Menin-MLL1 complex, but not either of them separately [114]. In the MLL1(IBM1)LEDGF(IBD) interface, LEDGF's Phe427 forms a hydrogen bond with Asn125 of MLL1. MLL1 residues Phe129 and Phe133 are located in a large hydrophobic pocket of LEDGF consisting of Thr394, Ile397, Tyr420, Lys424 and Phe427. Mutations of the Phe129 and Phe133 to Ala severely disrupted the LEDGF-MLL1 interaction [114]. In the LEDGF-Menin interface, residues Val411 and Glu414 of LEDGF have hydrogen bond interactions with Menin Ser104. The hydrogen bond and electrostatic interactions between LEDGF Asn425 and Menin Arg92 also contribute to their binding. While LEDGF was found not to bind Menin directly, the binding affinity $\left(K_{\mathrm{d}}\right)$ of LEDGF to the Menin-MLL1 complex was determined to be 470-1400 nM using isothermal titration calorimetry $[45,69]$ (Table 1).

NMR structures of LEDGF(IBD) fused with an MLL1 peptide including IBM1 and 2 (PDB: 2MTN, 2MSR, and 6EMQ) were determined in solution [69-71]. The IBM1-LEDGF interaction exhibits a similar binding mode as described in the LEDGF-Menin-MLL1 complex (Fig. 4d). MLL1 IBM1 forms an $\alpha$-helix, with the key residues Phe129 and Phe133 favorably located in the hydrophobic cavity of LEDGF. For the IBM2-LEDGF interaction which was also found to be critical to biological functions of MLL1/onco-MLL1 $[69,70]$, the IBM2 peptide is bound in a hydrophobic groove of LEDGF IBD, with Phe148, Leu149 and Phe151 of IBM2 having favorable hydrophobic interactions with the pocket. Mutations of Phe148 and Phe149 of MLL1 abolished the LEDGFMLL1 interaction in vitro and impaired the leukemic transformation ability of MLL1-AF9 in cells and in vivo. The binding affinity of MLL1 peptide (1-160) to LEDGF was determined with a $K_{\mathrm{d}}$ of $14.7 \mu \mathrm{M}$ [69], while complexation with Menin can significantly increase the binding affinity to $\sim 1 \mu \mathrm{M}$ (Table 1 ) $[45,69]$.

Since the binding between LEDGF PWWP and the chromatin is critical to MLL1-r leukemia, the NMR structure of LEDGF PWWP (PDB: 2M16) was determined and used to map the binding of H3K36-Me3 and DNA [27]. Similar to other PWWP domains, LEDGF PWWP was found to adopt a characteristic fold with 5 anti-parallel $\beta$-strands forming a barrel-shaped core (Fig. 4e), in which there is a hydrophobic cavity, formed by resides Trp21, Phe44, Ala51, Arg74, Lys75, Met15, Tyr18, Pro19, Thr47 and Glu49, to accommodate H3K36Me3. Adding an H3K36-Me3 peptide, but not unmethylated H3K36 peptide, caused significant changes of the chemical shifts of these residues, indicating H3K36-Me3 interacts with the cavity. In addition, a large adjacent basic surface area is implicated to bind DNA through non-specific electrostatic interactions [27]. Interactions with both H3K36-Me3 and DNA are important and cooperative for the tight binding, as PWWP exhibited significantly reduced affinity to either H3K36-Me3 peptide or reconstituted mono-nucleosomes with unmethylated H3К 36.

\section{Inhibitors}

As the HIV integrase binding site in LEDGF IBD overlaps with that of MLL1 IBM2 and HIV integrase showed $>100$-fold enhanced affinity, it was found to be a potent inhibitor $\left(\mathrm{IC}_{50}=301 \mathrm{nM}\right)$ of the LEDGF-MLL1 interaction [69]. Expression of HIV integrase in MLL-r leukemia cells suppressed the expression of HoxA9 in a dosedependent manner and exerted antiproliferative activity. Similarly, short MLL1 peptides (residues 146-153, 
8-mer) [69] and LEDGF peptides (residues 424-435 and 375-386) [130] were also found to be inhibitors of such PPI. These peptides impaired proliferation of MLL-AF9 transformed leukemic cells. As LEDGF IBD was responsible for the interaction with HIV integrase for the viral replication, there was a significant interest in finding inhibitors targeting the IBD-integrase interaction. Through a phage display strategy, cyclic peptides CP64 and CP65 were found to specifically bind IBD and inhibit the IBD-integrase interaction as well as HIV replication [131]. Later, CP65 was found to also inhibit the MLL1LEDGF interaction in vitro [70]. In addition, co-expression of CP65 inhibited MLL1-AF9-mediated leukemic transformation and downregulated expression of HoxA9 in these cells.

\section{PPIs involving MLL1 PHD domains Biological function}

PHD domains ( $\sim 50$ amino acids) exist in many nuclear proteins in eukaryotic species [132-134] and recognize methylated histone lysine residues for transcription regulation [135-138]. It is characterized by a conserved $\mathrm{C} 4 \mathrm{HC} 2 \mathrm{C} / \mathrm{H}$ motif that chelate two $\mathrm{Zn}^{2+}$ ions $[139,140]$. MLL1 contains 4 PHD domains and a bromodomain (BRD) located in between PHD3 and 4. The biological functions of PHD1, 2 and 4 are not well understood. PHD1 and 4 were found to be involved in intramolecular interactions between MLL1-N and -C [140], while PHD2 plays a role in ubiquitination and proteasome-mediated degradation of MLL1 [141].

MLL1 PHD3 domain is most studied and characterized. It recognizes and binds $\mathrm{H} 3 \mathrm{~K} 4-\mathrm{Me} 2$ or 3 , which is known to be a histone mark for active gene transcription. While the adjacent BRD was found not to recognize acetylated histone lysine residues (as other bromodomain proteins), it can enhance the binding affinity of PHD3 to H3K4Me3 by sevenfold from a $K_{\mathrm{d}}$ value of $\sim 30 \mu \mathrm{M}$ to $4.3 \mu \mathrm{M}$ (Table 1) [30, 31, 72]. PHD3 has been found to facilitate MLL1 to bind at the HoxA9 gene locus and maintain active transcription of the gene [15, 31]. W1594A or H1596A mutation of PHD3 with impaired binding to H3K4-Me3 caused loss of localization of MLL1 at the HoxA9 and Meis1 loci, as well as suppressed expression of these MLL1-target genes [31]. However, M1585A of PHD3 led to reduced binding to H3K4-Me3 and lowered expression of HoxA9 and Meis1, but it did not affect MLL1's binding to the two genes. These results suggest MLL1 PHD3's ability to bind H3K4-Me3 might not affect MLL1's localization in the genome, but it seems to be critical to the expression of MLL1 target genes.

In addition, PHD3 also interacts with the RNA recognition motif (RRM) of the nuclear cyclophilin Cyp33 [142], a transcription co-repressor protein which recruits histone deacetylase 1 (HDAC1) and suppresses the expression of MLL1 target genes [142, 143]. Moreover, the binding of Cyp33 to PHD3-BRD inhibits their interaction with H3K4-Me3 [72]. In addition to its RRM, Cyp33 contains a C-terminal peptidyl prolyl isomerase domain [144], which catalyzes the cis-trans isomerization of Pro1629 in the linker region of PHD3-BRD and such conformational change disrupts the PHD3-BRD interaction and unblocks the PHD3-Cyp33 RRM interaction [30]. Thus, the cis-trans isomerization of MLL1's Pro1629 appears to act as a gene expression switch. The cis-configuration favors BRD-PHD3-H3K4-Me3 which turns on MLL1-target gene transcription, while transPro1629 enables PHD3 to recruit Cyp33 and suppresses the gene expression. Biologically, overexpression of Cyp33 decreased the levels of H3K4-Me3 at MLL1 target gene loci and downregulated MLL1-mediated gene transcription [72]. No inhibitors have been reported to disrupt the PPIs between PHD3-BRD and H3K4-Me3 or Cyp33.

PHD domains are lost for all oncogenic fusion MLL1. In addition, inclusion of PHD3 in MLL1-ENL abrogated the leukemic transformation ability of the oncogene [145, 146]. These results suggest loss of PHD domains seems to be required for MLL1-r leukemia.

\section{Structures involving MLL1 PHD3}

The crystal structures of MLL1 PHD3-BRD in apo-form (PDB: 3LQH) as well as in complex with H3K4-Me2 and 3 peptides (PBD: 3LQI and 3LQJ) were determined [30]. In the apo-structure (Fig. 5a, b), a flexible loop (residues 1625-1631, in orange) links the structured PHD3 and BRD domains, both of which adopt a characteristic fold of their family proteins [147]. Pro1629 in cis-conformation serves as a crucial turn point, facilitating the PHD3BRD interaction and inhibiting that of PHD3-Cyp33. For the PHD3-BRD interaction, Glu1605 in PHD3 interacts with Leu1724 and Val1723 in BRD through two hydrogen bonds and Glu1600 in PHD3 forms another hydrogen bond with Arg1633 in BRD. In addition, there are favorable hydrophobic interactions between Met1606, Glu1608, Ile1609, and Tyr1619 in PHD3 and Trp1632, Glu1639 and Trp1768 in BRD.

There are no major conformational changes when the H3K4-Me3 peptide binds to PHD3-BRD, except that the loop consisting of the residues $1612-1618$ is moved slightly to widen the binding groove for the H3K4-Me3 peptide. The peptide forms a $\beta$-turn and interacts with PHD3. Without interactions with the H3K4-Me3 peptide, BRD can enhance the binding affinity of the peptide to PHD3 by $\sim 20$-fold, presumably through its interactions with PHD3 [30, 31, 72]. The trimethylated lysine sidechain is inserted into an aromatic cage formed by 
a

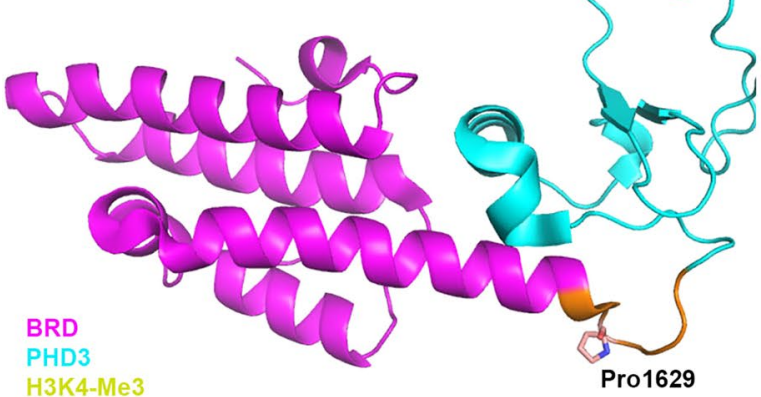

C

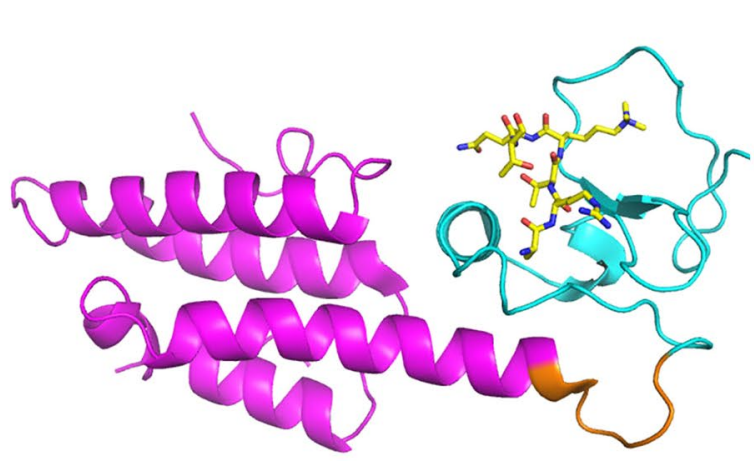

b

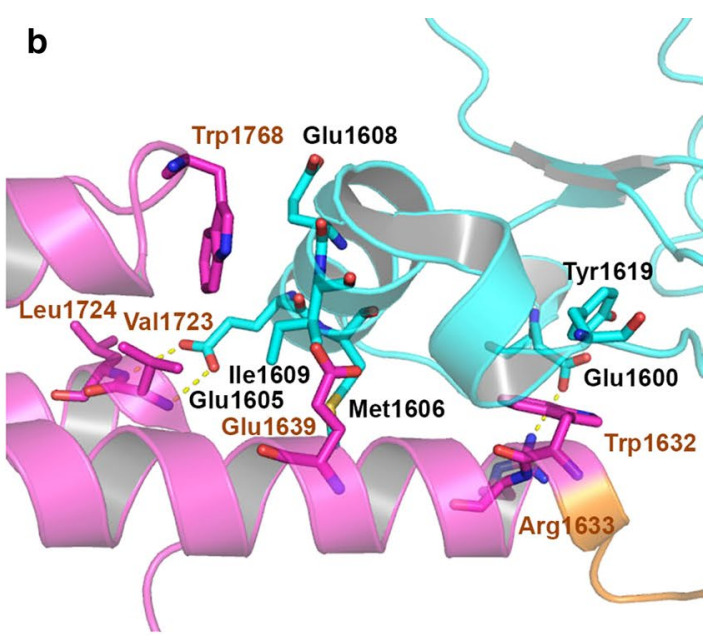

d

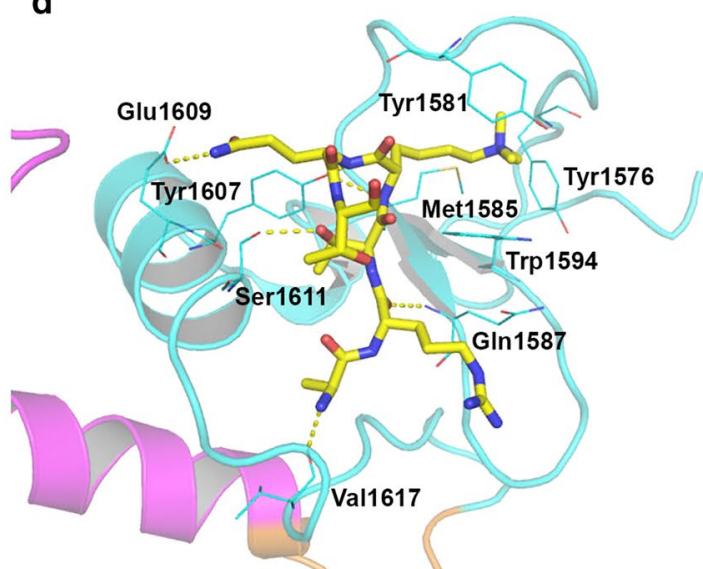

e

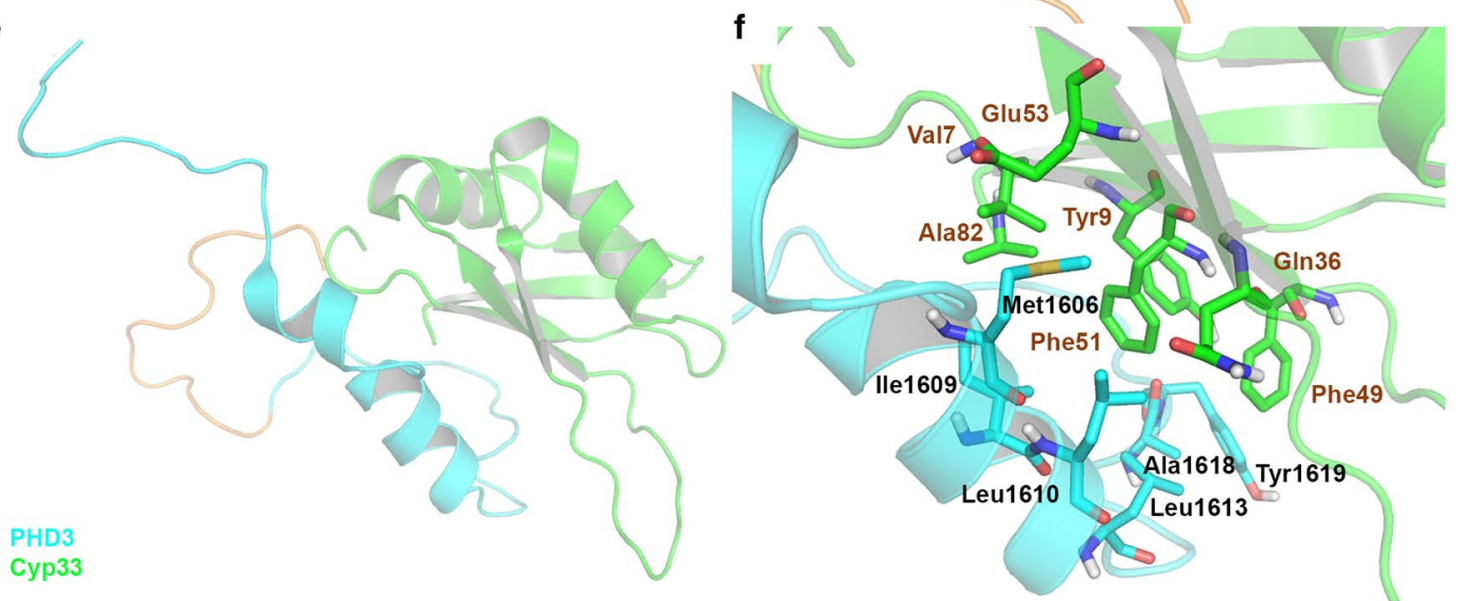

Fig. 5 Structure of PHD3-BRD and Cyp33-MLL1(PHD3) complex. a-d X-ray structures of the PHD3-BRD protein complexes. PHD3 is shown in cyan, $B R D$ in magenta and the flexible loop in between the two domains in orange. Overview of apo-PHD3-BRD (PDB: $3 L Q H)$ in (a). A close-up view of the PHD3-BRD interaction in b. Overview of the PHD3-BRD-H3K4-Me3 complex (PBD: 3LQJ) in c. A close-up view of the PHD3-H3K4-Me3 interaction in d. The H3K4-Me3 peptide is shown as a stick model with C atoms in yellow. Hydrogen bonds are shown as yellow dashed lines. $\mathbf{e}, \mathbf{f}$ Solution NMR structure of the Cyp33-MLL1(PHD3) complex with PHD3 in cyan, Cyp33 in green and the linker between them in orange (PDB: 2KU7). Overview of Cyp33-MLL1(PHD3) complex in $\mathbf{e}$, and a close-up view of Cyp33-MLL1 (PHD3) interaction in $\mathbf{f}$ 
Try1576, Try1581, Met1585 and Trp1594 of PHD3. It is of interest that as compared to the apo-structure, the orientations of these residue sidechains are changed significantly to accommodate H3K4-Me3. The peptide form hydrogen bond and electrostatic interactions with Met1585, Gln1587, Try1607, Glu1608, Ser1611, and Val1617 of PHD3. The H3K4-Me2 peptide exhibits almost the same binding mode to PHD3-BRD. Mutagenesis studies confirmed the importance of the residues Tyr1581, Gln1587, and Trp1594 in the interactions between PHD3-BRD and H3K4-Me2/3. Consistent with structure analysis, H3K4-Me2/3 show similar binding affinity to PHD3-BRD in ITC assay with $K_{\mathrm{d}}$ values of 6.9 and $4.3 \mu \mathrm{M}$ [30] (Table 1), respectively.

As described earlier, Cyp33's peptidyl prolyl isomerase domain [144] catalyzes the cis-trans isomerization of Pro1629, which disrupts the PHD3-BRD interaction and the released PHD3 interacts with Cyp33's RRM domain [30]. The PHD3-Cyp33 binding recruits HDAC1 and suppresses the expression of MLL1 target genes [142, 143]. An NMR structure of Cyp33(RRM) in complex with MLL1(PHD3) (Fig. 7e/f, PDB: 2KU7) [30] shows that formation of the RRM-PHD3 complex is mostly driven by hydrophobic interactions. The sidechains of Met1606, Ile1609, and Leu1610 of PHD3 occupy a hydrophobic groove formed by the RRM residues Val7, Gln36, Phe51, Glu53 and Ala82. There are also favorable interactions between Leu1613, Ala1618 and Tyr1619 of PHD3 and Tyr9 and Phe49 of RRM. The binding affinity $\left(K_{\mathrm{d}}\right)$ of the PPI was determined to be $14.7 \mu \mathrm{M}$ [72].

\section{MLL1(TAD)-CBP(KIX) interaction}

Human CBP (cAMP-response element binding protein (CREB)-binding protein), as well as its paralog p300 (E1A-associated protein $\mathrm{p} 300$ ), is a multidomain transcription coactivator containing a histone acetyltransferase (HAT) domain. Through acetylation at various histone lysine residues, $\mathrm{CBP} / \mathrm{p} 300$ play important roles in active gene transcription [148, 149]. Moreover, CBP/p300 can acetylate a number of transcription factors to regulate gene expression [150, 151]. In addition to its HAT activity, CBP/p300 also serves as a hub protein for the assembly of transcriptional protein complexes [148]. The KIX domain of CBP/p300 mediates PPI with a number of transcription factors, including MLL1, CREB, and c-Myb $[152,153]$. The MLL1(TAD)-CBP(KIX) interaction has been found to be critical to MLL1-mediated gene expression [73]. Moreover, the MLL1-CBP interaction can enhance the interaction between CBP and c-Myb [73, 154].

The solution structure of an MLL1(TAD)-CBP(KIX)c-Myb ternary complex (PDB: 2AGH) was determined using NMR [75]. MLL1 (residues 2844-2857) forms an $\alpha$-helix, occupies a large groove of the KIX domain of CBP, and has no contact with c-Myb (Fig. 6a). MLL1's binding is mostly driven by hydrophobic interactions with the groove of KIX formed by Ile611, Phe612, Arg624, Leu628, Tyr631, Leu664, Arg668, and 669 (Fig. 6b). A mutagenesis study confirmed the importance of Leu628 to the PPI [155]. The binding affinity $\left(K_{\mathrm{d}}\right)$ was determined to be $\sim 3 \mu \mathrm{M}[73,74]$ (Table 1 ).

In addition to a MLL1-mimetic peptide inhibitor [78], a series of isoxazolidines were found to bind the KIX domain of CBP and inhibit the MLL1-CBP interaction [76]. The representative compound iTAD 1 exhibited a modest $\mathrm{IC}_{50}$ of $38 \mu \mathrm{M}$ (Fig. $6 \mathrm{c}$ ). In addition, sekikaic and lobaric acid were also identified to be weak inhibitors of the PPI [77].

\section{PPIs involving MLL1's H3K4 methyltransferase SET domain Biological function}

The SET domain of human MLL1 (residues 3829-3945) is highly conserved during evolution, which was first found in Drosophila proteins $\mathrm{Su}(\mathrm{Var}) 3-9$, Enhancer-ofzeste and Trithorax [156]. Based on this homology, MLL1 has been classified into a family of histone/protein lysine methyltransferases (KMT) in mammals, which include MLL2-5 and SET1A and B. In complexation with several proteins, MLL1's SET catalyzes mono-, di-, and tri-methylation of H3K4 [157]. Because methylated H3K4 has been linked to active gene transcription [158], MLL1 SET as well as its mediated H3K4 methylation was believed to be essential for MLL1 to regulate gene expression. However, although germline knockout of MLL1 is embryonic lethal [11], mouse embryos bearing homozygous MLL1 with SET truncated (MLL1 $(\triangle \mathrm{SET})$ ) can develop and grow into adulthood without apparent weight or growth differences, except that there were minor skeletal defects and altered gene expression associated with reduced H3K4 mono-methylation at certain Hox gene loci [159]. Global H3K4 methylation was not significantly affected by the SET deletion. More investigation showed that the hematopoietic stem/progenitor cells (which are particularly sensitive to the loss of MLL1) of these MLL1( $\triangle \mathrm{SET})$ mice had normal hematopoiesis as well as expression of MLL1 target genes [160]. These mouse model and cellbased studies support that MLL1 SET is largely dispensable for MLL1-regulated hematopoiesis. Moreover, MLL1-AF9 was found to cause leukemic transformation of the MLL1 $(\triangle \mathrm{SET})$ hematopoietic stem/progenitor cells without significant differences from those with WT MLL1 [160], indicating SET is also dispensable for onco-MLL1-mediated leukemogenesis. Collectively, SET as well as its $\mathrm{H} 3 \mathrm{~K} 4$ methylation activity is not responsible for MLL1's major biological functions and more studies of MLL1 SET are therefore needed. 


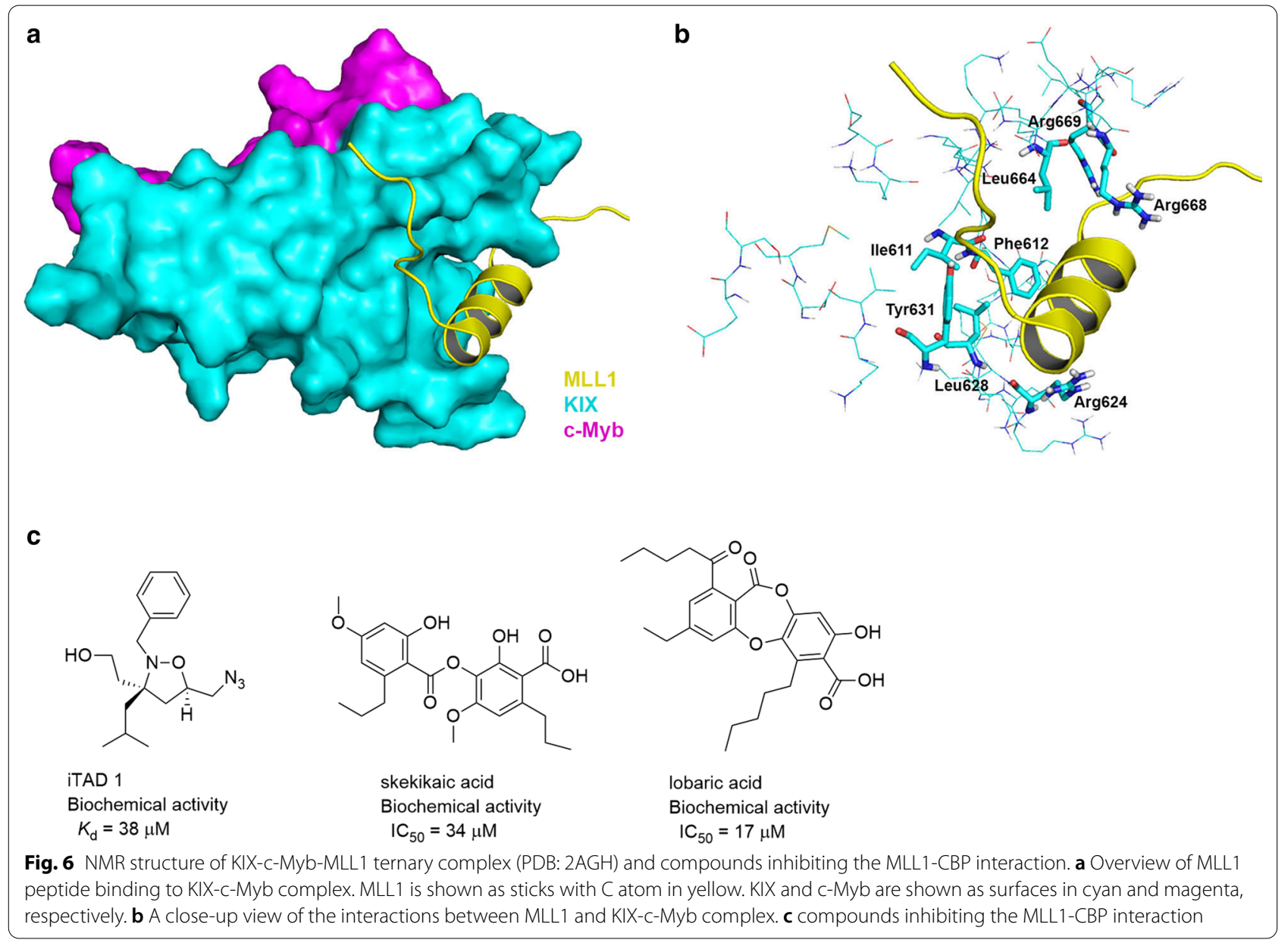

Nonetheless, biochemistry and structural biology of the H3K4 methyltransferase of MLL1 have been well studied. All the MLL family KMTs exhibit a similar mechanism of action. Their SET domain itself is catalytically inactive. Complexation with RbBP5 and ASH2L is required for SET to become an active methyltransferase [19]. Moreover, different from other MLL family proteins, MLL1 does not bind to RbBP5-ASH2L strongly (with $K_{\mathrm{d}} \sim 126 \mu \mathrm{M}$, versus $K_{\mathrm{d}} \sim 130 \mathrm{nM}$ for MLL3). Therefore, MLL1-RbBP5-ASH2L exhibited only weak activity. Further inclusion of WDR5 can significantly enhance the catalytic activity [19], because WDR5 binds both MLL1 and RbBP5 to link the two proteins. In contrast, the ternary complexes of MLL2-4, SET1A or B with RbBP5 and ASH2L are fully active and WDR5 is unnecessary. These proteins showed a high binding affinity to the RbBP5ASH2L complex in pull-down and fluorescence polarization assays, with MLL3 being the strongest.

The structural basis of these PPIs has been investigated. X-ray structures of MLL3 and N3861I/Q3867L mutant MLL1 (which has a high affinity to RbBP5-ASH2L) in complex with RbBP5-ASH2L, including a SAM analog
$S$-adenosyl- $L$-homocysteine and the substrate histone H3(1-9) peptide (PDB: 5F6K and 5F6L), were determined and reveal the PPIs among these proteins [19]. The C-terminal SPRY domain of ASH2L interacts with the ASH2L binding motif (ABM) of RbBP5 [161, 162]. RbBP5 also has a WDR5-binding motif (WBM) which can bind and recruit WDR5. For MLL1, structural analysis showed that the hydrophilicity and/or bulkiness of Asn3861 and Gln3867 (as contrast to Ile/Leu or Thr/Val in MLL2 or 3) significantly weaken MLL1's affinity to RbBP5-ASH2L, such that WDR5 is required for MLL1 to strongly associate with two cofactor proteins for H3K4 methylation [19]. A double-mutant MLL1 with N3861I and Q3867L behaved similarly to MLL3 and WDR5 is unnecessary for its catalytic activity. Mechanistically, the SET domain of the MLL family proteins alone was thought to adopt an open conformation that does not allow an efficient methyl transfer from SAM to the amino group of the lysine sidechain [163]. However, it was later found that upon binding with RbBP5-ASH2L, the active enzyme exhibits no conformational changes [19]. Rather, the conformation of the MLL family SET is highly dynamic and 

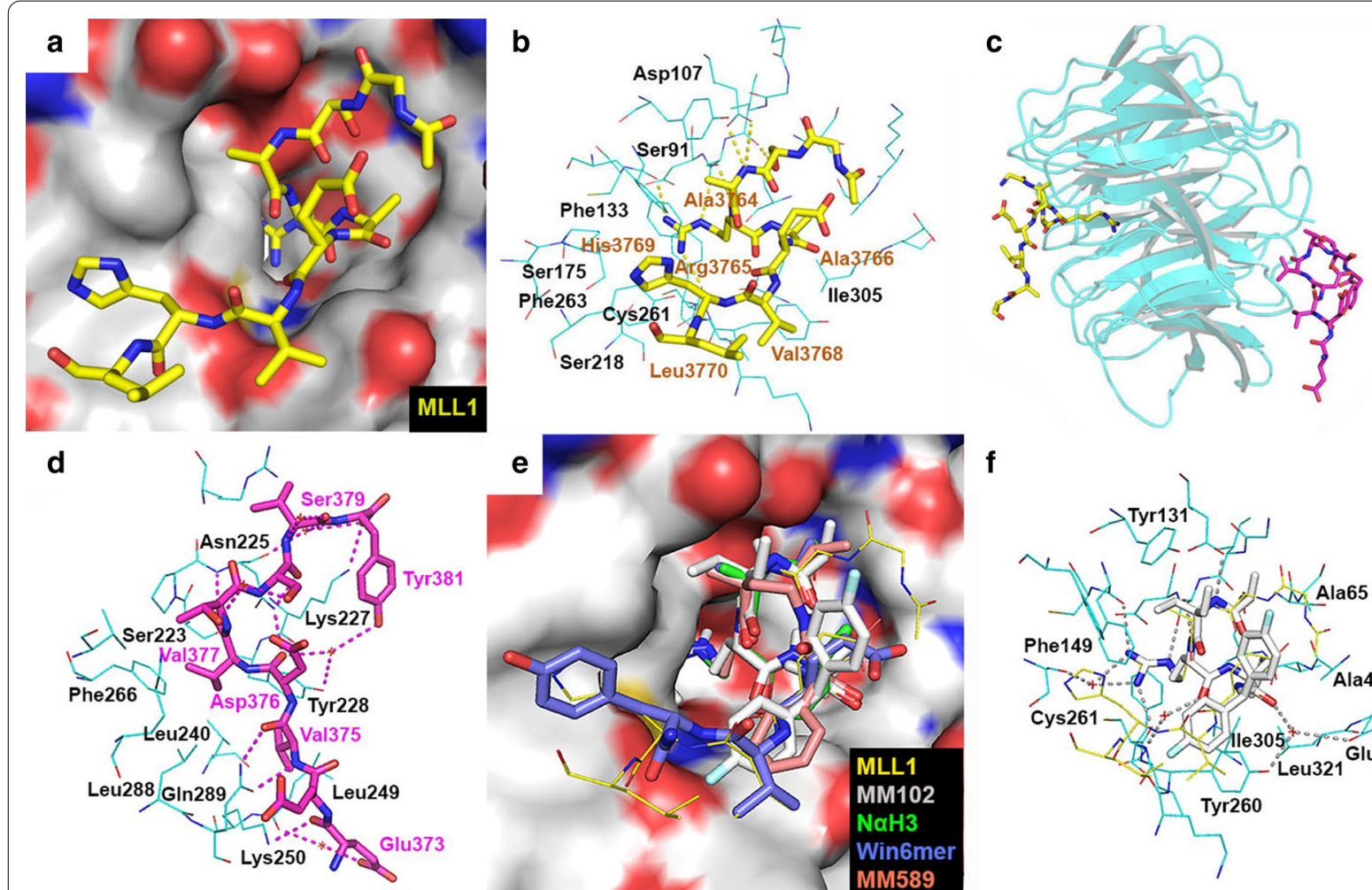

MLL1
WDR5
RbBp5
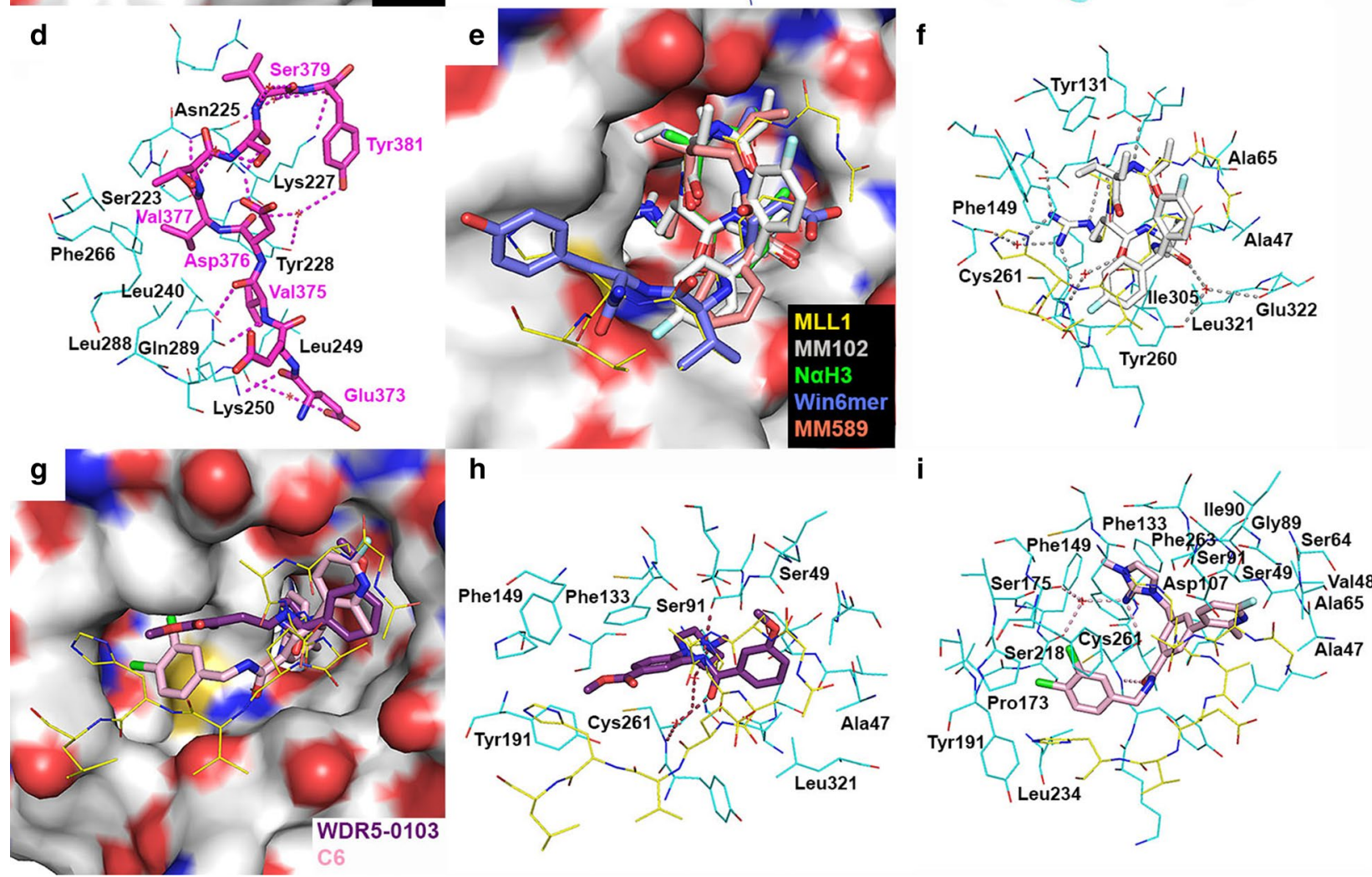

Fig. 7 X-ray structures of the PPIs involving MLL1 SET and WDR5 in complex with its inhibitors. a A close-up view of the binding site of MLL1 peptide in WDR5 (PDB: 3EG6). b A close-up view of the WDR5-MLL1 interaction. c Overview of the MLL1-WDR5-RBBP5 complex (PDB: 3P4F). WDR5 is shown as cartoon in cyan and RbBP5 and MLL1 as stick models with C atoms in magentas and yellow, respectively. $\mathbf{d}$ A close-up view of the RbBP5-WDR5 interaction. e The active site of WDR5-MLL1 complex (PDB: 3EG6), WDR5-NaH3 (PDB: 3PSL), WDR5-Win6mer (PDB: 5SXM), WDR5-MM102 (PDB: 4GM8) and WDR5-MM589 (PDB: 5VFC). f The active site of WDR5-MM102 (PDB: 4GM8), superimposed with the structure of WDR5-MLL1 complex (PDB: 3EG6). g The active site of WDR5-MLL1 complex (PDB: 3EG6), WDR5-WDR5-0103 (PDB: 3UR4) and WDR5-C6 (PDB: 6E23). $\mathbf{h}$ The active site of WDR5-WDR5-0103 (PDB: 3UR4), superimposed with the structure of WDR5-MLL1 (PDB: 3EG6). $\mathbf{i}$ The active site of WDR5-C6 (PDB: 6E23), superimposed with the structure of WDR5-MLL1 (PDB: 3EG6). Compounds NaH3, Win6mer, MM102, MM589, WDR5-0103 and C6 are shown as stick models with $C$ atoms in green, blue, grey, orange, purple and pink, respectively. In these structures, WDR5 is shown as an electrostatic surface and the MLL1 peptide as a line model with C atoms in yellow. Hydrogen bonds are shown as dashed lines

it cannot efficiently perform the catalytic reaction. Complexation with RbBP5-ASH2L significantly reduces the flexibility and enhances the MLL family proteins' ability to bind SAM and recognize the substrate.
Given WDR5's critical role in MLL1-catalyzed H3K4 methylation, the WDR5-MLL1 interaction has been investigated as a potential target for intervention. In addition, since WDR5 is only essential for MLL1 SET, targeting WDR5-MLL1 could achieve a high selectivity 
over other MLL family methyltransferases. Knockdown of WDR5 was found to decrease cellular H3K4me3 levels on HoxA9 and HoxC8 loci and suppressed the expression of these genes [164]. The residues 3745-3969 in MLL1 was identified to be the Win using sedimentation velocity analysis, with the key residue Arg3765 bound to the arginine binding pocket of WDR5, which was previously found for the recognition of histone H3K4me2 [80, 82]. Substitution of Arg3765 with an alanine or mutation of the residues in the arginine binding pocket of WDR5 disrupted the PPI [80]. A Win-derived peptide can dosedependently inhibit the WDR5-MLL1 interaction and prevent MLL1 from association with WDR5-RbBP5ASH2L, thereby inhibiting the catalytic activity of MLL1. Thus, disruption of WDR5-MLL1 interaction can selectively inhibit MLL1's catalytic activity in vitro, although as described above, more convincing evidence is needed to clarify whether targeting such PPI as well as MLL1catalyzed H3K4 methylation affects MLL1-mediated hematopoiesis and MLL1-r leukemia.

\section{Structures of the MLL1-WDR5-RbBP5 complex}

The crystal structure of WDR5 in complex with an MLL1 Win-derived 13- or 17-mer peptide (PDB: 3EG6, 3EMH, and 4ESG) show the peptide occupies a funnel-like pocket of WDR5 (Fig. 7a) [81-83], with the critical residue Arg3765 (of MLL1) deeply inserted into the narrow opening. Arg3765 has hydrogen bond and electrostatic interactions with Phe133, Cys261 and Ser91 of WDR5, together with hydrophobic interactions with Ser175, Ser218, Phe263, and Ile305 that surround its carbon sidechain. These interactions are essential for the MLL1WDR5 binding, as a point mutation of Arg3765 abrogates the PPI [80]. Furthermore, the F133A mutation of WDR5 also significantly decreased the interaction between MLL1 and WDR5 in biochemical study [80, 165]. In addition, Ala3764 and Ala3766 have hydrogen bond as well as hydrophobic interactions with WDR5 residues Ser91 and Asp107. Val3768, His3769 and Leu3770 of the peptide recognize a nearby surface pocket of WDR5. The binding affinity of MLL1 to WDR5 was determined with $K_{\mathrm{d}}$ values of $0.12-1.7 \mu \mathrm{M}[80,81]$ (Table 1 ).

In addition, the ternary structure of WDR5 in complex with RbBP5 and MLL1 was determined (PDB: 3P4F), which reveals structural basis for WDR5 to bridge MLL1 and RbBP5 [79]. In this complex, the RbBP5 and MLL1 peptide bind to the opposite sides of WDR5 (Fig. 7c). MLL1 binds to WDR5 similarly as found in the MLL1WDR5 binary complex. There are a network of hydrogen bonds stabilizing the RbBP5-WDR5 interaction (Fig. 7d). RbBP5 residues Asp376, Val377, Ser379 form multiple hydrogen bonds with WDR5 residue Asn225. Glu373, Val375, and Tyr381 of RbBP5 also interact with WDR5 residues Lys250, Gln289, and Lys227 through hydrogen bonds. In addition, Glu373 and Asp376 of RbBP5 engage in a water molecule-mediated hydrogen bond interactions with Leu249 and Tyr228 of WDR5. Tyr381 of RbBP5 also forms two water-mediated hydrogen bonds with Tyr228 and Asn225 of WDR5. Moreover, there are favorable hydrophobic interactions between RbBP5 residues Val375 and Val377 and WDR5 residues Leu249, Tyr228, Leu240, Lys250, Phe266, Ser223, and Leu288. Mutagenesis studies showed that mutation of WDR5 residues Asn225 and Gln289 resulted in > 20-fold decreased binding affinity to RbBP5 as well as $\sim$ threefold reduced HMT activity. Similarly, mutations of RbBP5 residues Val375 and Val377 also reduces its affinity to WDR5 with a considerably decreased catalytic activity.

\section{WDR5-binding compounds that inhibit MLL1 SET methyltransferase.}

A histone H3-based peptide $\mathrm{N \alpha H3}$ (AcARTKQA) was developed and showed high binding affinity $\left(K_{\mathrm{d}}=0.13 \mu \mathrm{M}\right)$ to WDR5 as well as inhibited the KMT activity of MLL1 with an $\mathrm{IC}_{50}$ value of $4.1 \mu \mathrm{M}$ [87]. The $\mathrm{X}$-ray structure of the WDR5-NaH3 complex (PDB: 3PSL) shows that the peptide occupies the binding pocket of the MLL1 peptide and mimics its binding pose (Fig. 7e, f). An MLL1 Win-derived 12-mer peptide (GSARAEVHLRKS) was found to bind WDR5 with a $K_{\mathrm{d}}$ of $1.7 \mu \mathrm{M}$ [81] and modestly inhibit H3K4 methylation with an $\mathrm{IC}_{50}$ of $\sim 400 \mu \mathrm{M}$ [80]. Subsequently, a structurebased design led to the finding of a Win-derived 6-mer peptide Win6mer (ARTEVY), which exhibited considerably increased binding affinity to WDR 5 with a $K_{\mathrm{d}}$ value of $2.9 \mathrm{nM}$ [88]. The X-ray structure of the WDR5-Win6mer complex (PDB: 5SXM) shows it exhibits a similar binding pose (Fig. 7e, f). Win6mer selectively inhibited MLL1's KMT activity with an $\mathrm{IC}_{50}$ value of $2.3 \mu \mathrm{M}$ [88].

Efforts on shortening the 12-mer Win-derived peptide yielded a 3-mer peptide Ac-ARA- $\mathrm{NH}_{2}$, which showed a $K_{\mathrm{i}}$ of $120 \mathrm{nM}$ [89]. Further investigation found an H3-derived 3-mer peptide Ac-ART- $\mathrm{NH}_{2}$ exhibited a higher binding affinity $\left(K_{\mathrm{i}}=20 \mathrm{nM}\right)$ [89]. Modifications based on Ac-ARA- $\mathrm{NH}_{2}$ produced a peptidomimetic compound MM-102 (Fig. 8) with a $K_{\mathrm{d}}$ of $<1 \mathrm{nM}$ and $\mathrm{IC}_{50}$ of $400 \mathrm{nM}$ against KMT. It also inhibited proliferation of MLL1-r leukemia cells with an $\mathrm{EC}_{50}$ of $\sim 25 \mu \mathrm{M}$ [84]. Its structure in WDR5 (PDB: 4GM8) shows that in addition to the interactions between the MLL1 peptide and WDR5, MM-102 has additional interactions with the protein (Fig. 7e, f). The two fluorophenyl groups of MM-102 make hydrophobic interactions with WDR5 residues Ala47, Ala65, Tyr131, Phe149, Ile305, and Leu321. The carbonyl of its Arg moiety interacts with the backbone of Cys261 of WDR5. The carbonyl close to 


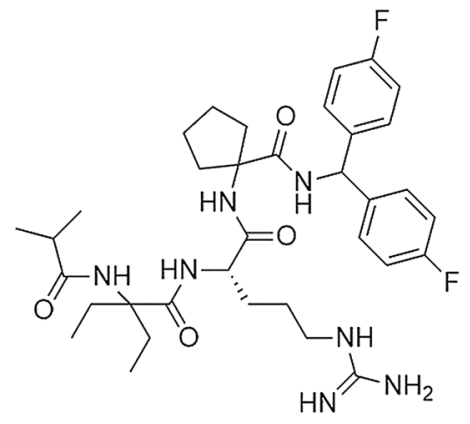

MM-102

Biochemical activity

$\mathrm{IC}_{50}=2.4 \mathrm{nM}$

$K_{\mathrm{d}}<1 \mathrm{nM}$

$\mathrm{IC}_{50}$ (HMT inhibition) $=0.4 \mu \mathrm{M}$

Cellular anti-proliferation activity

$\mathrm{EC}_{50}$ (MLL1-r leukemia cell lines)

$=25 \mu \mathrm{M}$<smiles>CC[C@H](NC(=O)[C@H](CCCNC(=N)NC)NC(=O)[C@](C)(CCNC(=O)C(NC(=O)C(C)C)c1ccccc1)NC(=O)C(C)C)C(=O)NC</smiles>

MM-589

Biochemical activity

$\mathrm{IC}_{50}=0.9 \mathrm{nM}$

$K_{\mathrm{i}}<1 \mathrm{nM}$

$\mathrm{IC}_{50}$ (HMT inhibition) $=12.7 \mathrm{nM}$

Cellular anti-proliferation activity

$\mathrm{EC}_{50}$ (MLL1-r leukemia cell lines)

$=0.21-0.25 \mu \mathrm{M}$<smiles>COC(=O)c1ccc(N2CCN(C)CC2)c(NC(=O)c2cccc(OC)c2)c1</smiles>

WDR5-0103

Biochemical activity

$K_{\mathrm{d}}($ ITC $)=0.45 \mu \mathrm{M}$

$K_{\mathrm{d}}(\mathrm{FP})=3.0 \mu \mathrm{M}$

$\mathrm{IC}_{50}$ (HMT inhibition) $=39 \mu \mathrm{M}$<smiles>CN1CCN(c2ccc(-c3cccc(CN4CCOCC4)c3)cc2NC(=O)c2c[nH]c(=O)cc2C(F)(F)F)CC1</smiles>

OlCR-9429

Biochemical activity $K_{d}(F P)=93 n M$<smiles>COc1cc(C(=O)NC2CCc3ccc(-c4cn5c(n4)CCC5)cc32)cc(OC)c1C</smiles>

$6 e$

Biochemical activity

$K_{\mathrm{i}}(\mathrm{FP})<1 \mathrm{nM}$

$K_{i}($ TR-FRET $)=0.902 \mathrm{nM}$

$\mathrm{IC}_{50}$ (HMT inhibition $)=3.20 \mu \mathrm{M}$

Cellular anti-proliferation activity

$\mathrm{EC}_{50}(\mathrm{MV} 4 ; 11)=7.25 \mu \mathrm{M}$<smiles>Cc1nc(F)ccc1-c1cc(Cn2ccn(C)c2=N)cc(C(=O)NCc2ccc(Cl)c(Cl)c2)c1</smiles>

C6

Biochemical activity $K_{d}(S P R)=189 \mathrm{pM}$ $K_{i}($ TR-FRET $)=0.106 \mathrm{nM}$

$I_{50}$ (HMT inhibition $)=19.9 \mathrm{nM}$

Cellular anti-proliferation activity

$\mathrm{EC}_{50}$ (MLL1-r leukemia cell lines)

$=3.20-6.43 \mu \mathrm{M}$

Fig. 8 Inhibitors of the MLL1-WDR5 interaction

the fluorophenyl groups forms a water-bridged hydrogen bond interaction with Tyr260 and Glu322. Macrocyclic peptides are also inhibitors [36, 90], such as 14-membered cyclic peptide MM-589. It showed more binding affinity to WDR5 as well as inhibitory activity against H3K4 methylation $\left(\mathrm{IC}_{50}=12.7 \mathrm{nM}\right)$ [90]. Crystallography studies (Fig. 7e, PDB: 5VFC) revealed that MM-589 with the small macrocyclic ring nicely fits into the funnel of WDR5. MM-589 selectively inhibited proliferation of MLL1-r leukemia cells with $\mathrm{EC}_{50} \mathrm{~s}$ of $\sim 250 \mathrm{nM}$, significantly more potent than other WDR5 inhibitors.

Through compound screening, a series of N-(2-(4methylpiperazin-1-yl)-5-nitrophenyl)benzamide compounds have been discovered to be small-molecule inhibitors of the MLL1-WDR5 interaction, with compound WDR5-0103 (Fig. 8) being the most potent [91]. It exhibited a low micromolar binding affinity to WDR5 in biophysical assays and selectively inhibited the KMT activity with an $\mathrm{IC}_{50}$ of $39 \mu \mathrm{M}$. Its crystal structure in WDR5 (PDB: 3UR4) shows its binding is quite different from that of the MLL1 peptide (Fig. $7 \mathrm{~g}, \mathrm{~h}$ ). The positively charged $N$-methylpiperazine group (at the physiological $p \mathrm{H}$ ) mimics Arg of the peptidic inhibitors and is inserted into the WDR5 deep tunnel (Fig. 7g, h), with its distal $\mathrm{N}$ atom forming a water-mediated hydrogen bond with Cys261. The central phenyl ring has a $\pi-\pi$ 
interaction with Phe133, with its attached ester moiety well fitted in a hydrophobic cleft formed by Tyr191 and Phe149. The amide group interacts with Cys261 through a water-bridged hydrogen bond. In addition, the methoxylphenyl moiety is located a shallow cavity surrounded by residues Ala47, Ser49, Ser91, and Leu32. Modifications based on compound WDR5-0103 furnished inhibitors with considerably improved affinity $[85,86,92-96]$, such as OICR-9429 $\left(K_{\mathrm{d}}=93 \mathrm{nM}\right.$, Fig. 8) [85, 86]. In cell-based assays, OICR-9429 inhibited proliferation and induced the differentiation of AML patient cells.

An NMR-based fragment screening has identified a series of imidazole-containing inhibitors, with compound $6 \mathrm{e}$ (Fig. 8) being the most potent with a $K_{\mathrm{i}}$ value of $<1 \mathrm{nM}$. This compound moderately inhibited the KMT activity $\left(\mathrm{IC}_{50}=3.2 \mu \mathrm{M}\right)$ [97]. It also exhibited a modest anti-proliferative activity against MLL1-r leukemia cells. The same strategy led to the discovery of compound C6 (Fig. 8) with a $K_{\mathrm{d}}=0.2 \mathrm{nM}$ (to WDR5) as well as $\mathrm{IC}_{50}$ of $20 \mathrm{nM}$ against H3K4 methylation [98-100]. The X-ray structure of the WDR5-C6 complex (PDB: 6E23) shows that its basic 2-imino-2,3-dihydroimidazole group mimics the Arg of the MLL1 Win peptide (Fig. $7 \mathrm{~g}$, i). It forms direct and water-bridged hydrogen bonds and has electrostatic interactions with Ser175, Ser218 and Cys261. Moreover, the imidazole ring is sandwiched in between the aromatic side chains of Phe133 and Phe263 with favorable $\pi-\pi$ interactions. The amide group of compound C6 forms a hydrogen bond with Cys261. The lipophilic dichlorobenzyl group resides in a hydrophobic pocket formed by the side chains of Phe149, Pro173, Tyr191, Leu234, Ser218 and Cys261. In addition, the binding of $\mathrm{C} 6$ is further enhanced by the hydrophobic interactions of its pyridine moiety with a hydrophobic pocket surrounded by Ser91, Asp107, Ile90, Gly89, Ser49, Ser64, Ala65, Val48, and Ala47. In cell-based assays, compound C6 was found to selectively inhibit the proliferation of MLL1-r leukemia cells with $\mathrm{EC}_{50}$ values of 3-6 $\mu \mathrm{M}$. Moreover, piribedil [101], rabeprazole [102], DC_M4_1 and DC_M5_2 [103] were reported to be small-molecule inhibitors of the MLL1-WDR5 interaction.

\section{Other PPIs involving MLL1}

Several other PPIs involving MLL1 play important roles in health and diseases. For example, the MLL-N and MLL-C interaction through their FYRN and FYRC domains is important for the stability and functions of MLL1 [42] and disruption of such interaction by expression of a competing FYRC peptide caused significant MLL1 degradation [166]. In addition to its DNA-binding ability, MLL1's CxxC domain interacts with PAFc, which facilitates MLL1 binding to its target genes (e.g., HoxA9 and Meis1) for transcription [15, 29]. Inhibition of the MLL1-PAFc interaction by expression of a competing MLL1 peptide blocked MLL1-mediated gene expression as well as onco-MLL1-induced leukemogenesis [167]. In addition to CBP/p300 described above, MLL1's TAD domain interact with other histone/protein acetyltransferases $\mathrm{MOZ}$ and MOF for target gene expression activation [32, 160]. However, these PPIs have not been well characterized and their biochemistry, structural biology and pharmacological inhibition await further investigation.

\section{PPIs involving MLL1 fusion proteins}

In MLL1-r leukemia, chromosome translocations produce an oncogenic fusion protein consisting of the N-terminal DNA-interacting domains of MLL1 ( 1400 residues) fused with one of $>70$ fusion partner proteins (Fig. 1a) [12-14], among which transcription cofactors AF9 and its paralog ENL, AF4 (also known as AFF1) and its paralog AFF4, and ELL are found in $>70 \%$ MLL1$r$ leukemias (Fig. 1b) [10, 38]. These proteins have been found to associate with each other in several isolated transcription complexes, which have been commonly named super elongation complexes (SEC) [25, 39, 40]. Formation of SEC is required for expression of characteristic genes of MLL1-r leukemia (e.g., HoxA9 and Meis1) as well as leukemia transformation. Moreover, SEC was also found to be recruited by MLL1-AF6 and -AF10, two other common fusion oncogenes (Fig. 1b) [25, 40]. The common feature of these frequent MLL1 fusion partners is their ability to recruit SEC and other associated proteins.

Together with P-TEFb (positive transcription elongation factor), MLL1 fusion partners AF4/AFF4, AF9/ ENL and ELL are essential members of SEC. AF4 and its paralog AFF4 are the scaffold for the formation of SEC. AF4/AFF4 contain intrinsically disordered binding domains for P-TEFb, ELL, and AF9/ENL as well as a structured C-terminal homology domain (CHD) (Fig. 9a) [168]. Figure 9b schematically illustrates the recruitment of SEC by MLL1-AF4. Other major onco-MLL1 (e.g., MLL1-AF9/ENL and -ELL) can recruit SEC similarly. MLL1(1-1400) functions as a transcription factor to bind to its target gene promoters. AF4/AFF4 form a heterodimer, which interact with other SEC member proteins and serve as a scaffold for SEC assembly. P-TEFb, consisting of cyclin-dependent kinase 9 (CDK9) in complex with regulatory cyclin-T1 protein, phosphorylates Pol II, while ELL binds Pol II and enhances its activity [169, 170]. Both of these two events are key steps for Pol II to leave promoter-proximal pausing and start transcription elongation of a gene. AF9 and homologous ENL contain an N-terminal YEATS (Yaf9, ENL, AF9, Taf14, and 


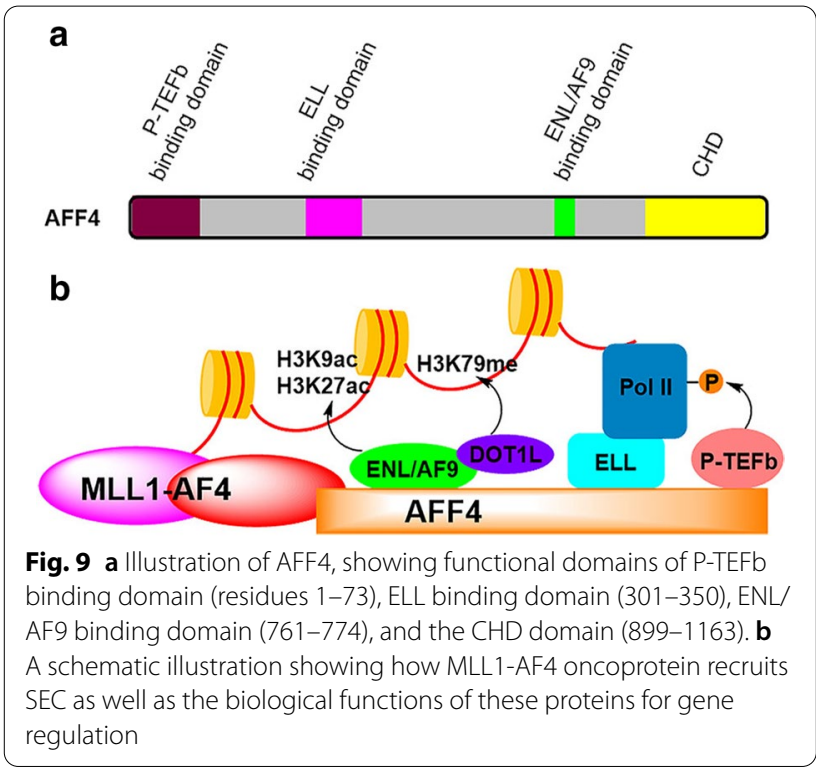

Sas5) and a C-terminal AHD (ANC1 homology domain) domain. The conserved YEATS domain recognizes and binds acetylated H3K9 or H3K27 [171, 172]. The AHD domain of AF9/ENL plays critical roles in MLL-r leukemia. AHD is found in all fusion MLL1-AF9/-ENL, while YEATS is lost in almost all clinical variances of MLLAF9/-ENL [25]. Transformation of murine hematopoietic progenitor cells with MLL1 fused with various truncated forms of AF9 confirmed that AHD is essential for MLLAF9/ENL leukemia, but YEATS is dispensable $[25,173]$. The AHD domain of AF9/ENL interacts with AF4/AFF4, which is critical to the formation of SEC as well as MLL1AF9/ENL-mediated SEC recruitment. Moreover, AF9/ ENL AHD's another binding partner DOT1L is a H3K79 methyltransferase $[174,175]$, which can methylate H3K79 (Fig. 9b). Hypermethylation of H3K79 has been found to be characteristic to MLL1-r leukemias [176]. DOT1L has been found to be required for expression of MLL1-target genes such as HoxA9 and Meis1 and therefore a drug target for MLL1-r leukemia. During the past few years, potent inhibitors of DOT1L have been developed [177-184], showing potent and selective activities against MLL1-r leukemia. An advanced DOT1L inhibitor EPZ-5676 [184] has been in clinical trials against the malignancy.

In addition to MLL1-r leukemia, SEC has been found to play critical roles in transcription elongation of HIV gene in the human genome [185-188]. Pol II is recruited to the HIV promoter and initiated transcription of HIV gene, but after $\sim 50$ transcripts, transcription is paused in a transactivating response region (TAR). HIV viral protein Tat is a transactivator protein, which binds to TAR
Table 3 Binding affinity $\left(K_{d}\right)$, structure, and inhibitors of the critical PPIs involving MLL1 fusion proteins

\begin{tabular}{|c|c|c|c|}
\hline PPIs & $K_{d}(\mu \mathrm{M})$ & Structures (PDB) & Inhibitors \\
\hline AFF4-ELL2 & 0.086 [190] & 5JW9 [190] & None \\
\hline AFF4-Cyclin T1 & 0.1 [191] & $4 \operatorname{MY}[191]$ & [192] \\
\hline AFF4-P-TEFb & $0.01[191]$ & 4IMY [191] & [192] \\
\hline AFF4-Tat-P-TEFb & 0.0009 [191] & 4OR5 [193] & None \\
\hline AF9(AHD)-AF4 & $0.0002[194]$ & 2LM0 [194] & [195] \\
\hline AF9(AHD)-DOT1L & $0.0016[194]$ & 2MV7 [196] & [197] \\
\hline ENL(AHD)-DOT1L & 0.2 or 1.34 [198] & None & None \\
\hline $\begin{array}{l}\text { AF9 or ENL AHD- } \\
\text { CBX8 }\end{array}$ & $>0.5$ or 0.11 [199] & 2N4Q [199] & None \\
\hline $\begin{array}{l}\text { AF9 or ENL AHD- } \\
\text { BCoR }\end{array}$ & $\begin{array}{l}0.018 \text { or } 0.002 \mathrm{nM} \\
{[199]}\end{array}$ & 6B7G [199] & None \\
\hline AF9(YEATS)-H3K9ac & $3.7[172]$ & 4TMP [172] & [200-204] \\
\hline ENL(YEATS)-H3K9ac & $32.2[205]$ & None & [200-204] \\
\hline ENL(YEATS)-H3K27ac & $30.5[205]$ & 5J9S [205] & [200-204] \\
\hline
\end{tabular}

and recruits SEC. This event causes phosphorylation of Pol II and release from transcription pausing. Moreover, SEC also regulates expression of transcription factor Myc, a master regulator for cancer cell growth, implicating such PPIs' roles in other cancers and HIV infection. Biological functions of SEC were recently reviewed [189]. Table 3 summarizes the binding affinity, availability of the X-ray or NMR structure and inhibitors of the PPIs involving MLL1 fusion partners.

\section{AF4-AFF4 heterodimerization Biological function}

AF4 and AFF4 share a high degree of homology[206], particularly for their domains involved in PPIs. AFF4 is required for MLL1-r leukemia, as its knockdown resulted in the decreased expression of MLL1 target genes [39]. Formation of AF4-AFF4 heterodimer has been found to be preferred biochemically [168] and in cells [25] over their homodimers. Further investigation using MLL1AF4 and AFF4 with deletion of various AF4/AFF4 domains showed that only the CHD domain of AFF4/ AF4 is required for leukemic transformation, while other AF4/AFF4's interacting domains with P-TEFb, ELL and AF9/ENL are dispensable for MLL1-AF4/AFF4 leukemia [39]. These results underscore the critical role for CHDmediated AF4-AFF4 heterodimerization in the leukemia and it is therefore a potential drug target for MLL1-r leukemia. However, there have been no inhibitors of the PPI.

\section{Structure}

Although the crystal structure of AF4-AFF4 heterodimer is not available, that of the homodimer of AFF4 CHD domain has been determined (PDB: 6R80) [168, 207, 


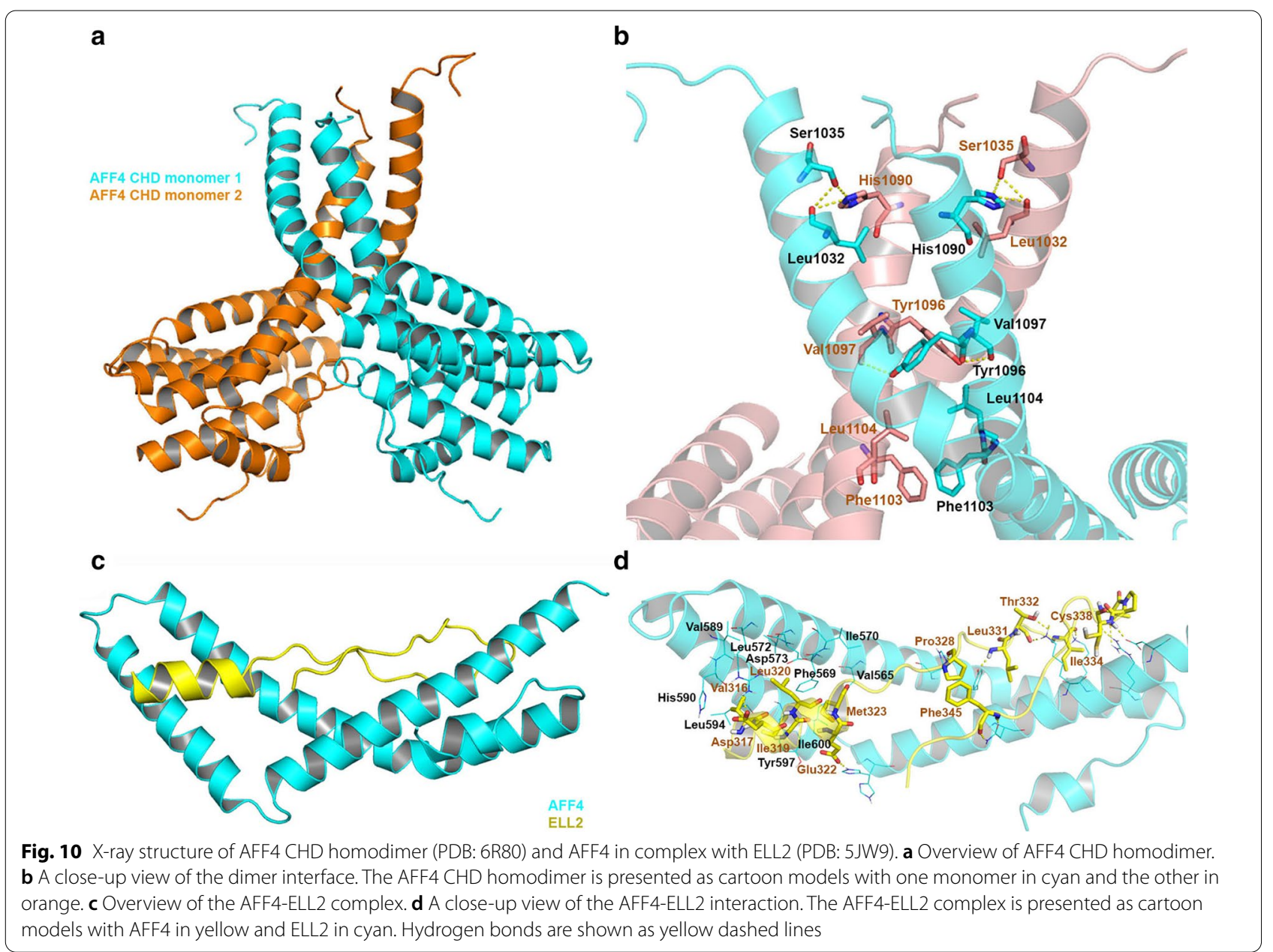

208]. Biochemical including mutagenesis studies revealed that the interface between AF4 and AFF4 heterodimer overlap with that of AFF4 homodimer, thanks to a high degree of homology between the two CHD domains. Each monomer of AFF4 CHD contains $8 \alpha$-helices, among which the two longest helices together with the loop between them participate in homodimerization (Fig. 10). They form a large hydrophobic surface, mainly consisting of His1090, Tyr1096, Val1097, Phe1103, and Leu1104, interacting with that of the other monomer. Replacement of these key residues with alanine disrupted AFF4 dimerization in solution. In addition to the hydrophobic interactions, a network of hydrogen bond interactions among Leu1032, Ser1035, His1090, Tyr1096, and Val1097 contribute to the stability of the homodimer (Fig. 10b).

\section{AF4/AFF4-ELL interaction \\ Biological function}

ELL (also known as ELL1) is also a major MLL1 fusion partner (Fig. 1b). ELL as well as its paralog ELL2 was discovered as a RNA polymerase elongation factor [209], which has been found to be a core component of SEC and required for transcription elongation for a number of genes [39]. Biologically, ELL binds to Pol II and increases the catalytic activity of the Pol II elongation complex $[169,170]$, facilitating transcription elongation of a gene. Similar to MLL1-AF4, MLL1-ELL can recruit the other member proteins through the ELL-AF4/AFF4 interaction to form SEC for leukemic transformation. The AF4/AFF4-ELL interaction is a potential drug target for MLL1-ELL and/or other MLL1-r leukemia. No inhibitors have been found for the PPIs between AF4/AFF4 and ELL1/2.

\section{Structure}

$\mathrm{X}$-ray structure of a fusion protein consisting of AFF4(318-337) and ELL2 C-terminal domain (519-640) was determined (PDB: 5JW9) [190], providing the structure basis for the PPI. ELL2 forms $4 \alpha$-helices and folds into an arch-shaped conformation, with its large concave surface to interact with AFF4. The AFF4 peptide contains 
a small $\alpha$-helix followed by an extended hairpin. The $\alpha$-helix of AFF4 occupies a hydrophobic groove constituted by the first two $\alpha$-helixes of ELL2 at the $\mathrm{N}$-terminal (Fig. 10c, d). The AFF4 residues Val316, Ile319, Leu320 and Met323 have mostly hydrophobic interactions with the residues Val565, Phe569, Ile570, Leu572, Asp573, Val589, His590, Tyr597, Leu594, and Ile600 of ELL2. In addition, there are extended hydrophobic interactions between the AFF4 hairpin and ELL2 hydrophobic surface. Moreover, a network of hydrogen bond and electrostatic interactions between the AFF4 residues Asp317, Glu322, Pro328, Leu331, Thr332, Ile334, Cys338 and Phe345 and ELL2 also contribute to the binding, giving a strong binding affinity with $K_{\mathrm{d}}$ values of $0.086-4.0 \mu \mathrm{M}$ depending on assay methods (Table 3) [190]. Mutagenesis studies showed that the hydrophobic interactions between the residues of the AFF $4 \alpha$-helix and ELL2 contribute the most to the binding.

\section{AFF4-P-TEFb interaction \\ Biological function}

P-TEFb consists of a catalytic component CDK9 and an associated regulatory component cyclin-T1, playing a critical role in transcription elongation. P-TEFb is recruited to a gene promoter through the cyclinT1-AFF4/AF4 interaction, with CDK9 phosphorylating the Serine-2 residue of Pol II and triggering transcription elongation process [210]. Onco-MLL1 recruits SEC for transcription elongation, leading to aberrant gene expression and leukemogenesis. SEC also mediates expression of the HIV gene in human genome [211, 212]. HIV protein Tat forms a ternary complex with AFF4 and cyclinT1 [193] and thus recruits SEC to HIV gene promoter for transcription elongation. Pharmacological inhibition of CDK9 was found to block Pol II-mediated gene transcription [213] as well as HIV gene transcription and viral replication [214]. Therefore, targeting the PPIs between cyclin-T1 and AFF4/AF4 represents a potential therapeutic approach to the treatment of MLL1-r leukemia and HIV infection. Moreover, targeting the PPI may only affect SEC-regulated gene transcription and spare recruitment of P-TEFb by other transcription cofactors. Given the critical roles of P-TEFb in aberrant gene expression in MLL-r leukemia, targeting the cyclinT1-AFF4 interaction is selective and could be less toxic.

\section{Structure}

The crystal structure of P-TEFb in complex with an AFF4 peptide (PDB: 4IMY) [191] shows AFF4 binds to CyclinT1 through a combination of hydrophobic, hydrogenbond and other polar interactions (Fig. 11a, b), while it does not interact with CDK9. Residues Leu48, Ile52, Met55, Leu56 and Tyr59 in the two $\alpha$-helices of AFF4 sit in a shallow groove of Cyclin-T1 with hydrophobic interactions. Cyclin T1's Leu163, Val164, Arg165, Trp221, and Tyr224 residues form a hydrophobic cleft, which accommodates the AFF4 residues Leu34, Phe35 and Ala36. Another hydrophobic pocket of Cyclin-T1 (Trp210, Leu170 and Ile 212) holds the Pro38 residue of AFF4. In addition, Leu34, Phe35, Tyr39, Lys40, Val41, Asp46, Met55, Gly57, and Tyr59 of AFF4 form multiple hydrogen bonds and have electrostatic interactions with Cyclin T1. While the binding affinity between AFF4 and Cyclin T1 alone is high $\left(K_{\mathrm{d}}=102-130 \mathrm{nM}\right)$, formation of P-TEFb significantly increases the binding affinity with $K_{\mathrm{d}}$ values of 10-36 nM [191] (Table 3).

$\mathrm{X}$-ray structures of the quaternary Tat-AFF4-P-TEFb complexes were determined (PDB: 4OR5) [191, 193]. Cyclin-T1 of P-TEFb served as a receptor platform for the binding of the Tat and AFF4 peptides (Fig. 11c, d). CDK9 resides in the other side of Cyclin-T1 without interactions with AFF4, while the remote residues Glu9 and Lys12 of Tat can reach CDK9 and form multiple hydrogen bond interactions with the residues Lys144, Asn 183 and Gln181 of CDK9. The binding of Tat to Cyclin $\mathrm{T} 1$ relies on multiple hydrophobic, hydrogen bond, and electrostatic interactions. Hydrogen bonds and other polar interactions between Ser16 and Gln17 of Tat and Val54 and Asn53 of Cyclin T1 constitute an important anchor point, while another major anchoring site is located between the Tat residues Thr40, Lys41, and Ala42 and Cyclin T1's Arg251 and Leu252. Furthermore, participation of Tat significantly (>tenfold) enhances the binding affinity of between AFF4 and P-TEFb complex [191] (Table 3).

\section{Inhibitors}

Compound KL-2 (Fig. 11e) was reported to bind to Cyclin $\mathrm{T} 1$ at a low micromolar concentration and inhibit the Cyclin T1-AFF4 interaction [192]. The disruption of the PPI resulted in reduced SEC-dependent transcriptional responses and downregulation of Myc expression as well as Myc-dependent transcriptional programs. KL-2 can also suppress tumor growth in vitro and in a mouse model of Myc-dependent cancer. However, it is noted that KL-2 containing an electrophilic, chemically reactive $\alpha, \gamma$-di-keto-amide group could covalently bind to a protein non-specifically. Specificity as well as possible off-target effects of this compound might need to be examined carefully.

\section{PPIs involving the AHD domain of AF9 and its paralog ENL Biological function}

AF9 and its paralog ENL contain an N-terminal YEATS domain ( 110 residues) and a C-terminal AHD domain 

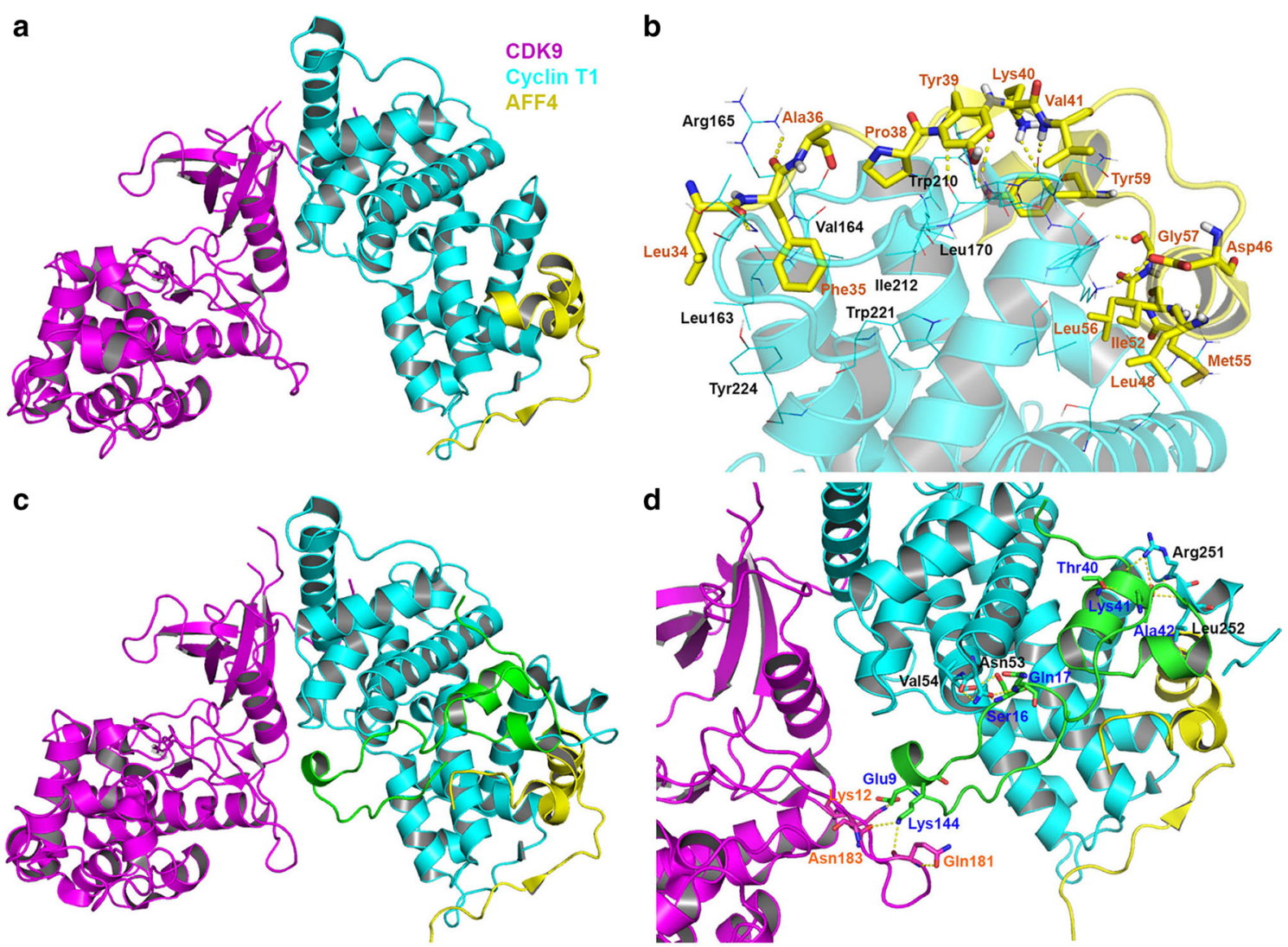

e<smiles>Cc1ccc(Cl)cc1NC(=O)C(=O)CC(=O)c1ccc(F)cc1</smiles>

$\mathrm{KL}-2$

Biochemical activity

$K_{\mathrm{i}}($ Cyclin $\mathrm{T} 1)=1.50 \mu \mathrm{M}$

Fig. 11 X-ray structures of P-TEFb in complex with AFF4 and the structure of SEC disruptor. a Overview of P-TEFb-AFF4 (PDB: 4IMY). b A close-up view of the AFF4-P-TEFb(Cyclin T1) interactions. c Overview of the ternary P-TEFb-Tat-AFF4 complex (PDB: 4OR5). d A close-up view of the Tat-P-TEFb-AFF4 interface. AFF4 is shown in yellow, CDK9 in magenta, Cyclin T1 in cyan, and Tat in green. Hydrogen bonds are shown as yellow dashed lines. e Structure of SEC disruptor

( 70 residues). AF9 [215] and ENL [9] were first identified as a fusion partner of MLL1. Later they were found to be homologous nuclear proteins that play a role in activating gene transcription in lymphoid and myeloid cells, with their AHD domain required for the activity [216]. ENL is required for MLL1-r leukemia [25] as well as a broader range of AMLs [205], as its knockdown inhibited aberrant gene expression and cell proliferation of these cells.
The AHD domain alone is intrinsically disordered, but it binds a short peptide segment of DOT1L or AF4/AFF4 with a consensus sequence of $\mathrm{LxVxIxLxxV/L}$ and forms a structured complex [194, 196]. High affinity binding between AF9 and DOT1L or AF4 (Table 3) is required for oncogenesis of MLL-AF9. MLL1-AF9 with D546R or D544R mutation, which has a significantly reduced affinity to DOT1L or AF4, failed to transform murine hematopoietic stem/progenitor cells [173]. Disruption of AF9-AF4 interaction by an AF4-derived peptide 
inhibited the cell proliferation with enhanced cell apoptosis $[217,218]$, while it did not affect the proliferative of normal hematopoietic cells. These results suggest inhibiting the AF9/ENL-AF4/AFF4/DOT1L interactions could be useful to treat MLL1-r leukemia.

In addition to AF4/AFF4 and DOT1L, AF9/ENL AHD interacts with CBX8 (chromobox homolog 8) [219, 220] and BCoR (BCL-6 corepressor) [221] with a similar binding mode [194]. BCoR also possesses the consensus sequence of LxVxIxLxxL and exhibits a high-affinity binding to AF9 AHD $\left(K_{\mathrm{d}}=32 \mathrm{nM}\right)$, while CBX8 with LxAxIxLxxI has $30 \times$ less affinity [194]. Binding of AF9/ ENL with their binding partners is mutually exclusive. The interactions between AF9/ENL and CBX8 or BCoR were also found to be critical for MLL1-AF9/-ENL induced leukemic transformation through gene knockdown and other biological experiments in vitro and in vivo [219, 220, 222, 223].

The YEATS domain of AF9/ENL is conserved from yeast to humans, which was found to recognize and bind acetylated H3K9 and H3K27 [172, 205]. Binding to H3K9ac facilitates AF9 to occupy its target genes and recruit DOT1L for H3K79 methylation. H3K9ac-binding deficient mutants of AF9 (F59A and Y78A) conferred the impaired localization of AF9 as well as the decreased levels of H3K79me3. Knockout of ENL significantly suppressed proliferation of a broader range of AML (including MLL1-r) cells [205]. These ENL-depleted leukemia cells can be rescued by transfecting WT ENL, but not F59A mutant ENL that cannot bind H3K27ac, showing that YEATS as well as its binding to H3K27ac is of importance. In addition, ENL knockout did not affect the growth of several solid tumors, showing ENL is only essential for leukemias. Chromatin immunoprecipitation followed by sequencing showed ENL is enriched and colocalized with H3K27ac (and H3K9ac) on the promoters of leukemia relevant genes. Moreover, disruption of the interactions between YEATS and H3K27ac through structure-based mutagenesis reduced the recruitment of Pol II to the gene promoters, causing suppression of gene expression as well as growth arrest. Another research also revealed critical roles of ENL and its YEATS-H3K27ac interaction in leukemogenesis [224].

\section{Structure and inhibition of AF9/ENL-AF4/DOT1L/CBX8/BCOR}

The NMR solution structures of fusion proteins AF9AF4 (PDB: 2LM0) and AF9-DOT1L (PDB: 2MV7) have been determined (Fig. 12) [194, 196]. The fusion protein consists of the AHD domain of AF9 and the AF4 peptide (residues 738-779) or the DOT1L peptide (residues 3877-3900), interconnected with a flexible linker peptide. The two structures are similar. The $\beta$-strand of

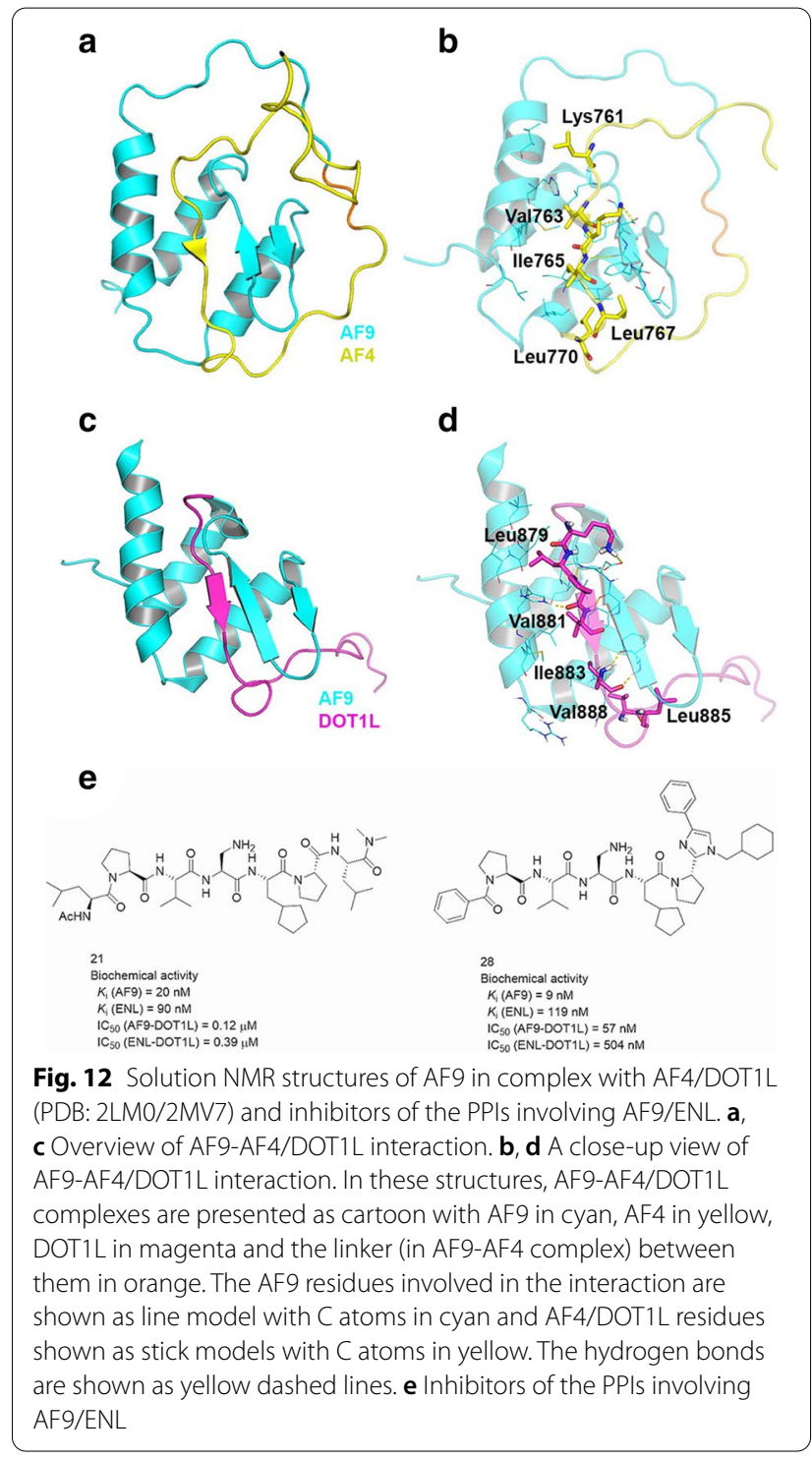

AF4 or DOT1L peptide is bound to a hydrophobic cleft formed by three $\alpha$-helices and one $\beta$-hairpin of AF9, driven by mostly hydrophobic interactions. The consensus residues Leu761, Val763, Ile765, Leu767, Leu770 of AF4 peptide (or Leu879, Val881, Ile883, Leu885, and Val888 of DOT1L) have favorable interactions with the hydrophobic groove of AF9 AHD. Moreover, there are hydrogen bond and electrostatic interactions between AF9 and the ligand peptide to stabilize the PPIs. The solution NMR structures of AF9-CBX8 and BCoR complexes have also been solved (PDB: 2N4Q, 6B7G), in which $\mathrm{CBX} 8 / \mathrm{BCoR}$ bind to the AF9 hydrophobic groove similarly to AF4/DOT1L [222].

AF4-derived PFWT 13-mer peptide is an inhibitor the AF9-AF4 interaction and can disrupt such PPI 
at the concentrations of $10-10,000 \mathrm{ng} / \mathrm{mL}[217,218]$. When conjugated with a penetration transporter or a penetrating peptide, these peptides can inhibit proliferation of MLL1-r leukemia cell lines, while showing no apparent toxicity to hematopoietic progenitor cells. The SPK111 peptide, which was derived from the PFWT peptide by conjugation with a modified HIV Tat protein domain, exhibited better in vivo stability and prolonged the survival of mice bearing MLL1-AF9 and MLL1ENL rearranged leukemia cells [195].

A DOT1L 10-mer peptide was found to inhibit the AF9- and ENL-DOT1L interactions with $\mathrm{IC}_{50}$ values of $490 \mathrm{nM}$ and $1340 \mathrm{nM}$, respectively [198]. It can also inhibit colony-forming ability of MLL1-AF9 transformed leukemic cells. Medicinal chemistry optimization yielded a series of 7-mer peptidomimetic compounds $\mathbf{2 1}$ and $\mathbf{2 8}$ (Fig. 12e) against the interaction between $\mathrm{AF} 9 / \mathrm{ENL}$ and DOT1L with $\mathrm{IC}_{50}$ values as low as $57 \mathrm{nM}[197]$

\section{Structure and inhibition of the AF9/ENL(YEATS)-H3K27ac interaction}

X-ray structures of the YEATS domain of AF9 and ENL in complex with acetylated or crotonylated histone peptide were determined (PDB: 4TMP, 5J9S, 5HJB, 5HJD) $[172,205,225]$ and these structures are similar because of the high homology between AF9 and ENL. The YEATS domain contains eight antiparallel $\beta$-strands and two $\alpha$-helices (Fig. 13), which is different from BRD (which also binds an acetylated lysine) with four conserved $\alpha$ helices [226]. The central deep hydrophobic pocket of YEATS is responsible for recognizing of the acetylated lysine. H3K9ac is bound to YEATS in an orientation perpendicular to the $\beta$-stands with K9ac docked into an aromatic cage formed by AF9 residues Phe28, His56, Ser58, Phe59, Try78, and Phe81 with favorable hydrophobic interactions as well as hydrogen bonds with Ser58, Try78 and Ala79. Mutation of these residues resulted in significantly reduced binding affinity. In addition, acylation of K9 is important as it neutralizes the positive charge of the lysine sidechain and gains hydrophobic interactions with the pocket. In addition to K9ac, the other residues of H3K9ac peptide participate in the binding to YEATS. Lys4, Thr6, Ala7 and Arg8 of H3K9ac form hydrogen bond interactions with AF9 residues Leu108, Leu106, Gly80, and Asp103, respectively. Replacement of Arg8 with an alanine reduced the binding affinity by $\sim 200$ fold. The binding affinity of H3K9ac to AF9 and ENL were determined with $K_{\mathrm{d}}$ values of $5 \mu \mathrm{M}$ and $57 \mu \mathrm{M}$ [225] (Table 3), respectively.

Peptidic and small molecule inhibitors of ENL YEATS have been reported [200-202]. Peptidic inhibitors XL07i and XL-13m (Fig. 13h) inhibited ENL-H3K9cr with
$\mathrm{IC}_{50} \mathrm{~S}$ of 1.3 and $0.56 \mu \mathrm{M}$, respectively. The structure of AF9 YEATS in complex with XL-07i has been determined (PDB: 5YYF). XL-07i occupies the H3K9ac binding pocket in YEATS with multiple hydrogen bond and hydrophobic interactions (Fig. 13b, c). In addition, $\pi-\pi$ stacking interactions between the furan-2-carbonamide group of XL-07i sandwiched in between Phe59 and Tyr58 seem to strengthen the binding. Additionally, the benzyloxycarbonyl group of XL-07i also has favorable interactions with His107 and His111.

A structure-based approach led to the discovery of a series of benzimidazole inhibitors of ENL YEATS, with SGC-iMLLT (compound 92, Fig. 13h) exhibiting an $\mathrm{IC}_{50}$ of $260 \mathrm{nM}$ [200]. The inhibitor was found to suppress expression of leukemia relevant genes such as Myc. The crystal structure of the protein-inhibitor complex (PDB: 6HT1) reveals that the imidazole ring of SGCiMLLT interacts with Ser76 and the amide is sandwiched between residues Phe59 and Tyr78 with $\pi-\pi$ stacking interactions. The amide also acts as a hydrogen bond donor to interact with the hydroxyl group of Ser58. The indazole moiety of the inhibitor is located in a hydrophobic pocket formed by His56, Phe81, Gly80, Ala79, and Tyr78. There is a hydrogen bond between the N-2 atom of the indazole and His56. The 2-methylpyrrolidinyl group of SGC-iMLLT also strengthen the binding by forming a hydrogen bond with Glu75. A high-throughput screening identified a series of piperazine-urea compounds as inhibitors of ENL YEATS [203, 204] with the best compound 1 having an $\mathrm{IC}_{50}$ of $3.7 \mu \mathrm{M}$ (Fig. 13h). Its binding structure has been determined (PDB: 6T1I), showing its piperazine-urea group mimics K9ac (Fig. 13f, g). The 2-methoxyl-pyridine moiety has favorable interactions with His56. In addition, the inhibitor forms hydrogen bonds with ENL residues Ser58 and Tyr78.

\section{Conclusion and perspectives}

MLL1 with 3,696 amino acid residues is an important transcription factor as well as H3K4 methyltransferase. It is a master regulator for transcription of important genes during embryonic development and hematopoiesis, such as clustered Hox genes. MLL1 is essential for development, while it is largely dispensable in matured cells. Dysregulation of MLL1 in these cells leads to constitutive or over-expression of certain Hox genes (e.g., HoxA9) and eventually leukemia initiation. Chromosome translocations involving MLL1 cause $~ 75 \%$ of acute leukemia in infants and $5-10 \%$ in children and adults with a poor prognosis. Less toxic, targeted therapeutics against oncoMLL1 are needed. Onco-MLL1 consists of the N-terminal DNA-interacting domains of MLL1 fused with one of $>70$ fusion partners, among which transcription cofactors AF4, AF9 and its paralog ENL, and ELL are the most 


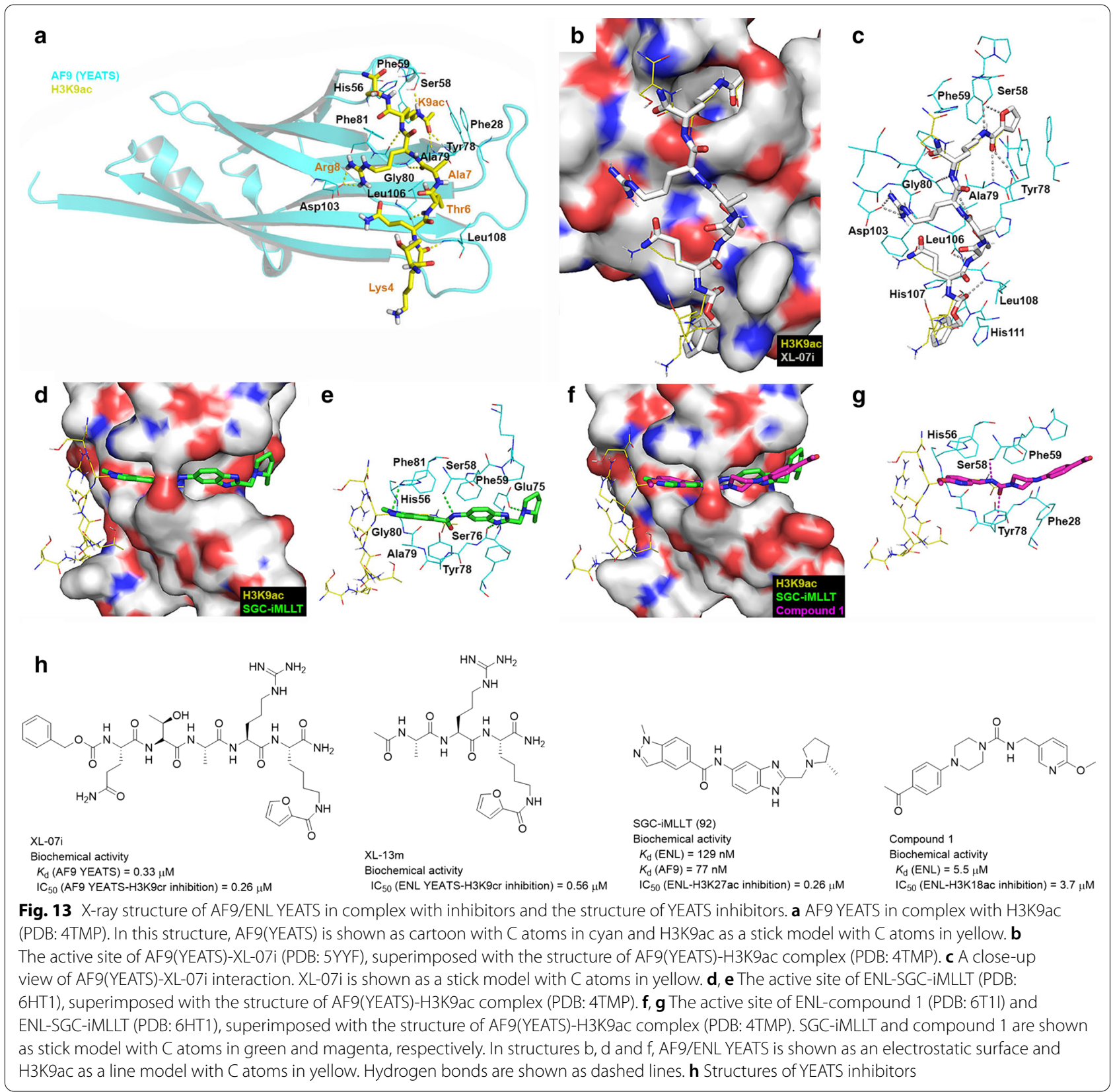

frequent. WT- and onco-MLL1 have numerous PPIs, which play critical roles in regulating gene expression in normal physiology and leukemia. Moreover, WT-MLL1 has been found to be essential for MLL1-r leukemia. Therefore, PPIs involving MLL1 as well as its fusion partners are potential drug targets.

Rigorous biological, biochemical and structural studies of such PPIs have been performed to understand their structures, structure-function relationships and the mechanisms for activating gene transcription as well as leukemic transformation. These studies have also revealed and validated that many of these PPIs are promising drug targets for MLL1-r leukemia, such as those in the Menin-MLL1-LEDGF complex and SEC. However, more investigations are needed for the biological functions as well as drug target identification and validation of other PPIs. There are still debates and therefore, a need to address whether MLL1's H3K4 methyltransferase (SET domain) activity is critical to its biological functions in normal physiology and MLL1-r leukemia. Switching interactions of MLL1's PHD3-BRD between H3K4-Me3 and Cyp33 have been found to be of importance in gene 
expression regulation of MLL1, while more in-depth biological studies, particularly in the context of MLL-r leukemia, and pharmacological inhibition of such PPIs are anticipated. Moreover, functions of MLL1's other PHD domains are poorly understood.

Comparatively, medicinal chemistry progress targeting these PPIs has been considerably falling behind. To date, potent drug-like inhibitors have been discovered and developed for only two cases, i.e., the MLL1-Menin and MLL1-WDR5 interactions. Cellularly expressed peptides or proteins, small peptides, or peptidomimetic compounds were commonly used as an inhibitor for biological investigations. However, these protein or peptide-based inhibitors have poor cell permeability and metabolic stability. Drug-like small molecule inhibitors are desirable, but it is generally difficult for a small molecule to disrupt a PPI with large and shallow surface interactions. However, the MLL1-Menin and -WDR5 interactions are not a typical PPI. Rather, they are (small) MLL1 peptide-protein interactions (Fig. 2a, 7a), similar to a druggable protein such as an enzyme (e.g., kinase) with a peptide substrate. Finding a small molecule inhibitor is more feasible for this kind of PPIs. Fortunately, several other critical PPIs involving MLL1 and its fusion proteins fall into this category, including MLL1-LEDGF and -H3K4Me3, AF9/ENL-AF4/AFF4/DOT1L and AF4/ AFF4-cyclin T1. Medicinal chemistry studies targeting these PPIs could be fruitful in the perspectives of drug discovery targeting MLL1-r leukemia. Availability of the $\mathrm{X}$-ray or NMR structures and biochemical assays of these PPIs could further facilitate this process.

Small molecule inhibitors of the MLL1-Menin interaction have shown excellent activity against MLL1-r leukemia in cells and animal models $[16,49,50,52-54,59,61$, 63], which are generally correlated with their biochemical activities. Many inhibitors also possess good pharmacokinetic profiles, among which KO-539 and SNDX 5613 have entered into Phase I clinical trials for AML (Table 2) [16]. On the other hand, despite high biochemical potencies, the small molecule inhibitors of the MLL1-WDR5 interaction showed less or inconsistent cellular anti-leukemia activities, presumably due to complex functions of MLL1's H3K4 methyltransferase activity or off-target effects.

Potential toxicities related to inhibiting the PPIs involving MLL1 and its fusion partners are a concern. Since MLL1 is critical to embryonic development and hematopoiesis, but largely dispensable in matured cells including hematopoiesis in adult mice, inhibition of these PPIs in the context of targeting MLL1-r leukemia appears to be selective with a likely high therapeutic index. This has been observed for the inhibitors of MLL1-Menin. However, MLL1 plays a role in selfrenewal of hematopoietic stem cells in bone marrow and its conditional knockout in adult mice showed some defects [227]. Moreover, Menin has been reported to be a tumor suppressor and its mutation is involved in inherited tumor syndrome multiple endocrine neoplasia type 1 [104]. Similarly, germline knockout of Menin is embryonic lethal in mice [228] and its conditional knockout in adult mice could also affect hematopoiesis and myeloid transformation [113]. Potential toxicities of these compounds that bind to Menin and inhibit the MLL1-Menin interaction need to be closely observed during clinical trials. Similar scenarios exist for other PPIs involving MLL1 (e.g., MLL1-LEDGF) as well as those in SEC.

In conclusion, PPIs involving MLL1 and its fusion partners play critical roles in gene expression regulation during development, while they are largely dispensable in adults. However, these PPIs have been found to be essential for MLL1-r leukemia, making them potential drug targets for intervention. Pharmacological inhibition of several such PPIs has been pursued. Inhibitors of MLL1-Menin have shown promising preclinical results and entered clinical trials against AML. Further drug discovery efforts targeting other PPIs including biological and medicinal chemistry investigation are warranted.

\section{Abbreviations}

MLL1/MLL: Mixed lineage leukemia 1; Onco-MLL1: Oncogenic fusion MLL1; MLL1-r: MLL1-rearranged; ALL: Acute lymphoblastic leukemia; AML: Acute myeloid leukemia; PPIs: Protein-protein interactions; ATH: AT-hooks; H3K4: Histone-H3 lysine-4; KMT: Lysine methyltransferase; MBM: Menin-binding motif; LEDGF: Lens epithelium-derived growth factor; LBD: LEDGF-binding domain; NLS: Nuclear localization signal; PHD: Plant homology domains; BRD: Bromodomain; TCS: Taspase 1 cleavage site; PAFc: Polymerase-associated factor complex; TAD: Transactivation domain; WT: Wild type; FYRN: Phe/Tyr-rich N-terminal; FYRC: Phe/Tyr-rich C-terminal; WDR5: WD repeat protein 5; Win: WDR5 interaction motif; SET: Su(Var)3-9, enhancer-of-zeste, trithorax domain; MLL1-N: MLL1 N-terminal fragment; MLL1-C: MLL1 C-terminal fragment; RbBP5: Retinoblastoma binding protein 5; ASH2L: Set1/Ash2 histone methyltransferase complex subunit ASH2-like; DPY30: Protein dpy-30 homolog; AF4: ALL-1 fused chromosome 4; SEC: Superelongation complex; Pol II: RNA polymerase II; HTS: High throughput screening; SAR: Structure-activity relationship; MBM: Menin-MLL1 binding motif; IBD: Integrase binding domain; HIV: Human immunodeficiency virus; HMT: Histone methyltransferase; SPR: Surface plasmon resonance; AHD: ANC1 homology domain; CBX8: Chromobox homolog 8; PRC1: Polycomb repressive complex 1; PK: Pharmacokinetics; PDX: Patient-derived xenograft; NPM1: Nucleophosmin 1; PWWP: Pro-Try-Try-Pro; CR: Charged regions; IBM: IBD-binding motifs; H3K36-Me3: Trimethylated H3K36; RRM: RNA recognition motif; HDAC1: Histone deacetylase 1; CBP: CAMP-response element binding protein (CREB)-binding protein; HAT: Histone acetyltransferase; ABM: ASH2L binding motif; WBM: WDR5-binding motif; P-TEFb: Positive transcription elongation factor; CHD: C-terminal homology domain; CDK9: Cyclin-dependent kinase 9; TAR: Transactivating response region; YEATS: Yaf9, ENL, AF9, Taf14, and Sas5; BCoR: BCL-6 corepressor.

\section{Acknowledgements}

Not applicable. 


\section{Authors' contributions}

$X . L$. and Y.S. performed the literature search, wrote the manuscript, and have read and approved the final version. Both authors read and approved the final manuscript.

\section{Funding}

This work was supported by grants (RP150129 and RP180177) from Cancer Prevention and Research Institute of Texas and a grant (W81XWH-18-1-0368) from USAMRAA of the U.S. Department of Defense to Y.S.

\section{Availability of data and materials}

Not applicable.

\section{Declarations}

\section{Ethics approval and consent to participate}

Not applicable.

\section{Consent for publication}

Not applicable.

\section{Competing interests}

The authors declare no competing interests.

\section{Author details}

${ }^{1}$ Department of Pharmacology and Chemical Biology, Baylor College of Medicine, 1 Baylor Plaza, Houston, TX 77030, USA. ${ }^{2}$ Dan L. Duncan Comprehensive Cancer Center, Baylor College of Medicine, 1 Baylor Plaza, Houston, TX 77030, USA.

Received: 19 January 2021 Accepted: 5 March 2021

Published online: 06 April 2021

\section{References}

1. Chen C-W, Chan AK. Rewiring the epigenetic networks in MLLrearranged leukemias: epigenetic dysregulation and pharmacological interventions. Front Cell Dev Biol. 2019;7:81.

2. Liang K, Volk AG, Haug JS, Marshall SA, Woodfin AR, Bartom ET, Gilmore $J M$, Florens L, Washburn MP, Sullivan KD. Therapeutic targeting of MLL degradation pathways in MLL-rearranged leukemia. Cell. 2017; 168(1-2): 59-72. e13.

3. Tomizawa D, Koh K, Sato T, Kinukawa N, Morimoto A, Isoyama K, Kosaka Y, Oda T, Oda M, Hayashi Y. Outcome of risk-based therapy for infant acute lymphoblastic leukemia with or without an $M L L$ gene rearrangement, with emphasis on late effects: a final report of two consecutive studies, MLL96 and MLL98, of the Japan Infant Leukemia Study Group. Leukemia. 2007;21(11):2258-63.

4. Hilden JM, Dinndorf PA, Meerbaum SO, Sather H, Villaluna D, Heerema NA, McGlennen R, Smith FO, Woods WG, Salzer WL. Analysis of prognostic factors of acute lymphoblastic leukemia in infants: report on CCG 1953 from the Children's Oncology Group. Blood. 2006;108(2):441-51.

5. Pediatric acute leukemia fact sheet. https://www.epizyme.com/wpcontent/uploads/2014/05/EPZM_Acute_Leukemia_Fact_Sheet_5.9.pdf. Accessed 1 Jan 2021.

6. Super H, McCabe NR, Thirman MJ, Larson RA, Le Beau MM, PedersenBjergaard J, Philip P, Diaz M, Rowley J. Rearrangements of the MLL gene in therapy-related acute myeloid leukemia in patients previously treated with agents targeting DNA-topoisomerase II. Blood. 1993;82(12):3705-11.

7. Felix CA. Secondary leukemias induced by topoisomerase-targeted drugs. Biochimica et Biophysica Acta (BBA)-Gene Structure and Expression. 1998; 1400(1-3): 233-55.

8. Gu Y, Nakamura T, Alder H, Prasad R, Canaani O, Cimino G, Croce C, Canaani $\mathrm{E}$. The $\mathrm{t}(4 ; 11)$ chromosome translocation of human acute leukemias fuses the ALL-1 gene, related to Drosophila trithorax, to the AF-4 gene. Cell. 1992;71(4):701-8.
9. Tkachuk DC, Kohler S, Cleary ML. Involvement of a homolog of Drosophila trithorax by 11 q23 chromosomal translocations in acute leukemias. Cell. 1992;71(4):691-700.

10. Krivtsov AV, Armstrong SA. MLL translocations, histone modifications and leukaemia stem-cell development. Nat Rev. 2007;7(11):823-33.

11. Benjamin DY, Hanson RD, Hess JL, Horning SE, Korsmeyer SJ. MLL, a mammalian trithorax-group gene, functions as a transcriptional maintenance factor in morphogenesis. Proc Natl Acad Sci. 1998:95(18):10632-6.

12. Thirman MJ, Gill HJ, Burnett RC, Mbangkollo D, McCabe NR, Kobayashi H, Ziemin-van der Poel S, Kaneko Y, Morgan R, Sandberg AA. Rearrangement of the $M L L$ gene in acute lymphoblastic and acute myeloid leukemias with 11 q23 chromosomal translocations. N Engl J Med. 1993; 329(13): 909-14.

13. Cuthbert G, Thompson K, McCullough S, Watmore A, Dickinson H, Telford N, Mugneret F, Harrison C, Griffiths M, Bown N. MLL amplification in acute leukaemia: a United Kingdom Cancer Cytogenetics Group (UKCCG) study. Leukemia. 2000;14(11):1885-91.

14. Meyer C, Burmeister T, Gröger D, Tsaur G, Fechina L, Renneville A, Sutton R, Venn N, Emerenciano M, Pombo-de-Oliveira M. The MLL recombinome of acute leukemias in 2017. Leukemia. 2018;32(2):273-84.

15. Milne TA, Kim J, Wang GG, Stadler SC, Basrur V, Whitcomb SJ, Wang Z, Ruthenburg AJ, Elenitoba-Johnson KS, Roeder RG. Multiple interactions recruit MLL1 and MLL1 fusion proteins to the HOXA9 locus in leukemogenesis. Mol Cell. 2010;38(6):853-63.

16. Burrows F, Wu T, Kessler L, Li S, Zhang J, Zarrinkar P, Li L, Cierpicki T, Grembecka J, Ren P. A novel small molecule menin-MLL inhibitor for potential treatment of MLL-rearranged leukemias and NPM1/DNMT3Amutant AML. Molecular Cancer Therapeutics. 2018; 17(suppl): Abstract LB-A27.

17. Rao RC, Dou Y. Hijacked in cancer: the KMT2 (MLL) family of methyltransferases. Nat Rev Cancer. 2015;15(6):334-46.

18. Herz HM. Enhancer deregulation in cancer and other diseases. BioEssays. 2016;38(10):1003-15

19. Li Y, Han J, Zhang Y, Cao F, Liu Z, Li S, Wu J, Hu C, Wang Y, Shuai J. Structural basis for activity regulation of MLL family methyltransferases. Nature. 2016;530(7591):447-52.

20. Ansari KI, Mishra BP, Mandal SS. MLL histone methylases in gene expression, hormone signaling and cell cycle. Front Biosci (Landmark edition). 2009;14:3483-95.

21. Guenther MG, Jenner RG, Chevalier B, Nakamura T, Croce CM, Canaani E, Young RA. Global and Hox-specific roles for the MLL1 methyltransferase. Proc Natl Acad Sci USA. 2005;102(24):8603-8.

22. Zeleznik-Le NJ, Harden AM, Rowley JD. 11q23 translocations split the "AT-hook" cruciform DNA-binding region and the transcriptional repression domain from the activation domain of the mixed-lineage leukemia (MLL) gene. Proc Natl Acad Sci USA. 1994;91(22):10610-4.

23. McMahon KA, Hiew SY-L, Hadjur S, Veiga-Fernandes H, Menzel U, Price AJ, Kioussis D, Williams O, Brady HJ. MII has a critical role in fetal and adult hematopoietic stem cell self-renewal. Cell Stem Cell. 2007; 1(3): 338-45.

24. Abramovich C, Humphries RK. Hox regulation of normal and leukemic hematopoietic stem cells. Curr Opin Hematol. 2005;12(3):210-6.

25. Yokoyama A, Lin M, Naresh A, Kitabayashi I, Cleary ML. A higher-order complex containing AF4 and ENL family proteins with P-TEFb facilitates oncogenic and physiologic MLL-dependent transcription. Cancer Cell. 2010;17(2):198-212.

26. García-Alai MM, Allen MD, Joerger AC, Bycroft M. The structure of the FYR domain of transforming growth factor beta regulator 1. Protein Sci. 2010:19(7):1432-8.

27. Eidahl JO, Crowe BL, North JA, McKee CJ, Shkriabai N, Feng L, Plumb M, Graham RL, Gorelick RJ, Hess S, Poirier MG, Foster MP, Kvaratskhelia M. Structural basis for high-affinity binding of LEDGF PWWP to mononucleosomes. Nucleic Acids Res. 2013;41(6):3924-36.

28. Cosgrove MS, Patel A. Mixed lineage leukemia: a structure-function perspective of the MLL1 protein. FEBS J. 2010;277(8):1832-42.

29. Muntean AG, Tan J, Sitwala K, Huang Y, Bronstein J, Connelly JA, Basrur V, Elenitoba-Johnson KS, Hess JL. The PAF complex synergizes with MLL fusion proteins at HOX loci to promote leukemogenesis. Cancer Cell. 2010;17(6):609-21. 
30. Wang Z, Song J, Milne TA, Wang GG, Li H, Allis CD, Patel DJ. Pro isomerization in MLL1 PHD3-bromo cassette connects H3K4me readout to CyP33 and HDAC-mediated repression. Cell. 2010;141(7):1183-94.

31. Chang P-Y, Hom RA, Musselman CA, Zhu L, Kuo A, Gozani O, Kutateladze TG, Cleary ML. Binding of the MLL PHD3 finger to histone H3K4me3 is required for MLL-dependent gene transcription. J Mol Biol. 2010;400(2):137-44.

32. Slany R. The molecular mechanics of mixed lineage leukemia. Oncogene. 2016;35(40):5215-23.

33. Xu J, Li L, Xiong J, Ye A, Karatas H, Liu L, Wang H, Qin ZS, Wang S, Dou Y. MLL1 and MLL1 fusion proteins have distinct functions in regulating leukemic transcription program. Cell Discovery. 2016;2(1):1-11.

34. Wang Q-f, Wu G, Mi S, He F, Wu J, Dong J, Luo RT, Mattison R, Kaberlein $J$ J, Prabhakar S. MLL fusion proteins preferentially regulate a subset of wild-type MLL target genes in the leukemic genome. Blood, The Journal of the American Society of Hematology. 2011; 117(25): 6895-905.

35. Thiel AT, Blessington P, Zou T, Feather D, Wu X, Yan J, Zhang H, Liu Z, Ernst P, Koretzky GA. MLL-AF9-induced leukemogenesis requires coexpression of the wild-type MII allele. Cancer Cell. 2010;17(2):148-59.

36. Cao F, Townsend EC, Karatas H, Xu J, Li L, Lee S, Liu L, Chen Y, Ouillette P, Zhu J. Targeting MLL1 H3K4 methyltransferase activity in mixed-lineage leukemia. Mol Cell. 2014;53(2):247-61.

37. Chen Y, Anastassiadis K, Kranz A, Stewart AF, Arndt K, Waskow C, Yokoyama A, Jones K, NeffT, Lee Y. MLL2, not MLL1, plays a major role in sustaining MLL-rearranged acute myeloid leukemia. Cancer Cell. 2017; 31(6): 755-70. e6.

38. Daser A, Rabbitts TH. The versatile mixed lineage leukaemia gene MLL and its many associations in leukaemogenesis. Semin Cancer Biol. 2005;15(3):175-88.

39. Lin C, Smith ER, Takahashi H, Lai KC, Martin-Brown S, Florens L, Washburn MP, Conaway JW, Conaway RC, Shilatifard A. AFF4, a component of the ELL/P-TEFb elongation complex and a shared subunit of MLL chimeras, can link transcription elongation to leukemia. Mol Cell. 2010;37(3):429-37.

40. Mohan M, Herz HM, Takahashi YH, Lin C, Lai KC, Zhang Y, Washburn MP, Florens L, Shilatifard A. Linking H3K79 trimethylation to Wnt signaling through a novel Dot1-containing complex (DotCom). Genes Dev. 2010;24(6):574-89.

41. Ross ME, Mahfouz R, Onciu M, Liu H-C, Zhou X, Song G, Shurtleff SA, Pounds S, Cheng C, Ma J, Ribeiro RC, Rubnitz JE, Girtman K, Williams WK, Raimondi SC, Liang D-C, Shih L-Y, Pui C-H, Downing JR. Gene expression profiling of pediatric acute myelogenous leukemia. Blood. 2004;104(12):3679-87.

42. Pless B, Oehm C, Knauer S, Stauber R, Dingermann T, Marschalek R. The heterodimerization domains of MLL-FYRN and FYRC — are potential target structures in $\mathrm{t}(4 ; 11)$ leukemia. Leukemia. 2011;25(4):663-70.

43. Sutherland HG, Newton K, Brownstein DG, Holmes MC, Kress $C$, Semple CA, Bickmore WA. Disruption of Ledgf/Psip1 results in perinatal mortality and homeotic skeletal transformations. Mol Cell Biol. 2006;26(19):7201-10.

44. Grembecka J, Belcher AM, Hartley T, Cierpicki T. Molecular basis of the mixed lineage leukemia-menin interaction implications for targeting mixed lineage leukemias. J Biol Chem. 2010;285(52):40690-8.

45. Huang J, Gurung B, Wan B, Matkar S, Veniaminova NA, Wan K, Merchant $J L$, Hua $X$, Lei $M$. The same pocket in menin binds both MLL and JUND but has opposite effects on transcription. Nature. 2012;482(7386):542-6.

46. Shi A, Murai MJ, He S, Lund G, Hartley T, Purohit T, Reddy G, Chruszcz M, Grembecka J, Cierpicki T. Structural insights into inhibition of the bivalent menin-MLL interaction by small molecules in leukemia. Blood J Am Soc Hematol. 2012;120(23):4461-9.

47. Grembecka J, He S, Shi A, Purohit T, Muntean AG, Sorenson RJ, Showalter HD, Murai MJ, Belcher AM, Hartley T. Menin-MLL inhibitors reverse oncogenic activity of MLL fusion proteins in leukemia. Nat Chem Biol. 2012;8(3):277-84

48. Brzezinka K, Nevedomskaya E, Lesche R, Steckel M, Eheim AL, Haegebarth A, Stresemann C. Functional diversity of inhibitors tackling the differentiation blockage of MLL-rearranged leukemia. J Hematol Oncol. 2019;12(1):66

49. Brzezinka K, Nevedomskaya E, Lesche R, Haegebarth A, ter Laak A, Fernández-Montalván AE, Eberspaecher U, Werbeck ND, Moenning U,
Siegel S. Characterization of the Menin-MLL interaction as therapeutic cancer target. Cancers. 2020;12(1):201.

50. Borkin D, He S, Miao H, Kempinska K, Pollock J, Chase J, Purohit T, Malik B, Zhao T, Wang J. Pharmacologic inhibition of the Menin-MLL interaction blocks progression of MLL leukemia in vivo. Cancer Cell. 2015;27(4):589-602.

51. Ren J, Xu W, Tang L, Su M, Chen D, Chen Y-L, Zang Y, Li J, Shen J, Zhou Y. Design and synthesis of benzylpiperidine inhibitors targeting the menin-MLL1 interface. Bioorg Med Chem Lett. 2016;26(18):4472-6.

52. He S, Malik B, Borkin D, Miao H, Shukla S, Kempinska K, Purohit T, Wang J, Chen L, Parkin B. Menin-MLL inhibitors block oncogenic transformation by MLL-fusion proteins in a fusion partner-independent manner. Leukemia. 2016;30(2):508-13.

53. Borkin D, Pollock J, Kempinska K, Purohit T, Li X, Wen B, Zhao T, Miao H, Shukla S, He M. Property focused structure-based optimization of small molecule inhibitors of the protein-protein interaction between menin and mixed lineage leukemia (MLL). J Med Chem. 2016;59(3):892-913.

54. Borkin D, Klossowski S, Pollock J, Miao H, Linhares BM, Kempinska K, Jin Z, Purohit T, Wen B, He M. Complexity of blocking bivalent protein-protein interactions: development of a highly potent inhibitor of the menin-mixed-lineage leukemia interaction. J Med Chem. 2018;61(11):4832-50.

55. Klossowski S, Miao H, Kempinska K, Wu T, Purohit T, Kim E, Linhares BM, Chen D, Jih G, Perkey E. Menin inhibitor MI-3454 induces remission in MLL1-rearranged and NPM1-mutated models of leukemia. J Clin Investig. 2020;130(2):981-97.

56. He S, Senter TJ, Pollock J, Han C, Upadhyay SK, Purohit T, Gogliotti RD, Lindsley CW, Cierpicki T, Stauffer SR. High-affinity small-molecule inhibitors of the menin-mixed lineage leukemia (MLL) interaction closely mimic a natural protein-protein interaction. J Med Chem. 2014:57(4):1543-56.

57. Manka J, Daniels RN, Dawson E, Daniels JS, Southall N, Jadhav A, Zheng W, Austin C, Grembecka J, Cierpicki T In Probe Reports from the NIH Molecular Libraries Program [Internet]; National Center for Biotechnology Information (US): 2013.

58. Senter T, Gogliotti RD, Han C, Locuson CW, Morrison R, Daniels JS, Cierpicki T, Grembecka J, Lindsley CW, Stauffer SR. Progress towards small molecule menin-mixed lineage leukemia (MLL) interaction inhibitors with in vivo utility. Bioorg Med Chem Lett. 2015;25(13):2720-5.

59. Xu S, Aguilar A, Xu T, Zheng K, Huang L, Stuckey J, Chinnaswamy K, Bernard D, Fernández-Salas E, Liu L. Design of the first-in-class, highly potent irreversible inhibitor targeting the Menin-mll protein-protein interaction. Angew Chem Int Ed. 2018;57(6):1601-5.

60. Xu S, Aguilar A, Huang L, Xu T, Zheng K, McEachern D, Przybranowski S, Foster C, Zawacki K, Liu Z. Discovery of M-808 as a highly potent, covalent, small-molecule inhibitor of the Menin-MLL interaction with strong in vivo antitumor activity. J Med Chem. 2020;63(9):4997-5010.

61. Aguilar A, Zheng K, Xu T, Xu S, Huang L, Fernandez-Salas E, Liu L, Bernard D, Harvey KP, Foster C. Structure-based discovery of M-89 as a highly potent inhibitor of the menin-mixed lineage leukemia (MeninMLL) protein-protein interaction. J Med Chem. 2019;62(13):6015-34.

62. Fortuna P, Linhares BM, Purohit T, Pollock J, Cierpicki T, Grembecka J, Berlicki $Ł$. Covalent and noncovalent constraints yield a figure eight-like conformation of a peptide inhibiting the menin-MLL interaction. Eur J Med Chem. 2020;207:112748.

63. Krivtsov AV, Evans K, Gadrey JY, Eschle BK, Hatton C, Uckelmann HJ, Ross KN, Perner F, Olsen SN, Pritchard T. A Menin-MLL inhibitor induces specific chromatin changes and eradicates disease in models of MLLrearranged leukemia. Cancer Cell. 2019; 36(6): 660-73. e11.

64. Kurmasheva RT, Bandyopadhyay A, Favours E, Pozo VD, Ghilu S, Phelps DA, McGeehan GM, Erickson SW, Smith MA, Houghton PJ. Evaluation of VTP-50469, a menin-MLL1 inhibitor, against Ewing sarcoma xenograft models by the pediatric preclinical testing consortium. Pediatr Blood Cancer. 2020;67(7):e28284.

65. Li L, Zhou R, Geng H, Yue L, Ye F, Xie Y, Liu J, Kong X, Jiang H, Huang J. Discovery of two aminoglycoside antibiotics as inhibitors targeting the menin-mixed lineage leukaemia interface. Bioorg Med Chem Lett. 2014;24(9):2090-3.

66. Yue L, Du J, Ye F, Chen Z, Li L, Lian F, Zhang B, Zhang Y, Jiang H, Chen K. Identification of novel small-molecule inhibitors targeting menin-MLL 
interaction, repurposing the antidiarrheal loperamide. Org Biomol Chem. 2016;14(36):8503-19.

67. Xu Y, Yue L, Wang Y, Xing J, Chen Z, Shi Z, Liu R, Liu Y-C, Luo X, Jiang $H$. Discovery of novel inhibitors targeting the menin-mixed lineage leukemia interface using pharmacophore-and docking-based virtual screening. J Chem Inf Model. 2016;56(9):1847-55.

68. Zhong H-J, Lee BR, Boyle JW, Wang W, Ma D-L, Chan PWH, Leung C-H. Structure-based screening and optimization of cytisine derivatives as inhibitors of the menin-MLL interaction. Chem Commun. 2016;52(34):5788-91.

69. Murai MJ, Pollock J, He S, Miao H, Purohit T, Yokom A, Hess JL, Muntean AG, Grembecka J, Cierpicki T. The same site on the integrase-binding domain of lens epithelium-derived growth factor is a therapeutic target for MLL leukemia and HIV. Blood J Am Soc Hematol. 2014;124(25):3730-7.

70. Čermáková K, Tesina P, Demeulemeester J, El Ashkar S, Méreau H, Schwaller J, Řezáčová P, Veverka V, De Rijck J. Validation and structural characterization of the LEDGF/p75-MLL interface as a new target for the treatment of MLL-dependent leukemia. Can Res. 2014;74(18):5139-51.

71. Sharma S, Čermáková K, De Rijck J, Demeulemeester J, Fábry M, El Ashkar S, Van Belle S, Lepšík M, Tesina P, Duchoslav V. Affinity switching of the LEDGF/p75 IBD interactome is governed by kinase-dependent phosphorylation. Proc Natl Acad Sci. 2018;115(30):E7053-62.

72. Park S, Osmers U, Raman G, Schwantes RH, Diaz MO, Bushweller JH. The PHD3 domain of MLL acts as a CYP33-regulated switch between MLLmediated activation and repression. Biochemistry. 2010;49(31):6576-86.

73. Goto NK, Zor T, Martinez-Yamout M, Dyson HJ, Wright PE. Cooperativity in transcription factor binding to the coactivator CREB-binding protein (CBP) The mixed lineage leukemia protein (MLL) activation domain binds to an allosteric site on the KIX domain. J Biol Chem. 2002;277(45):43168-74.

74. Toto A, Giri R, Brunori M, Gianni S. The mechanism of binding of the KIX domain to the mixed lineage leukemia protein and its allosteric role in the recognition of c-Myb. Protein Sci. 2014;23(7):962-9.

75. De Guzman RN, Goto NK, Dyson HJ, Wright PE. Structural basis for cooperative transcription factor binding to the CBP coactivator. J Mol Biol. 2006;355(5):1005-13.

76. Buhrlage SJ, Bates CA, Rowe SP, Minter AR, Brennan BB, Majmudar CY, Wemmer DE, Al-Hashimi H, Mapp AK. Amphipathic small molecules mimic the binding mode and function of endogenous transcription factors. ACS Chem Biol. 2009:4(5):335-44.

77. Majmudar CY, Højfeldt JW, Arevang CJ, Pomerantz WC, Gagnon JK, Schultz PJ, Cesa LC, Doss CH, Rowe SP, Vásquez V. Sekikaic acid and lobaric acid target a dynamic interface of the coactivator CBP/p300. Angew Chem. 2012;124(45):11420-4.

78. Rooklin D, Modell AE, Li H, Berdan V, Arora PS, Zhang Y. Targeting unoccupied surfaces on protein-protein interfaces. J Am Chem Soc. 2017;139(44):15560-3.

79. Avdic V, Zhang P, Lanouette S, Groulx A, Tremblay V, Brunzelle J, Couture J-F. Structural and biochemical insights into MLL1 core complex assembly. Structure. 2011;19(1):101-8.

80. Patel A, Vought VE, Dharmarajan V, Cosgrove MS. A conserved argininecontaining motif crucial for the assembly and enzymatic activity of the mixed lineage leukemia protein-1 core complex. J Biol Chem. 2008;283(47):32162-75.

81. Patel A, Dharmarajan V, Cosgrove MS. Structure of WDR5 bound to mixed lineage leukemia protein-1 peptide. J Biol Chem. 2008;283(47):32158-61.

82. Song J-J, Kingston RE. WDR5 interacts with mixed lineage leukemia (MLL) protein via the histone H3-binding pocket. J Biol Chem. 2008;283(50):35258-64.

83. Dharmarajan V, Lee J-H, Patel A, Skalnik DG, Cosgrove MS. Structural basis for WDR5 interaction (Win) motif recognition in human SET1 family histone methyltransferases. J Biol Chem. 2012;287(33):27275-89.

84. Karatas H, Townsend EC, Cao F, Chen Y, Bernard D, Liu L, Lei M, Dou Y, Wang S. High-affinity, small-molecule peptidomimetic inhibitors of MLL1/WDR5 protein-protein interaction. J Am Chem Soc. 2013;135(2):669-82

85. Grebien F, Vedadi M, Getlik M, Giambruno R, Grover A, Avellino R, Skucha A, Vittori S, Kuznetsova E, Smil D. Pharmacological targeting of the
Wdr5-MLL interaction in C/EBPa N-terminal leukemia. Nat Chem Biol. 2015;11(8):571-8.

86. Getlik Mu, Smil D, Zepeda-Velázquez C, Bolshan Y, Poda G, Wu H, Dong A, Kuznetsova E, Marcellus R, Senisterra G. Structure-based optimization of a small molecule antagonist of the interaction between WD repeatcontaining protein 5 (WDR5) and mixed-lineage leukemia 1 (MLL1). J Med Chem. 2016; 59(6): 2478-96.

87. Avdic V, Zhang P, Lanouette S, Voronova A, Skerjanc I, Couture J-F. Finetuning the stimulation of MLL1 methyltransferase activity by a histone H3-based peptide mimetic. FASEB J. 2011;25(3):960-7.

88. Alicea-Velázquez NL, Shinsky SA, Loh DM, Lee J-H, Skalnik DG, Cosgrove MS. Targeted disruption of the interaction between WD-40 repeat protein 5 (WDR5) and mixed lineage leukemia (MLL)/SET1 family proteins specifically inhibits MLL1 and SETd1 A methyltransferase complexes. J Biol Chem. 2016;291(43):22357-72.

89. Karatas H, Townsend EC, Bernard D, Dou Y, Wang S. Analysis of the binding of mixed lineage leukemia 1 (MLL1) and histone 3 peptides to WD repeat domain 5 (WDR5) for the design of inhibitors of the MLL1 1WDR5 interaction. J Med Chem. 2010;53(14):5179-85.

90. Karatas H, Li Y, Liu L, Ji J, Lee S, Chen Y, Yang J, Huang L, Bernard D, Xu J. Discovery of a highly potent, cell-permeable macrocyclic peptidomimetic (MM-589) targeting the WD repeat domain 5 protein (WDR5)mixed lineage leukemia (MLL) protein-protein interaction. J Med Chem. 2017;60(12):4818-39.

91. Senisterra G, Wu H, Allali-Hassani A, Wasney GA, Barsyte-Lovejoy D, Dombrovski L, Dong A, Nguyen KT, Smil D, Bolshan Y. Small-molecule inhibition of MLL activity by disruption of its interaction with WDR5. Biochem J. 2013;449(1):151-9.

92. Bolshan Y, Getlik Mu, Kuznetsova E, Wasney GA, Hajian T, Poda G, Nguyen KT, Wu H, Dombrovski L, Dong A. Synthesis, optimization, and evaluation of novel small molecules as antagonists of WDR5-MLL interaction. ACS Med Chem Lett. 2013; 4(3): 353-57.

93. Li D-D, Chen W-L, Xu X-L, Jiang F, Wang L, Xie Y-Y, Zhang X-J, Guo $X-K$, You Q-D, Sun H-P. Structure-based design and synthesis of small molecular inhibitors disturbing the interaction of MLL1-WDR5. Eur J Med Chem. 2016;118:1-8.

94. Li D-D, Chen W-L, Wang Z-H, Xie Y-Y, Xu X-L, Jiang Z-Y, Zhang X-J, You Q-D, Guo X-K. High-affinity small molecular blockers of mixed lineage leukemia 1 (MLL1)-WDR5 interaction inhibit MLL1 complex H3K4 methyltransferase activity. Eur J Med Chem. 2016;124:480-9.

95. Chen W-L, Li D-D, Wang Z-H, Xu X-L, Zhang X-J, Jiang Z-Y, Guo X-K, You Q-D. Design, synthesis, and initial evaluation of affinity-based small molecular probe for detection of WDR5. Bioorg Chem. 2018;76:380-5.

96. Li D-D, Wang Z-H, Chen W-L, Xie Y-Y, You Q-D, Guo X-K. Structure-based design of ester compounds to inhibit MLL complex catalytic activity by targeting mixed lineage leukemia 1 (MLL1)-WDR5 interaction. Bioorg Med Chem. 2016;24(22):6109-18.

97. Wang F, Jeon KO, Salovich JM, Macdonald JD, Alvarado J, Gogliotti RD, Phan J, Olejniczak ET, Sun Q, Wang S. Discovery of potent 2-Aryl-6, 7-dihydro-5 H-pyrrolo [1, 2-a] imidazoles as WDR5-WIN-site inhibitors using fragment-based methods and structure-based design. J Med Chem. 2018;61(13):5623-42.

98. Aho ER, Wang J, Gogliotti RD, Howard GC, Phan J, Acharya P, Macdonald JD, Cheng K, Lorey SL, Lu B. Displacement of WDR5 from chromatin by a WIN site inhibitor with picomolar affinity. Cell Rep. 2019; 26(11): 2916-28. e13.

99. Aho ER, Weissmiller AM, Fesik SW, Tansey WP. Targeting WDR5: A WINning anti-cancer strategy? Epigenetics Insights. 2019:12:2516865719865282.

100. Gogliotti RD, Stauffer SR, Jeon K, Salovich JM, Macdonald JD, Mills JJ, Meyers KM, Alvarado JR, Changho H, Fesik SW; Google Patents: 2020.

101. Zhang X, Zheng X, Yang H, Yan J, Fu X, Wei R, Xu X, Zhang Z, Yu A, Zhou K. Piribedil disrupts the MLL1-WDR5 interaction and sensitizes MLL-rearranged acute myeloid leukemia (AML) to doxorubicin-induced apoptosis. Cancer Lett. 2018:431:150-60.

102. Chen W-L, Li D-D, Chen X, Wang Y-Z, Xu J-J, Jiang Z-Y, You Q-D, Guo X-K. Proton pump inhibitors selectively suppress MLL rearranged leukemia cells via disrupting MLL1-WDR5 protein-protein interaction. Eur J Med Chem. 2020;188:112027.

103. Ye X, Zhang R, Lian F, Zhang W, Lu W, Han J, Zhang N, Jin J, Luo C, Chen K. The identification of novel small-molecule inhibitors targeting 
WDR5-MLL1 interaction through fluorescence polarization based highthroughput screening. Bioorg Med Chem Lett. 2019;29(4):638-45.

104. Chandrasekharappa SC, Guru SC, Manickam P, Olufemi S-E, Collins FS, Emmert-Buck MR, Debelenko LV, Zhuang Z, Lubensky IA, Liotta LA. Positional cloning of the gene for multiple endocrine neoplasia-type 1. Science. 1997;276(5311):404-7.

105. Lemmens I, Van de Ven WJ, Kas K, Zhang CX, Giraud S, Wautot V, Buisson N, De Witte K, Salandre J, Lenoir G. Identification of the multiple endocrine neoplasia type 1 (MEN1) gene. Hum Mol Genet. 1997;6(7):1177-83.

106. Yokoyama A, Somervaille TC, Smith KS, Rozenblatt-Rosen O, Meyerson $M$, Cleary ML. The menin tumor suppressor protein is an essential oncogenic cofactor for MLL-associated leukemogenesis. Cell. 2005;123(2):207-18

107. Matkar S, Thiel A, Hua X. Menin: a scaffold protein that controls gene expression and cell signaling. Trends Biochem Sci. 2013;38(8):394-402.

108. Balogh K, Rácz K, Patócs A, Hunyady L. Menin and its interacting proteins: elucidation of menin function. Trends Endocrinol Metab. 2006;17(9):357-64.

109. Poisson A, Zablewska B, Gaudray P. Menin interacting proteins as clues toward the understanding of multiple endocrine neoplasia type 1. Cancer Lett. 2003;189(1):1-10.

110. Milne TA, Hughes CM, Lloyd R, Yang Z, Rozenblatt-Rosen O, Dou Y, Schnepp RW, Krankel C, LiVolsi VA, Gibbs D. Menin and MLL cooperatively regulate expression of cyclin-dependent kinase inhibitors. Proc Natl Acad Sci. 2005;102(3):749-54.

111. Yokoyama A, Wang Z, Wysocka J, Sanyal M, Aufiero DJ, Kitabayashi I, Herr W, Cleary ML. Leukemia proto-oncoprotein MLL forms a SET1-like histone methyltransferase complex with menin to regulate Hox gene expression. Mol Cell Biol. 2004;24(13):5639-49.

112. Hughes CM, Rozenblatt-Rosen O, Milne TA, Copeland TD, Levine SS, Lee JC, Hayes DN, Shanmugam KS, Bhattacharjee A, Biondi CA. Menin associates with a trithorax family histone methyltransferase complex and with the hoxc8 locus. Mol Cell. 2004;13(4):587-97.

113. Chen Y-X, Yan J, Keeshan K, Tubbs AT, Wang H, Silva A, Brown EJ, Hess JL, Pear WS, Hua X. The tumor suppressor menin regulates hematopoiesis and myeloid transformation by influencing Hox gene expression. Proc Natl Acad Sci. 2006;103(4):1018-23.

114. Yokoyama A, Cleary ML. Menin critically links MLL proteins with LEDGF on cancer-associated target genes. Cancer Cell. 2008;14(1):36-46.

115. Caslini C, Yang Z, El-Osta M, Milne TA, Slany RK, Hess JL. Interaction of MLL amino terminal sequences with menin is required for transformation. Can Res. 2007;67(15):7275-83.

116. Ye J, Zha J, Shi Y, Li Y, Yuan D, Chen Q, Lin F, Fang Z, Yu Y, Dai Y. Coinhibition of HDAC and MLL-menin interaction targets MLL-rearranged acute myeloid leukemia cells via disruption of DNA damage checkpoint and DNA repair. Clinical Epigenetics. 2019;1 1(1):1-14.

117. Dafflon C, Craig V, Mereau H, Gräsel J, Engstler BS, Hoffman G, Nigsch F, Gaulis S, Barys L, Ito M. Complementary activities of DOT1L and Menin inhibitors in MLL-rearranged leukemia. Leukemia. 2017;31 (6):1269-77.

118. Zhou H, Liu L, Huang J, Bernard D, Karatas H, Navarro A, Lei M, Wang S. Structure-based design of high-affinity macrocyclic peptidomimetics to block the menin-mixed lineage leukemia 1 (MLL1) protein-protein interaction. J Med Chem. 2013;56(3):1113-23.

119. McGeehan J. A first-in-class Menin-MLL1 antagonist for the treatment of MLL-r and NPM1 mutant leukemias. AACR Annual Meeting 2020, New Drugs on the Horizon Session 1, Abstract: DDT01-01, Oral Presentation. 2020.

120. Ge H, Si Y, Roeder RG. Isolation of CDNAs encoding novel transcription coactivators $p 52$ and $p 75$ reveals an alternate regulatory mechanism of transcriptional activation. EMBO J. 1998;17(22):6723-9.

121. Llano M, Vanegas M, Hutchins N, Thompson D, Delgado S, Poeschla EM. Identification and characterization of the chromatin-binding domains of the HIV-1 integrase interactor LEDGF/p75. J Mol Biol. 2006;360(4):760-73.

122. De Rijck J, Vandekerckhove L, Gijsbers R, Hombrouck A, Hendrix J, Vercammen J, Engelborghs Y, Christ F, Debyser Z. Overexpression of the lens epithelium-derived growth factor/p75 integrase binding domain inhibits human immunodeficiency virus replication. J Virol. 2006;80(23):11498-509.
123. Engelman AN. Multifaceted HIV integrase functionalities and therapeutic strategies for their inhibition. J Biol Chem. 2019;294(41):15137-57.

124. Christ F, Voet A, Marchand A, Nicolet S, Desimmie BA, Marchand D, Bardiot D, Van der Veken NJ, Van Remoortel B, Strelkov SV, De Maeyer M, Chaltin P, Debyser Z. Rational design of small-molecule inhibitors of the LEDGF/p75-integrase interaction and HIV replication. Nat Chem Biol. 2010;6(6):442-8.

125. Bartholomeeusen K, Christ F, Hendrix J, Rain J-C, Emiliani S, Benarous R, Debyser Z, Gijsbers R, De Rijck J. Lens epithelium-derived growth factor/p75 interacts with the transposase-derived DDE domain of PogZ. J Biol Chem. 2009;284(17):11467-77.

126. Tesina P, Čermáková K, Hořejší M, Procházková K, Fábry M, Sharma S, Christ F, Demeulemeester J, Debyser Z, De Rijck J. Multiple cellular proteins interact with LEDGF/p75 through a conserved unstructured consensus motif. Nat Commun. 2015;6(1):1-14.

127. Gijsbers R, Vets S, De Rijck J, Ocwieja KE, Ronen K, Malani N, Bushman FD, Debyser Z. Role of the PWWP domain of lens epithelium-derived growth factor (LEDGF)/p75 cofactor in lentiviral integration targeting. J Biol Chem. 2011;286(48):41812-25.

128. Gijsbers R, Ronen K, Vets S, Malani N, De Rijck J, McNeely M, Bushman FD, Debyser Z. LEDGF hybrids efficiently retarget lentiviral integration into heterochromatin. Mol Ther. 2010;18(3):552-60.

129. Meehan AM, Saenz DT, Morrison JH, Garcia-Rivera JA, Peretz M, Llano M, Poeschla EM. LEDGF/p75 proteins with alternative chromatin tethers are functional HIV-1 cofactors. PLoS Pathogens. 2009;5(7):e1000522.

130. Mereau H, De Rijck J, Čermáková K, Kutz A, Juge S, Demeulemeester J, Gijsbers R, Christ F, Debyser Z, Schwaller J. Impairing MLL-fusion gene-mediated transformation by dissecting critical interactions with the lens epithelium-derived growth factor (LEDGF/p75). Leukemia. 2013:27(6):1245-53.

131. Desimmie BA, Humbert M, Lescrinier E, Hendrix J, Vets S, Gijsbers R, Ruprecht RM, Dietrich U, Debyser Z, Christ F. Phage display-directed discovery of LEDGF/p75 binding cyclic peptide inhibitors of HIV replication. Mol Ther. 2012:20(11):2064-75.

132. Sutherland HG, Mumford GK, Newton K, Ford LV, Farrall R, Dellaire G, Cáceres JF, Bickmore WA. Large-scale identification of mammalian proteins localized to nuclear sub-compartments. Hum Mol Genet. 2001;10(18):1995-2011.

133. Aasland R, Gibson TJ, Stewart AF. The PHD finger: implications for chromatin-mediated transcriptional regulation. Trends Biochem Sci. 1995;20(2):56-9.

134. Stassen MJ, Bailey D, Nelson S, Chinwalla V, Harte PJ. The Drosophila trithorax proteins contain a novel variant of the nuclear receptor type DNA binding domain and an ancient conserved motif found in other chromosomal proteins. Mech Dev. 1995;52(2-3):209-23.

135. Li H, Ilin S, Wang W, Duncan EM, Wysocka J, Allis CD, Patel DJ. Molecular basis for site-specific read-out of histone H3K4me3 by the BPTF PHD finger of NURF. Nature. 2006:442(7098):91-5.

136. Pena PV, Davrazou F, Shi X, Walter KL, Verkhusha VV, Gozani O, Zhao R, Kutateladze TG. Molecular mechanism of histone H3K4me3 recognition by plant homeodomain of ING2. Nature. 2006;442(7098):100-3.

137. Wysocka J, Swigut T, Xiao H, Milne TA, Kwon SY, Landry J, Kauer M, Tackett AJ, Chait BT, Badenhorst P. A PHD finger of NURF couples histone $\mathrm{H} 3$ lysine 4 trimethylation with chromatin remodelling. Nature. 2006:442(7098):86-90.

138. Shi X, Kachirskaia I, Walter KL, Kuo J-HA, Lake A, Davrazou F, Chan SM, Martin DG, Fingerman IM, Briggs SD. Proteome-wide analysis in Saccharomyces cerevisiae identifies several PHD fingers as novel direct and selective binding modules of histone $\mathrm{H} 3$ methylated at either lysine 4 or lysine 36. Journal of Biological Chemistry. 2007; 282(4): 2450-55.

139. Ali M, Hom RA, Blakeslee W, Ikenouye L, Kutateladze TG. Diverse functions of PHD fingers of the MLL/KMT2 subfamily. Biochim et Biophys Acta (BBA)-Mol Cell Res. 2014; 1843(2): 366-71.

140. Yokoyama A, Ficara F, Murphy MJ, Meisel C, Naresh A, Kitabayashi I, Cleary ML. Proteolytically cleaved MLL subunits are susceptible to distinct degradation pathways. J Cell Sci. 2011;124(13):2208-19.

141. Wang J, Muntean AG, Wu L, Hess JL. A subset of mixed lineage leukemia proteins has plant homeodomain (PHD)-mediated E3 ligase activity. J Biol Chem. 2012;287(52):43410-6. 
142. Fair K, Anderson M, Bulanova E, Mi H, Tropschug M, Diaz MO. Protein interactions of the MLL PHD fingers modulate MLL target gene regulation in human cells. Mol Cell Biol. 2001;21(10):3589-97.

143. Xia Z-B, Anderson M, Diaz MO, Zeleznik-Le NJ. MLL repression domain interacts with histone deacetylases, the polycomb group proteins HPC2 and BMI-1, and the corepressor C-terminal-binding protein. Proc Natl Acad Sci. 2003;100(14):8342-7.

144. Mi H, Kops O, Zimmermann E, Jäschke A, Tropschug M. A nuclear RNA-binding cyclophilin in human T cells. FEBS Lett. 1996;398(2-3):201-5.

145. Chen J, Santillan DA, Koonce M, Wei W, Luo R, Thirman MJ, ZeleznikLe NJ, Diaz MO. Loss of MLL PHD Finger 3 is necessary for MLLENL-induced hematopoietic stem cell immortalization. Can Res. 2008;68(15):6199-207.

146. Muntean AG, Giannola D, Udager AM, Hess JL. The PHD fingers of MLL block MLL fusion protein-mediated transformation. Blood J Am Soc Hematol. 2008;112(12):4690-3.

147. Taverna SD, Li H, Ruthenburg AJ, Allis CD, Patel DJ. How chromatinbinding modules interpret histone modifications: lessons from professional pocket pickers. Nat Struct Mol Biol. 2007:14(11):1025-40.

148. Goodman RH, Smolik S. CBP/p300 in cell growth, transformation, and development. Genes Dev. 2000;14(13):1553-77.

149. Shiama N. The $\mathrm{p} 300 / \mathrm{CBP}$ family: integrating signals with transcription factors and chromatin. Trends Cell Biol. 1997;7(6):230-6.

150. Näär AM, Lemon BD, Tjian R. Transcriptional coactivator complexes. Annu Rev Biochem. 2001;70(1):475-501.

151. Kalkhoven E. CBP and p300: HATs for different occasions. Biochem Pharmacol. 2004;68(6):1145-55.

152. Thakur JK, Yadav A, Yadav G. Molecular recognition by the KIX domain and its role in gene regulation. Nucleic Acids Res. 2014;42(4):2112-25.

153. Dyson $\mathrm{HJ}$, Wright PE. Role of intrinsic protein disorder in the function and interactions of the transcriptional coactivators CREB-binding protein (CBP) and p300. J Biol Chem. 2016;291(13):6714-22.

154. Brüschweiler S, Schanda P, Kloiber K, Brutscher B, Kontaxis G, Konrat $\mathrm{R}$, Tollinger M. Direct observation of the dynamic process underlying allosteric signal transmission. J Am Chem Soc. 2009;131(8):3063-8.

155. Arai M, Dyson HJ, Wright PE. Leu628 of the KIX domain of CBP is a key residue for the interaction with the $M L L$ transactivation domain. FEBS Lett. 2010;584(22):4500-4.

156. Jenuwein $T$, Laible $G$, Dorn $R$, Reuter $G$. SET domain proteins modulate chromatin domains in eu- and heterochromatin. Cell Mol Life Sci: CMLS. 1998;54(1):80-93.

157. Dou Y, Milne TA, Tackett AJ, Smith ER, Fukuda A, Wysocka J, Allis CD, Chait BT, Hess JL, Roeder RG. Physical association and coordinate function of the H3 K4 methyltransferase MLL1 and the H4 K16 acetyltransferase MOF. Cell. 2005;121(6):873-85

158. Maunakea AK, Chepelev I, Zhao K. Epigenome mapping in normal and disease States. Circ Res. 2010;107(3):327-39.

159. Terranova R, Agherbi H, Boned A, Meresse S, Djabali M. Histone and DNA methylation defects at Hox genes in mice expressing a SET domain-truncated form of MII. Proc Natl Acad Sci. 2006;103(17):6629-34.

160. Mishra BP, Zaffuto KM, Artinger EL, Org T, Mikkola HK, Cheng C, Djabali $M$, Ernst P. The histone methyltransferase activity of MLL1 is dispensable for hematopoiesis and leukemogenesis. Cell Rep. 2014;7(4):1239-47.

161. Zhang P, Chaturvedi C-P, Tremblay V, Cramet M, Brunzelle JS, Skiniotis G, Brand M, Shilatifard A, Couture J-F. A phosphorylation switch on RbBP5 regulates histone H3 Lys4 methylation. Genes Dev. 2015;29(2):123-8.

162. Chen Y, Cao F, Wan B, Dou Y, Lei M. Structure of the SPRY domain of human Ash2L and its interactions with RbBP5 and DPY30. Cell Res. 2012;22(3):598-602

163. Southall SM, Wong PS, Odho Z, Roe SM, Wilson JR. Structural basis for the requirement of additional factors for MLL1 SET domain activity and recognition of epigenetic marks. Mol Cell. 2009;33(2):181-91.

164. Wysocka J, Swigut T, Milne TA, Dou Y, Zhang X, Burlingame AL, Roeder RG, Brivanlou $\mathrm{AH}$, Allis CD. WDR5 associates with histone $\mathrm{H} 3$ methylated at $\mathrm{K} 4$ and is essential for $\mathrm{H} 3 \mathrm{~K} 4$ methylation and vertebrate development. Cell. 2005;121(6):859-72.

165. Dou Y, Milne TA, Ruthenburg AJ, Lee S, Lee JW, Verdine GL, Allis CD, Roeder RG. Regulation of MLL1 H3K4 methyltransferase activity by its core components. Nat Struct Mol Biol. 2006;13(8):713-9.
166. Hsieh JJ-D, Ernst P, Erdjument-Bromage H, Tempst P, Korsmeyer SJ. Proteolytic cleavage of MLL generates a complex of N-and C-terminal fragments that confers protein stability and subnuclear localization. Mol Cell Biol. 2003; 23(1): 186-94.

167. Muntean AG, Chen W, Jones M, Granowicz EM, Maillard I, Hess JL. MLL fusion protein-driven AML is selectively inhibited by targeted disruption of the MLL-PAFc interaction. Blood J Am Soc Hematol. 2013;122(11):1914-22.

168. Chen Y, Cramer P. Structure of the super-elongation complex subunit AFF4 C-terminal homology domain reveals requirements for AFF homo-and heterodimerization. J Biol Chem. 2019;294(27):10663-73.

169. Shilatifard A, Haque D, Conaway RC, Conaway JW. Structure and function of RNA polymerase II elongation factor ELL. Identification of two overlapping ELL functional domains that govern its interaction with polymerase and the ternary elongation complex. J Biol Chem. 1997; 272(35): 22355-63.

170. Byun JS, Fufa TD, Wakano C, Fernandez A, Haggerty CM, Sung MH, Gardner K. ELL facilitates RNA polymerase II pause site entry and release. Nat Commun. 2012;3:633.

171. Wan L, Wen H, Li Y, Lyu J, Xi Y, Hoshii T, Joseph JK, Wang X, Loh YE, Erb MA, Souza AL, Bradner JE, Shen L, Li W, Li H, Allis CD, Armstrong SA, Shi $X$. ENL links histone acetylation to oncogenic gene expression in acute myeloid leukaemia. Nature. 2017;543(7644):265-9.

172. Li Y, Wen H, Xi Y, Tanaka K, Wang H, Peng D, Ren Y, Jin Q, Dent SY, Li W. AF9 YEATS domain links histone acetylation to DOT1L-mediated H3K79 methylation. Cell. 2014;159(3):558-71.

173. Kuntimaddi A, Achille NJ, Thorpe J, Lokken AA, Singh R, Hemenway CS, Adli M, Zeleznik-Le NJ, Bushweller JH. Degree of recruitment of DOT1L to MLL-AF9 defines level of H3K79 Di- and tri-methylation on target genes and transformation potential. Cell Rep. 2015;11(5):808-20.

174. Feng $\mathrm{Q}$, Wang $\mathrm{H}, \mathrm{Ng} \mathrm{HH}$, Erdjument-Bromage $\mathrm{H}$, Tempst $\mathrm{P}$, Struhl $\mathrm{K}$, Zhang Y. Methylation of H3-lysine 79 is mediated by a new family of HMTases without a SET domain. Curr Biol. 2002;12(12):1052-8.

175. Okada Y, Feng Q, Lin Y, Jiang Q, Li Y, Coffield VM, Su L, Xu G, Zhang Y. hDOT1L links histone methylation to leukemogenesis. Cell. 2005;121(2):167-78.

176. Krivtsov AV, Feng Z, Lemieux ME, Faber J, Vempati S, Sinha AU, Xia X, Jesneck J, Bracken AP, Silverman LB, Kutok JL, Kung AL, Armstrong SA. H3K79 methylation profiles define murine and human MLL-AF4 leukemias. Cancer Cell. 2008;14(5):355-68.

177. Basavapathruni A, Jin L, Daigle SR, Majer CR, Therkelsen CA, Wigle TJ, Kuntz KW, Chesworth R, Pollock RM, Scott MP, Moyer MP, Richon VM, Copeland RA, Olhava EJ. Conformational adaptation drives potent, selective and durable inhibition of the human protein methyltransferase DOT1L. Chem Biol Drug Des. 2012;80(6):971-80.

178. Daigle SR, Olhava EJ, Therkelsen CA, Majer CR, Sneeringer CJ, Song J, Johnston LD, Scott MP, Smith JJ, Xiao Y, Jin L, Kuntz KW, Chesworth R, Moyer MP, Bernt KM, Tseng JC, Kung AL, Armstrong SA, Copeland RA, Richon VM, Pollock RM. Selective killing of mixed lineage leukemia cells by a potent small-molecule DOT1L inhibitor. Cancer Cell. 2011;20(1):53-65.

179. Anglin JL, Deng L, Yao Y, Cai G, Liu Z, Jiang H, Cheng G, Chen P, Dong $S$, Song Y. Synthesis and structure-activity relationship investigation of adenosine-containing inhibitors of histone methyltransferase DOT1L. J Med Chem. 2012;55(18):8066-74.

180. Yao Y, Chen P, Diao J, Cheng G, Deng L, Anglin JL, Prasad BV, Song Y. Selective inhibitors of histone methyltransferase DOT1L: design, synthesis, and crystallographic studies. J Am Chem Soc. 2011;133(42):16746-9.

181. Deng L, Zhang L, Yao Y, Wang C, Redell MS, Dong S, Song Y. Synthesis, activity and metabolic stability of non-ribose containing inhibitors of histone methyltransferase DOT1L. Med Chem Commun. 2013;4:822-6.

182. Yu W, Chory EJ, Wernimont AK, Tempel W, Scopton A, Federation A, Marineau JJ, Qi J, Barsyte-Lovejoy D, Yi J, Marcellus R, lacob RE, Engen JR, Griffin C, Aman A, Wienholds E, Li F, Pineda J, Estiu G, Shatseva T, Hajian T, Al-Awar R, Dick JE, Vedadi M, Brown PJ, Arrowsmith CH, Bradner JE, Schapira M. Catalytic site remodelling of the DOT1L methyltransferase by selective inhibitors. Nat Commun. 2012;3:1288.

183. Yu W, Smil D, Li F, Tempel W, Fedorov O, Nguyen KT, Bolshan Y, Al-Awar R, Knapp S, Arrowsmith CH, Vedadi M, Brown PJ, Schapira M. Bromodeaza-SAH: a potent and selective DOT1L inhibitor. Bioorg Med Chem. 2013:21(7):1787-94. 
184. Daigle SR, Olhava EJ, Therkelsen CA, Basavapathruni A, Jin L, BoriackSjodin PA, Allain CJ, Klaus CR, Raimondi A, Scott MP, Waters NJ, Chesworth R, Moyer MP, Copeland RA, Richon VM, Pollock RM. Potent inhibition of DOT1L as treatment of MLL-fusion leukemia. Blood. 2013;122(6):1017-25.

185. Sobhian B, Laguette N, Yatim A, Nakamura M, Levy Y, Kiernan R, Benkirane M. HIV-1 Tat assembles a multifunctional transcription elongation complex and stably associates with the 7SK snRNP. Mol Cell. 2010;38(3):439-51.

186. He N, Liu M, Hsu J, Xue Y, Chou S, Burlingame A, Krogan NJ, Alber T, Zhou Q. HIV-1 Tat and host AFF4 recruit two transcription elongation factors into a bifunctional complex for coordinated activation of HIV-1 transcription. Mol Cell. 2010;38(3):428-38.

187. Chou S, Upton H, Bao K, Schulze-Gahmen U, Samelson AJ, He N, Nowak A, Lu H, Krogan NJ, Zhou Q, Alber T. HIV-1 Tat recruits transcription elongation factors dispersed along a flexible AFF4 scaffold. Proc Nat Acad Sci USA. 2013;110(2):E123-31.

188. Schulze-Gahmen U, Lu H, Zhou Q, Alber T. AFF4 binding to Tat-P-TEFb indirectly stimulates TAR recognition of super elongation complexes at the HIV promoter. eLife. 2014; 3: e02375.

189. Luo Z, Lin C, Shilatifard A. The super elongation complex (SEC) family in transcriptional control. Nat Rev Mol Cell Biol. 2012;13(9):543-7.

190. Qi S, Li Z, Schulze-Gahmen U, Stjepanovic G, Zhou Q, Hurley JH. Structural basis for ELL2 and AFF4 activation of HIV-1 proviral transcription. Nat Commun. 2017;8(1):1-10.

191. Schulze-Gahmen U, Upton H, Birnberg A, Bao K, Chou S, Krogan NJ, Zhou Q, Alber T. The AFF4 scaffold binds human P-TEFb adjacent to HIV Tat. Elife. 2013;2:e00327.

192. Liang K, Smith ER, Aoi Y, Stoltz KL, Katagi H, Woodfin AR, Rendleman EJ, Marshall SA, Murray DC, Wang L. Targeting processive transcription elongation via SEC disruption for MYC-induced cancer therapy. Cell. 2018; 175(3): 766-79.

193. Gu J, Babayeva ND, Suwa Y, Baranovskiy AG, Price DH, Tahirov TH. Crystal structure of HIV-1 Tat complexed with human P-TEFb and AFF4. Cell Cycle. 2014;13(11):1788-97.

194. Leach BI, Kuntimaddi A, Schmidt CR, Cierpicki T, Johnson SA, Bushweller JH. Leukemia fusion target AF9 is an intrinsically disordered transcriptional regulator that recruits multiple partners via coupled folding and binding. Structure. 2013;21(1):176-83.

195. Barretto NN, Karahalios DS, You D, Hemenway CS. An AF9/ENLtargted peptide with therapeutic potential in mixed lineage leukemias. J Exp Ther Oncol. 2014:10(4):293-300.

196. Kuntimaddi A, Achille NJ, Thorpe J, Lokken AA, Singh R, Hemenway CS, Adli M, Zeleznik-Le NJ, Bushweller JH. Degree of recruitment of DOT1L to MLL-AF9 defines level of H3K79 Di-and tri-methylation on target genes and transformation potential. Cell Reports. 2015;11(5):808-20

197. Du L, Grigsby SM, Yao A, Chang Y, Johnson G, Sun H, NikolovskaColeska Z. Peptidomimetics for targeting protein-protein interactions between DOT1L and MLL oncofusion proteins AF9 and ENL. ACS Med Chem Lett. 2018:9(9):895-900.

198. Shen C, Jo SY, Liao C, Hess JL, Nikolovska-Coleska Z. Targeting recruitment of disruptor of telomeric silencing 1-like (DOT1L) characterizing the interactions between DOT1L and mixed lineage leukemia (MLL) fusion proteins. J Biol Chem. 2013;288(42):30585-96.

199. Schmidt CR, Achille NJ, Kuntimaddi A, Boulton AM, Leach Bl, Zhang S, Zeleznik-Le NJ, Bushweller JH. BCOR binding to MLL-AF9 is essential for leukemia via altered EYA1, SIX, and MYC Activity. Blood Cancer Discov. 2020;1 (2):162-77.

200. Moustakim M, Christott T, Monteiro OP, Bennett J, Giroud C, Ward J, Rogers CM, Smith P, Panagakou I, Díaz-Sáez L. Discovery of an MLLT1/3 YEATS domain chemical probe. Angew Chem Int Ed. 2018;57(50):16302-7.

201. Li X, Li XM, Jiang Y, Liu Z, Cui Y, Fung KY, van der Beelen SHE, Tian G, Wan L, Shi X, Allis CD, Li H, Li Y, Li XD. Structure-guided development of YEATS domain inhibitors by targeting pi-pi-pi stacking. Nat Chem Biol. 2018;14(12):1140-9.

202. Christott T, Bennett J, Coxon C, Monteiro O, Giroud C, Beke V, Felce SL, Gamble V, Gileadi C, Poda G, Al-Awar R, Farnie G, Fedorov O. Discovery of a Selective Inhibitor for the YEATS Domains of ENL/AF9. SLAS Discov: Adv Life Sci R \& D. 2019;24(2):133-41.
203. Christott T, Bennett J, Coxon C, Monteiro O, Giroud C, Beke V, Felce SL, Gamble V, Gileadi C, Poda G. Discovery of a selective inhibitor for the YEATS domains of ENL/AF9. SLAS DISCOVERY: Adv Sci Drug Discov. 2019;24(2):133-41.

204. Ni X, Heidenreich D, Christott T, Bennett J, Moustakim M, Brennan PE, Fedorov O, Knapp S, Chaikuad A. Structural insights into interaction mechanisms of alternative piperazine-urea YEATS domain binders in MLLT1. ACS Med Chem Lett. 2019;10(12):1661-6.

205. Wan L, Wen H, Li Y, Lyu J, Xi Y, Hoshii T, Joseph JK, Wang X, Loh Y-HE, Erb MA. ENL links histone acetylation to oncogenic gene expression in acute myeloid leukaemia. Nature. 2017; 543(7644): 265-69.

206. Lu H, Li Z, Zhang W, Schulze-Gahmen U, Xue Y, Zhou Q. Gene target specificity of the Super Elongation Complex (SEC) family: how HIV-1 Tat employs selected SEC members to activate viral transcription. Nucleic Acids Res. 2015;43(12):5868-79.

207. Gao Y, Chen L, Han Y, Wu F, Yang W-S, Zhang Z, Huo T, Zhu Y, Yu C, Kim $\mathrm{H}$. Acetylation of histone H3K27 signals the transcriptional elongation for estrogen receptor alpha. Commun Biol. 2020;3(1):1-10.

208. Tang D, Chen C, Liao G, Liu J, Liao B, Huang Q, Chen Q, Zhao J, Jiang $\mathrm{H}$, Duan J. Structural and functional insight into the effect of AFF4 dimerization on activation of HIV-1 proviral transcription. Cell Discov. 2020;6(1):1-11.

209. Shilatifard A, Lane WS, Jackson KW, Conaway RC, Conaway JW. An RNA polymerase II elongation factor encoded by the human ELL gene. Science. 1996;271(5257):1873-6.

210. Chen FX, Smith ER, Shilatifard A. Born to run: control of transcription elongation by RNA polymerase II. Nat Rev Mol Cell Biol. 2018;19(7):464-78.

211. Mousseau G, Valente ST. Role of host factors on the regulation of Tatmediated HIV-1 transcription. Curr Pharm Des. 2017;23(28):4079-90.

212. He N, Zhou Q. New insights into the control of HIV-1 transcription: when Tat meets the 7SK snRNP and super elongation complex (SEC). J Neuroimmune Pharmacol. 2011;6(2):260-8.

213. Chao S-H, Price DH. Flavopiridol inactivates P-TEFb and blocks most RNA polymerase II transcription in vivo. J Biol Chem. 2001;276(34):31793-9.

214. Chao S-H, Fujinaga K, Marion JE, Taube R, Sausville EA, Senderowicz AM, Peterlin BM, Price DH. Flavopiridol inhibits P-TEFb and blocks HIV-1 replication. J Biol Chem. 2000;275(37):28345-8.

215. Nakamura T, Alder H, Gu Y, Prasad R, Canaani O, Kamada N, Gale RP, Lange B, Crist WM, Nowell PC, et al. Genes on chromosomes 4, 9, and 19 involved in 11q23 abnormalities in acute leukemia share sequence homology and/or common motifs. Proc Natl Acad Sci USA. 1993;90(10):4631-5.

216. Rubnitz JE, Morrissey J, Savage PA, Cleary ML. ENL, the gene fused with HRX in $t(1 ; 19)$ leukemias, encodes a nuclear protein with transcriptional activation potential in lymphoid and myeloid cells. Blood. 1994;84(6):1747-52.

217. Palermo CM, Bennett CA, Winters AC, Hemenway CS. The AF4mimetic peptide, PFWT, induces necrotic cell death in MV4-11 leukemia cells. Leuk Res. 2008;32(4):633-42.

218. Srinivasan R, Nesbit J, Marrero L, Erfurth F, LaRussa V, Hemenway C. The synthetic peptide PFWT disrupts AF4-AF9 protein complexes and induces apoptosis in $\mathrm{t}(4 ; 11)$ leukemia cells. Leukemia. 2004;18(8):1364-72.

219. Tan J, Jones M, Koseki H, Nakayama M, Muntean AG, Maillard I, Hess $J$ L. CBX8, a polycomb group protein, is essential for MLL-AF9-induced leukemogenesis. Cancer Cell. 2011;20(5):563-75.

220. Maethner E, Garcia-Cuellar M-P, Breitinger C, Takacova S, Divoky V, Hess JL, Slany RK. MLL-ENL inhibits polycomb repressive complex 1 to achieve efficient transformation of hematopoietic cells. Cell Rep. 2013;3(5):1553-66

221. Srinivasan RS, de Erkenez AC, Hemenway CS. The mixed lineage leukemia fusion partner AF9 binds specific isoforms of the BCL-6 corepressor. Oncogene. 2003;22(22):3395-406.

222. Schmidt CR, Achille NJ, Kuntimaddi A, Boulton AM, Leach BI, Zhang S, Zeleznik-Le NJ, Bushweller JH. BCOR Binding to MLL-AF9 Is Essential for Leukemia via Altered EYA1, SIX, and MYC Activity. Blood Cancer Discovery. 2020.

223. Bushweller JH, Schmidt C, Achille N, Kuntimaddi A, Boulton A, Leach $B$, Zhang S, Zeleznik-Le NJ. Direct binding of BCOR, but Not CBX8, to 
MLL-AF9 is essential for MLL-AF9 leukemia via regulation of the EYA1/ SIX1 gene network. Blood. 2018;132(Supplement 1):1316-416.

224. Erb MA, Scott TG, Li BE, Xie H, Paulk J, Seo H-S, Souza A, Roberts JM, Dastjerdi S, Buckley DL. Transcription control by the ENL YEATS domain in acute leukaemia. Nature. 2017;543(7644):270-4.

225. Li Y, Sabari BR, Panchenko T, Wen H, Zhao D, Guan H, Wan L, Huang $\mathrm{H}$, Tang Z, Zhao Y. Molecular coupling of histone crotonylation and active transcription by AF9 YEATS domain. Mol Cell. 2016:62(2):181-93.

226. Filippakopoulos P, Picaud S, Mangos M, Keates T, Lambert J-P, BarsyteLovejoy D, Felletar I, Volkmer R, Müller S, Pawson T. Histone recognition and large-scale structural analysis of the human bromodomain family. Cell. 2012;149(1):214-31
227. Gan T, Jude CD, Zaffuto K, Ernst P. Developmentally induced MII1 loss reveals defects in postnatal haematopoiesis. Leukemia. 2010;24(10):1732-41.

228. Bertolino P, Radovanovic I, Casse H, Aguzzi A, Wang Z-Q, Zhang C-X Genetic ablation of the tumor suppressor menin causes lethality at mid-gestation with defects in multiple organs. Mech Dev. 2003;120(5):549-60.

\section{Publisher's Note}

Springer Nature remains neutral with regard to jurisdictional claims in published maps and institutional affiliations.
Ready to submit your research? Choose BMC and benefit from:

- fast, convenient online submission

- thorough peer review by experienced researchers in your field

- rapid publication on acceptance

- support for research data, including large and complex data types

- gold Open Access which fosters wider collaboration and increased citations

- maximum visibility for your research: over $100 \mathrm{M}$ website views per year

At BMC, research is always in progress.

Learn more biomedcentral.com/submissions 